\title{
Simulations of Indoor Air Quality and Ventilation Impacts of Demand Controlled Ventilation in Commercial and Institutional Buildings
}

Andrew Persily

Amy Musser

Steven Emmerich

Michael Taylor 


\title{
Simulations of Indoor Air Quality and Ventilation Impacts of Demand Controlled Ventilation in Commercial and Institutional Buildings
}

\author{
Andrew Persily \\ Building and Fire Research Laboratory \\ Amy Musser \\ University of Nebraska \\ Steve Emmerich \\ Building and Fire Research Laboratory \\ Michael Taylor \\ University of Nebraska
}

Prepared for:

Architectural Energy Corporation

Boulder, Colorado

August 2003

U.S. Department of Commerce Donald L. Evans, Secretary

Technology Administration Phillip J. Bond, Undersecretary of Commerce for Technology

National Institute of Standards and Technology Arden L. Bement, Jr., Director

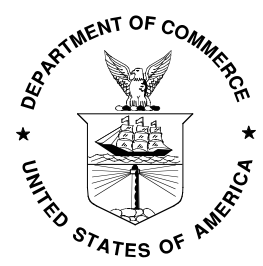




\begin{abstract}
Carbon-dioxide $\left(\mathrm{CO}_{2}\right)$ based demand controlled ventilation (DCV) offers the potential for more energy efficient building ventilation compared with constant ventilation rates based on design occupancy levels. A number of questions related to $\mathrm{CO}_{2}$-based DCV have been raised concerning the indoor air quality impacts, primarily with respect to contaminants with source strengths that are not dependent on the number of occupants. In addition, questions exist regarding potential energy efficiency benefits, optimal control strategies for different building types, and sensor performance and deployment. In order to obtain some insight into the issue of IAQ impacts of $\mathrm{CO}_{2}$-based DCV, a simulation study was performed in six commercial and institutional building spaces using the multizone airflow and IAQ model CONTAMW. These simulations compared seven different ventilation strategies, four of which used $\mathrm{CO}_{2} \mathrm{DCV}$. The simulations, performed for six U.S. cities, were used to compare ventilation rates, indoor $\mathrm{CO}_{2}$ levels, indoor concentrations of a generic volatile organic compound (VOC) as an indicator of non-occupant contaminant sources, and energy impacts. The results indicate that these impacts are dependent on the details of the spaces including occupancy patterns, design ventilation rate and ventilation system operating schedule, as well as the specific assumptions used in the analysis including contaminant source strengths and system-off infiltration rates. For the cases studied, the application of $\mathrm{CO}_{2} \mathrm{DCV}$ resulted in significant decreases in ventilation rates and energy loads accompanied by increased indoor $\mathrm{CO}_{2}$ and VOC concentrations. The increases in $\mathrm{CO}_{2}$ were not particularly large, in the range of $180 \mathrm{mg} / \mathrm{m}^{3}(100 \mathrm{ppm}(\mathrm{v}))$. The indoor VOC levels increased by a factor of two to three, but the absolute concentrations were still relatively low based on the assumed emission rates. The annual energy load reductions were significant in most of the cases, ranging from $10 \%$ to $80 \%$ depending on the space type, climate, occupancy schedule, and ventilation strategy.
\end{abstract}

Keywords: carbon dioxide, control, energy efficiency, indoor air quality, modeling, simulation, ventilation, volatile organic compounds

\title{
$\underline{\text { Disclaimer }}$
}

This report was prepared as a result of work sponsored by the California Energy Commission (Commission). It does not necessarily represent the views of the Commission, its employees, or the State of California. The Commission, the State of California, its employees, contractors, and subcontractors make no warranty, express or implied, and assume no legal liability for the information in this report; nor does any party represent that the use of this information will not infringe upon privately owned rights. This report has not been approved or disapproved by the Commission nor has the Commission passed upon the accuracy or adequacy of the information in this report. 


\section{TABLE OF CONTENTS}

Abstract

1. INTRODUCTION AND BACKGROUND

2. DESCRIPTION OF ANALYSIS

2.1 Study Spaces 4

2.2 Ventilation Rates and Control Approaches

2.3 Airflow and Contaminant Analysis 11

2.4 Energy Analysis 11

3. RESULTS 14

3.1 Ventilation Rates 14

3.2 Carbon Dioxide Concentrations 21

3.3 VOC Concentrations 26

3.4 Energy Loads 32

4. DISCUSSION 34

5. ACKNOWLEDGEMENTS 37

6. REFERENCES 37

Appendix A: Details of Energy Simulation Results 39

Appendix B: PIER RFP Issues 46 


\section{INTRODUCTION AND BACKGROUND}

Commercial building ventilation systems are designed, installed and operated to heat and cool occupied spaces to achieve thermal comfort and to provide outdoor air to the occupants. Outdoor air ventilation is provided to buildings primarily to dilute contaminants that are generated by building occupants and their activities and by building materials and furnishings. The rate at which outdoor air is brought into a building by its ventilation system is determined during the building design based on requirements of applicable building codes and standards. For example, ASHRAE Standard 62-2001 (ASHRAE 2001a) and California Energy Efficiency Standards, socalled Title 24, (CEC 2001) contain minimum ventilation requirements for a number of different occupancy types in units of $\mathrm{L} / \mathrm{s}(\mathrm{cfm})$ per person and in $\mathrm{L} / \mathrm{s}$ per $\mathrm{m}^{2}$ of floor area $\left(\mathrm{cfm} / \mathrm{ft}^{2}\right)$.

Determining design outdoor air ventilation rates for commercial buildings using Standard 622001 or Title 24 is a relatively straightforward process. For each space served by a given ventilation system, one determines the expected or design number of occupants for space types with ventilation requirements in units of $\mathrm{L} / \mathrm{s}(\mathrm{cfm})$ per person. In spaces with requirements in units of $\mathrm{L} / \mathrm{s}-\mathrm{m}^{2}\left(\mathrm{cfm} / \mathrm{ft}^{2}\right)$, one determines the floor area. Based on the ventilation requirements contained in the standard, these values (number of people and floor area) are used to determine the L/s (cfm) of outdoor air required by that space under full occupancy. Standard 62-2001 also requires that these rates be adjusted to account for ventilation effectiveness (degree of ventilation air mixing in the space). Also, if the spaces are served by a system that recirculates air from multiple spaces and redistributes it along with "new" outdoor air, Standard 62-2001 requires the use of the so-called "multiple spaces" approach to determine the outdoor air intake rate. If no such recirculation occurs, then the outdoor air intake rate is equal to the sum of the outdoor air requirements for all the spaces served by the system, after adjusting for ventilation effectiveness.

ASHRAE Standard 62-2001 also allows for a reduction in the design occupancy under conditions of intermittent occupancy. Basically, the standard allows one to use the average occupancy instead of the design occupancy for spaces where the design occupancy is based on a peak lasting $3 \mathrm{~h}$ or less. However, one is not permitted to reduce the design occupancy by any more than $50 \%$. The average occupancy is then multiplied by the per person ventilation requirement for the space to determine the design outdoor air intake rate. Note that this reduction cannot also be employed when demand controlled ventilation is also used.

Demand controlled ventilation (DCV) is a ventilation rate control strategy to address the concern that when a space is occupied at less than its design occupancy, unnecessary energy consumption can result if the space is ventilated at the design minimum rate rather than the ventilation rate based on the actual occupancy. Furthermore, early during a given day of building occupancy, contaminants generated by people and their activities will not yet have reached their ultimate levels based on the transient nature of contaminant buildup. As a result, it is sometimes possible to delay or lag the onset of the design ventilation rate to take credit for this transient effect. A number of approaches have been proposed to account for actual occupancy levels and to provide the ventilation rate corresponding to actual rather than design occupancy. These include timebased scheduling when occupancy patterns are predictable, occupancy sensors to determine when people have entered a space (though not necessarily how many), and carbon dioxide $\left(\mathrm{CO}_{2}\right)$ sensing and control as a means of estimating the number of people in a space or the strength of occupant-related contaminant sources.

Controlling outdoor air intake rates using $\mathrm{CO}_{2} \mathrm{DCV}$ offers the possibility of reducing the energy penalty of over-ventilation during periods of low occupancy, while still ensuring adequate levels of outdoor air ventilation. As discussed later in this report, depending on climate and occupancy 
patterns, $\mathrm{CO}_{2}$ DCV may provide significant energy savings in commercial and institutional buildings. While a number of studies have suggested the extent of such savings via field studies and computer simulations, additional work is needed to better define the magnitude of energy savings possible and the dependence of these savings on climate, building and system type, control approach, and occupancy patterns. In addition, important issues remain to be resolved in the application of $\mathrm{CO}_{2} \mathrm{DCV}$ including how best to apply the approach, which in turn includes issues such as which control algorithm to use in a given building, sensor location, sensor maintenance and calibration, and the amount of baseline ventilation required to control contaminant sources that don't depend on the number of occupants.

An earlier report presented a state-of-the-art review of $\mathrm{CO}_{2} \mathrm{DCV}$ technology and its application in commercial and institutional buildings (Emmerich and Persily 2001). That report presented discussions of $\mathrm{CO}_{2}$ generation rates by people, the relationship of indoor $\mathrm{CO}_{2}$ to building ventilation rates, and the basic concept of controlling ventilation based on indoor $\mathrm{CO}_{2}$ levels. It also contained a literature review of previous research on $\mathrm{CO}_{2} \mathrm{DCV}$, including field demonstration projects, computer simulation studies, studies of sensor performance and location, and discussions of the application of the approach. This earlier report and other discussions of $\mathrm{CO}_{2} \mathrm{DCV}$ identified indoor air quality impacts as an important issue in the application and performance of these systems. The key indoor air quality concern relates to contaminants that are generated in a building at a rate that does not depend on the number of occupants. For example, building materials and furnishings emit contaminants at an approximately constant rate independent of the occupancy level, including when the building is empty. Questions have been raised as to how well these contaminants will be controlled by a DCV system when the occupancy level is low. Some have proposed maintaining a minimum outdoor air ventilation rate at all times to control these contaminants, with the minimum based on a specific outdoor air intake rate per unit floor area expressed in $\mathrm{L} / \mathrm{s} \bullet \mathrm{m}^{2}\left(\mathrm{cfm} / \mathrm{ft}^{2}\right)(\mathrm{CEC} 2001)$ or as a fraction of the design outdoor air intake rate, for example $25 \%$ (Schell et al. 1998).

ASHRAE Standard 62-2001 allows for the outdoor air intake rate to be adjusted based on variations in occupancy (as noted earlier in the discussion of the intermittent occupancy approach), but regardless of the approach used to make these adjustments the system must still provide the required outdoor air ventilation rate per person. The standard does not explicitly discuss $\mathrm{CO}_{2}$-based DCV in terms of sensor location, minimum outdoor airflow rates or other details. However, a number of official interpretations to the standard issued by ASHRAE make it clear that these approaches can comply with the standard if properly implemented. Title 24 also allows the use of demand controlled ventilation. If fact, it is required in spaces with high occupant densities as an energy efficiency measure.

As noted above, the outdoor air ventilation requirements in ASHRAE Standard 62-2001 are largely expressed as airflow rates per person in L/s•person ( $\mathrm{cfm} /$ person). In some spaces, for example corridors and retail spaces, they are expressed in $\mathrm{L} / \mathrm{s} \bullet \mathrm{m}^{2}\left(\mathrm{cfm} / \mathrm{ft}^{2}\right)$ of floor area. The per person requirements are intended to address contaminants emitted by the occupants themselves as well as by the space they occupy, including building materials, furnishings and equipment. In developing the ventilation requirements per person, there is an implicit assumption as to the number of occupants per unit floor area in order to handle these non-occupant contaminants. If the space being designed has a different occupant density, it may receive more or less outdoor air than needed to handle the floor-area contaminants. In order to address that concern, a revision of the Ventilation Rate Procedure in ASHRAE Standard 62 has been developed that contains per person and per floor area outdoor air requirements for all spaces (Persily 2001). Under the revision, referred to as addendum $62 \mathrm{n}$, one multiplies the number of people in a space by a per 
person ventilation requirement $R_{p}$ and multiplies the floor area of the space by a per floor area requirement $\mathrm{R}_{\mathrm{a}}$. These two products are then added together to determine the outdoor air requirement in the occupied zone of the space. Further adjustments are required to account for mixing in the space and system effects in recirculating systems serving multiple spaces. This socalled additive approach has the advantage of addressing the concern about non-occupant contaminant sources and the provision of ventilation to handle these sources when occupancy is low or zero. It could also make the application of $\mathrm{CO}_{2} \mathrm{DCV}$ more challenging compared with ventilation requirements expressed solely in terms of per person rates, but control algorithms have been developed to implement $\mathrm{CO}_{2} \mathrm{DCV}$ for so-called "additive" ventilation requirements (Sowa 2002).

Resolving all the issues related to the application of $\mathrm{CO}_{2} \mathrm{DCV}$ in commercial buildings, including the energy and IAQ impacts, will require field testing and application experience, as well as simulation studies. A number of modeling studies have looked at energy impacts of $\mathrm{CO}_{2}$ DCV strategies in different building types and different climates (e.g., Brandemuehl and Braun 1999). Other simulation studies have focused on the indoor air quality implications of $\mathrm{CO}_{2} \mathrm{DCV}$ (e.g., Carpenter 1996, Emmerich et al. 1994, Enermodal 1995). The study described in this paper employs an airflow and contaminant dispersal model to investigate the issue of how $\mathrm{CO}_{2} \mathrm{DCV}$ and other ventilation strategies impact indoor air quality and ventilation. In particular, the simulations are focused on how $\mathrm{CO}_{2} \mathrm{DCV}$ impacts the control of non-occupant contaminants, in this case a generic volatile organic compound (VOC), generated at a constant rate to represent contaminants emitted by building materials and furnishings.

These simulations are performed using the airflow and indoor air quality model CONTAMW (Dols and Walton 2002) for six commercial and institutional building spaces. The results are then used to compare ventilation rates, contaminant concentrations and energy associated with ventilation for seven ventilation strategies: constant ventilation volumes specified in ASHRAE Standard 62-2001 and addendum 62n, a theoretical demand control strategy that perfectly tracks occupancy, and four $\mathrm{CO}_{2} \mathrm{DCV}$ strategies with different maximum and minimum flow rates, including one based on California's Title 24 requirements. 


\section{DESCRIPTION OF ANALYSIS}

The simulations in this study were performed using the multizone network airflow and contaminant dispersal model CONTAMW (Dols and Walton 2002). This model allows one to represent a building as a collection of interconnected zones and then calculates airflow rates induced by weather and ventilation system operation based on air leakage characteristics of the boundaries between zones and pressures and on ventilation system airflows. The user can also enter contaminant source strengths to calculate concentrations over time based on the calculated airflow rates and other mass transport mechanisms (e.g. filtration, deposition, chemical reaction). The latest version of CONTAMW can simulate the performance of controls, in which an airflow rate, fan or damper is controlled based on the contaminant concentration, temperature or pressure in a zone. The simulations described in this report employed this new capability in simple models of the six study spaces as a means of simulating $\mathrm{CO}_{2} \mathrm{DCV}$.

\subsection{Study Spaces}

Building models were created in CONTAMW for six different space types. Four of these were generic spaces devised for the purposes of this study: office, conference room, lecture hall and classroom. The two other spaces were based on actual buildings being monitored as part of a larger study on $\mathrm{CO}_{2}$ DCV being conducted as part of the same CEC-sponsored program that supported this work: portable classroom and playroom in a fast food restaurant. Table 1 summarizes the characteristics of the six spaces including floor area, ceiling height and design occupancy. For the first four spaces, the design occupancy is based on the default values given in ASHRAE Standard 62-2001 (ASHRAE 2001a). Actual dimensions of the two monitored spaces were used to construct models of the portable classroom and fast food playroom, and the occupancies were estimated based on available design information.

\begin{tabular}{|c|c|c|c|c|c|}
\hline Space type & $\begin{array}{c}\text { Floor area } \\
\mathbf{m}^{2}\left(\mathbf{f t}^{2}\right)\end{array}$ & $\begin{array}{c}\text { Ceiling } \\
\text { height } \\
\text { m (ft) }\end{array}$ & $\begin{array}{c}\text { Design } \\
\text { occupancy } \\
\text { \# of people }\end{array}$ & $\begin{array}{c}\text { Occupant density } \\
\# / 100 \mathrm{~m}^{2} \\
\left(\# / 1000 \mathrm{ft}^{2}\right)\end{array}$ & $\begin{array}{c}\text { Ventilation } \\
\text { system } \\
\text { operating time }\end{array}$ \\
\hline Office & $1000(10760)$ & $3.0(9.8)$ & 70 & $7.0(6.5)$ & 0600-1900 \\
\hline Conference Room & $100(1076)$ & $3.0(9.8)$ & 50 & $50.0(46.5)$ & $0600-1800$ \\
\hline Lecture Hall & $100(1076)$ & $6.0(19.7)$ & 150 & $150.0(139.4)$ & $0800-2100$ \\
\hline Classroom & $100(1076)$ & $3.0(9.8)$ & 35 & $35.0(32.5)$ & $0600-1800$ \\
\hline Portable classroom & $89(958)$ & $2.6(8.5)$ & 20 & $22.5(20.9)$ & $0700-1700$ \\
\hline Fast food restaurant & $125(1346)$ & $5.4(17.7)$ & 70 & $56.0(52.0)$ & $0600-2400$ \\
\hline
\end{tabular}

Table 1 Space Characteristics

Each space was modeled as a single zone with a ventilation system that provides outdoor air at a rate determined by the control strategy of interest, as outlined below. Details of the ventilation system equipment were not considered in this study, though they can be important; only the outdoor air intake rate is accounted for in the modeled ventilation systems. The systems are assumed to operate during the times indicated in the last column of Table 1 and to be off at night and during unoccupied periods over the weekends. A constant infiltration rate of 0.1 air changes per hour is assumed to exist in each space at all times, including when the ventilation system is operating. This value was chosen to represent a low infiltration condition that might exist under low wind speeds and moderate outdoor temperatures and result in significant buildup of contaminants before the system is activated. 
Occupancy profiles

Weekly occupancy schedules for each space are shown in Figure 1. Schedules for the four generic spaces (1a through 1d) were selected to represent realistic usage and to include scenarios that were significantly different from one another in order to test of each control scheme. The Office and Classroom tend to experience long periods at close to their design occupancies. Occupancy changes in the morning and evening are more gradual for the Office, where workers tend to arrive and depart at different times. The Classroom is more densely occupied than the Office, and operates on a more rigid schedule, with the students arriving, departing, and taking lunch at the same time. However, it was assumed that a teacher would arrive early and stay later than the students. In contrast, the Lecture Hall and Conference Room are intermittently occupied. The Lecture Hall schedule is the busier of the two, with more occupied hours in the day, and usually with $50 \%$ or more of the design capacity when the room was occupied. The Conference Room is modeled with two occupancy profiles, with a busier schedule specified for Mondays and Wednesdays. All four of these spaces are assumed to be unoccupied on weekends, and all occupants for these spaces are specified as adults.

The Portable Classroom was modeled with two adults and eighteen children. The occupancy profile specified for the Classroom is also used here for the children, with different $\mathrm{CO}_{2}$ generation rates for the adults and children based on body size. The occupancy profiles used for the Fast Food Restaurant simulations are based on actual occupancy data collected in the monitored restaurant. These data were used to develop an occupancy schedule between 0600 to 2400 seven days a week, with different schedules for weekdays and weekends. 


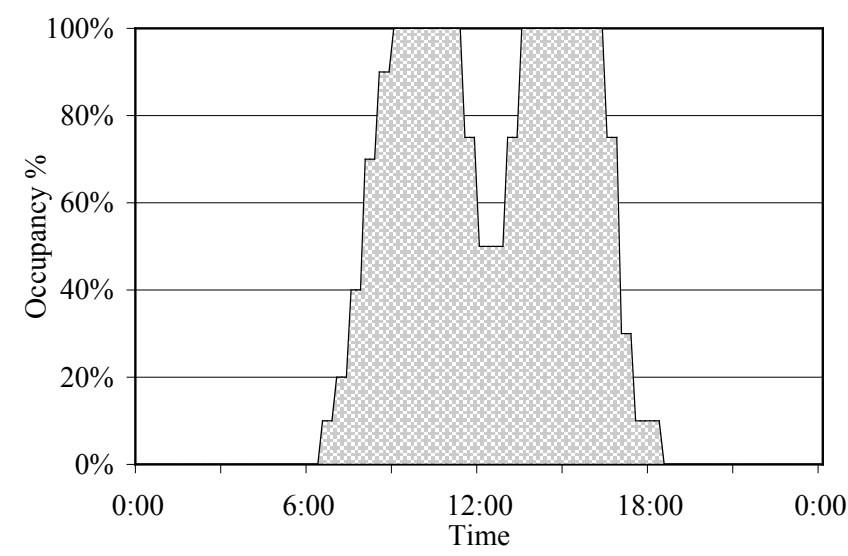

(a) Office

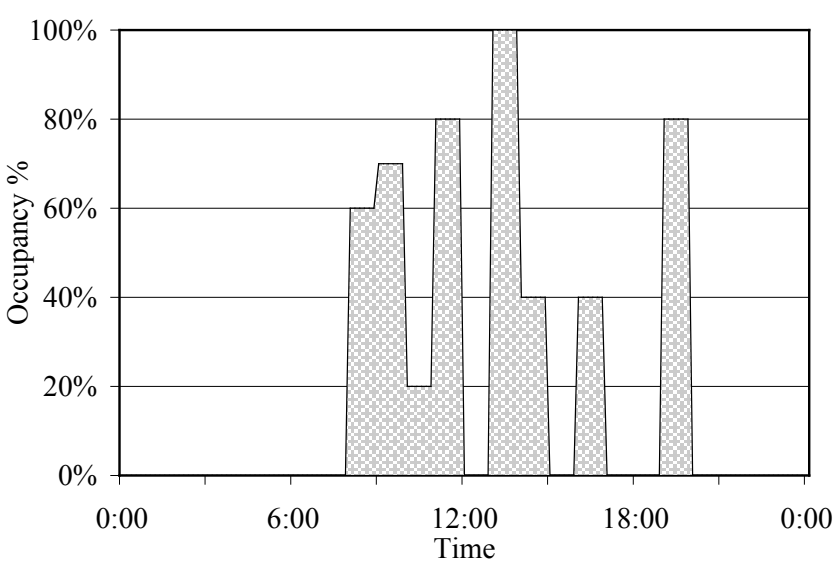

(c) Lecture Hall

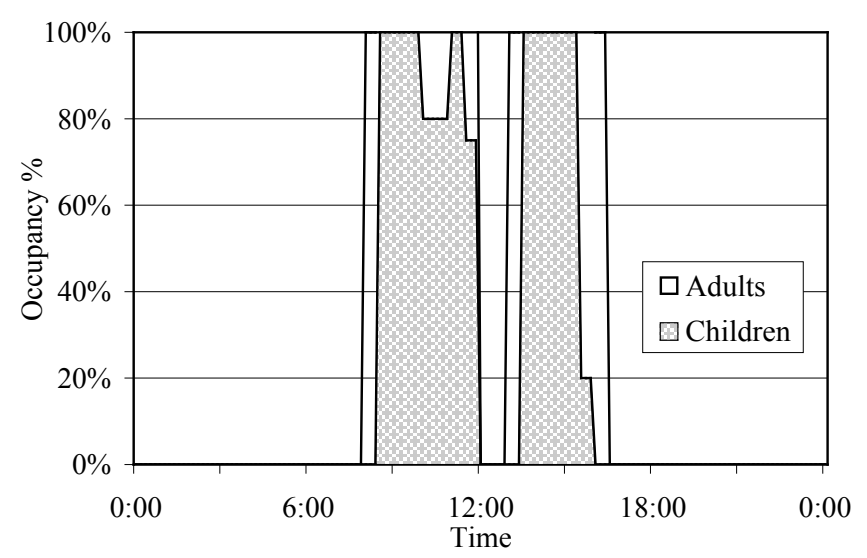

(e) Portable Classroom

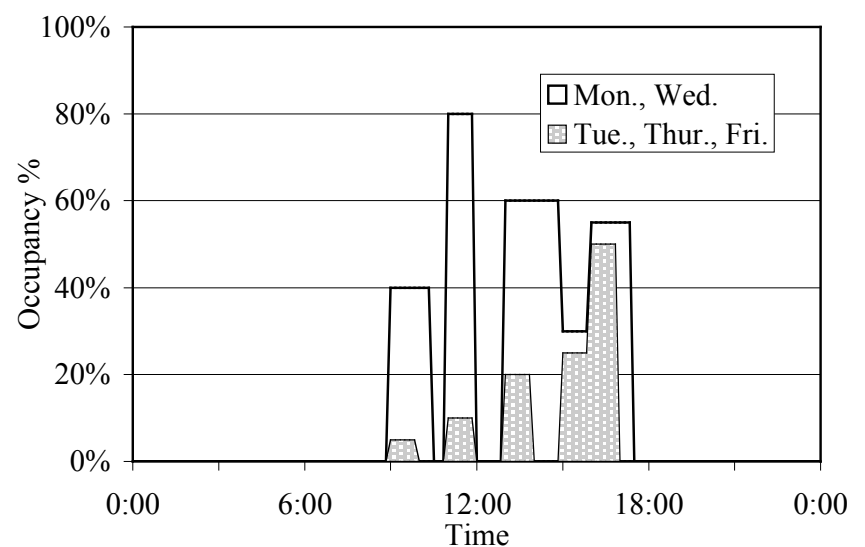

(b) Conference Room

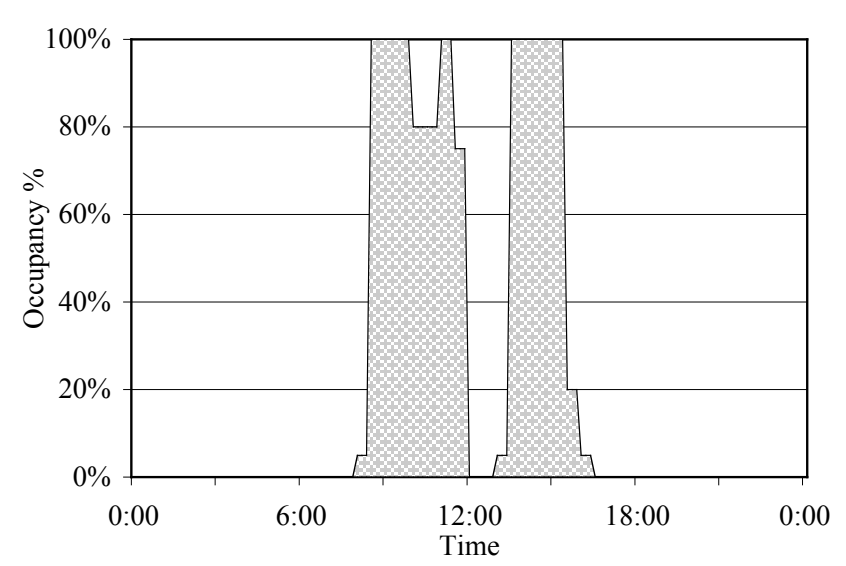

(d) Classroom

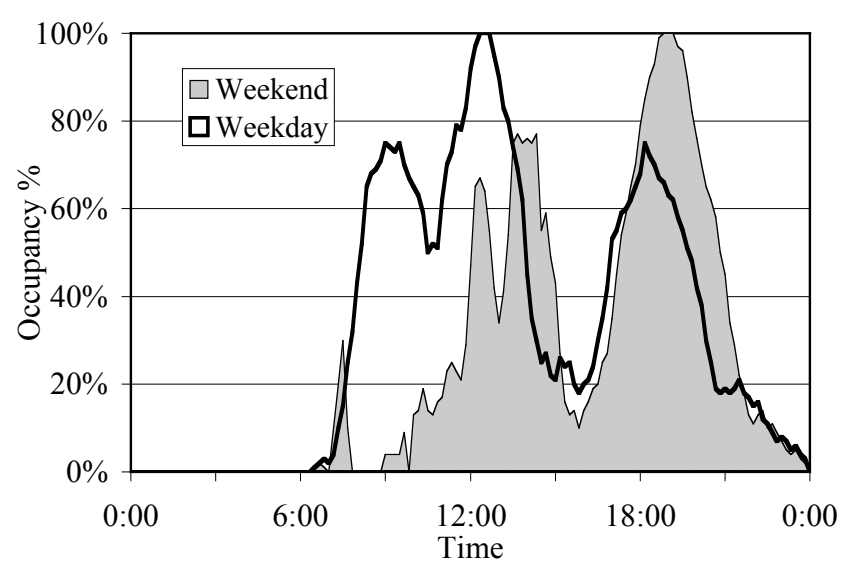

(f) Fast food restaurant

Figure 1 Occupancy Schedules 
Contaminant generation rates

The simulations accounted for two contaminants, occupant-generated carbon dioxide $\left(\mathrm{CO}_{2}\right)$ and a generic volatile organic compound (VOC) intended to represent contaminants from building materials and furnishings. While VOC emissions in buildings are far more complex than the simple approach used here (Levin 1995, Wolkoff 1995), the objective in including VOCs in these simulations was to capture the impact of DCV systems on non-occupant sources that are relatively constant over and time by including a source strength related to the floor area of the space.

In these simulations, $\mathrm{CO}_{2}$ was generated by adults at a rate of $0.3 \mathrm{~L} / \mathrm{min} \bullet$ person, which corresponds to an activity level consistent with office work (ASHRAE 2001b). In the Portable Classroom, children were assumed to generate $\mathrm{CO}_{2}$ at a rate of $0.18 \mathrm{~L} / \mathrm{min} \bullet$ person, a value based on the body size of a ten year old child. Carbon dioxide generation in the Fast Food Restaurant playroom was modeled as $0.3 \mathrm{~L} / \mathrm{min} \bullet$ person, a value appropriate for both sedentary adults and small school children at an activity level of 2.5 met (ASTM 2002, EPA 1999). The emission rate for the generic VOC was assumed to be constant at a rate of $0.25 \mathrm{mg} / \mathrm{h}$ per $\mathrm{m}^{2}$ of floor area during unoccupied periods and $0.50 \mathrm{mg} / \mathrm{h} \bullet \mathrm{m}^{2}$ during occupancy. These values are based on limited field measurements of VOC emission rates (Levin 1995). Although actual contaminant generation rates may differ significantly for different building types, there is not sufficient data available to justify varying these rates in this study. Sorption and re-emission of VOCs from surfaces were not modeled in these simulations, and the outdoor concentrations of $\mathrm{CO}_{2}$ and $\mathrm{VOC}$ were assumed to equal $720 \mathrm{mg} / \mathrm{m}^{3}(400 \mathrm{ppm}(\mathrm{v}))$ and $0 \mathrm{mg} / \mathrm{m}^{3}$ respectively over the entire simulation period.

\subsection{Ventilation Rates and Control Approaches}

The ventilation rates in the spaces were based on ASHRAE Standard 62-2001, the revision to those rates described earlier (Addendum 62n), and the requirements in California's Title 24 (CEC 2001). Table 2 presents the outdoor air requirements for each space based on 62-2001, addendum 62n, and Title 24. For Standard 62-2001, the outdoor air requirements are presented in $\mathrm{L} / \mathrm{s} \bullet$ person (cfm/person) followed by the outdoor air intake requirement for the space based on the number of occupants (see Table 1). These outdoor air intake rates for each space are presented in $\mathrm{L} / \mathrm{s}(\mathrm{cfm})$ and in $\mathrm{L} / \mathrm{s} \bullet \mathrm{m}^{2}\left(\mathrm{cfm} / \mathrm{ft}^{2}\right)$ of floor area. For addendum $62 \mathrm{n}$, the outdoor air requirements are presented as both the people and area rate, which are then combined based on the number of occupants and the floor area of the space given in Table 1. Title 24 requires $7.1 \mathrm{~L} / \mathrm{s}(15 \mathrm{cfm})$ per person based on the larger of the actual design occupancy or $50 \%$ of the exiting density specified by the Uniform Building Code (UBC), with a minimum ventilation rate of $0.76 \mathrm{~L} / \mathrm{s}^{\bullet} \mathrm{m}^{2}\left(0.15 \mathrm{cfm} / \mathrm{ft}^{2}\right)$. Under Title 24 , carbon dioxide DCV cannot be used in the Office, since the $0.76 \mathrm{~L} / \mathrm{s} \bullet \mathrm{m}^{2}\left(0.15 \mathrm{cfm} / \mathrm{ft}^{2}\right)$ minimum is larger than $7.1 \mathrm{~L} / \mathrm{s}(15 \mathrm{cfm})$ for the assumed occupant density. Therefore the outdoor air intake for the Office is based on the floor area rather than the number of people. Also, the assumed occupancy for the Portable Classroom (20 people) is less than $50 \%$ of the UBC exiting density, so the maximum flow rate for that case is based on 24 occupants. Note that since the simulations were originally performed using IP units, the ventilation requirements in Table 2 are correct for IP units. The SI values are converted from the IP values, resulting in slight differences relative to the SI values contained in Standard 62-2001, Addendum 62n and Title 24.

For each space type, Table 2 also contains the steady-state $\mathrm{CO}_{2}$ and VOC concentrations corresponding to the design outdoor air intake rate based on the assumed $\mathrm{VOC}$ and $\mathrm{CO}_{2}$ generation rates. Note that for the Standard 62-2001 ventilation rates, the steady-state $\mathrm{CO}_{2}$ 
concentrations range from about $1500 \mathrm{mg} / \mathrm{m}^{3}$ (900 ppm(v)) to $1900 \mathrm{mg} / \mathrm{m}^{3}$ (1100 ppm(v)), except in the two cases employing the intermittent occupancy provision of the standard. The VOC concentrations vary more widely, over a range of twenty to one, with the variation due primarily to the variation in the floor area per occupant among the spaces. The VOC levels are all range from less than $0.1 \mathrm{mg} / \mathrm{m}^{3}$ to $0.2 \mathrm{mg} / \mathrm{m}^{3}$, with the lowest concentrations in the more densely occupied spaces. Note that these concentrations are on the low end of those reported from field measurements in commercial buildings, which are in this range and even higher in non-problem buildings (Anderson et al. 1997, Brown et al. 1994, Daisey et al. 1994, Hadwen et al. 1997, Wolkoff 1995). Note that the concentrations in Table 2 are all steady-state values, i.e., the values that would eventually exist if the emission rate and ventilation rate were maintained long enough for steady-state conditions to be achieved. However, depending on the occupancy and ventilation schedules, steady-state conditions will not necessarily occur in these spaces.

The outdoor air ventilation rates for the six spaces based on Addendum 62n tend to be lower than those based on 62-2001, particularly in the more densely occupied spaces (Conference Room, Lecture Hall and Restaurant). In fact, part of the reason for the changes in this addendum was the concern that the existing rates in the standard were larger than necessary in densely occupied spaces due to "overcounting" of emissions from floor area-related contaminants. The ventilation rate in the Portable Classroom is slightly higher under 62n based on it having a lower occupancy density than assumed in Standard 62-2001. The lower ventilation rates under the addendum generally result in higher steady-state $\mathrm{CO}_{2}$ levels, particularly in the densely occupied spaces. Most of the values are still in the range of $1800 \mathrm{mg} / \mathrm{m}^{3}(1000 \mathrm{ppm}(\mathrm{v}))$, but the two most densely occupied spaces (Conference Room and Lecture Hall) are closer to $3600 \mathrm{mg} / \mathrm{m}^{3}$ (2000 ppm(v)). The VOC levels for the $62 \mathrm{n}$ rates are generally higher than those based on 62-2001, with the largest increases again seen in the densely occupied spaces. However, the VOC levels are still range from less than $0.1 \mathrm{mg} / \mathrm{m}^{3}$ to $0.3 \mathrm{mg} / \mathrm{m}^{3}$, again on the low end of concentrations measured in the field. Again, these are all steady-state concentrations, which may not necessarily occur in these spaces given the occupancy schedules. Also, these steady-state VOC concentrations are based on the ventilation rates and source strengths assumed to exist during occupied periods and neglect any impacts of higher concentrations that might occur overnight when the system is off.

For Title 24 the steady-state $\mathrm{CO}_{2}$ levels are all approximately $2000 \mathrm{mg} / \mathrm{m}^{3}$ (1100 ppm(v)), with lower levels in the Office and the Portable Classroom. In the office, the lower concentration results from its ventilation requirement under $\mathrm{CO}_{2} \mathrm{DCV}$ being based on $0.76 \mathrm{~L} / \mathrm{s}^{\bullet} \mathrm{m}^{2}$ $\left(0.15 \mathrm{cfm} / \mathrm{ft}^{2}\right)$, which is higher than $7.1 \mathrm{~L} / \mathrm{s}(15 \mathrm{cfm})$ per person. The Portable Classroom outdoor air intake rate is based on 24 occupants rather than the actual 20 occupants based on the Title 24 requirement to assume no less than $50 \%$ of the UBC exiting density. The steady-state VOC concentrations are similar to those seen for Standard 62-2001 and Addendum 62n. 


\begin{tabular}{|c|c|c|c|c|c|}
\hline \multicolumn{6}{|c|}{ Standard 62-2001 } \\
\hline & \multirow[b]{2}{*}{$\begin{array}{l}\text { Outdoor air requirement } \\
\mathrm{L} / \mathrm{s}(\mathrm{cfm}) \text { per person }\end{array}$} & \multicolumn{2}{|c|}{ Outdoor air intake } & \multicolumn{2}{|c|}{$\begin{array}{l}\text { Steady-state } \\
\text { concentration }\end{array}$} \\
\hline Space type & & $\mathrm{L} / \mathrm{s}(\mathrm{cfm})$ & $\begin{array}{c}\mathrm{L} / \mathrm{s} \bullet \mathrm{m}^{2} \\
\left(\mathrm{cfm} / \mathrm{ft}^{2}\right)\end{array}$ & $\begin{array}{l}\mathrm{CO}_{2} \mathrm{mg} / \mathrm{m}^{3} \\
(\mathrm{ppm}(\mathrm{v}))\end{array}$ & $\begin{array}{c}\mathrm{VOC} \\
\mathrm{mg} / \mathrm{m}^{3}\end{array}$ \\
\hline Office & $9.4(20)$ & $661(1400)$ & $0.7(0.13)$ & $1674(930)$ & 0.21 \\
\hline Conference Room & $9.4(20)$ & $472(1000)$ & $4.7(0.93)$ & $1674(930)$ & 0.03 \\
\hline Lecture Hall & $7.1(15)$ & $1062(2250)$ & $10.6(2.09)$ & $1991(1106)$ & 0.01 \\
\hline Classroom & $7.1(15)$ & $248(525)$ & $2.5(0.49)$ & $1991(1106)$ & 0.06 \\
\hline Portable classroom & $7.1(15)$ & $142(300)$ & $1.6(0.31)$ & $1532(851)$ & 0.09 \\
\hline Fast food restaurant & $9.4(20)$ & $661(1400)$ & $5.3(1.04)$ & $1674(930)$ & 0.03 \\
\hline Conference room* & $9.4(20)$ & $236(500)$ & $2.4(0.47)$ & $2626(1459)$ & 0.06 \\
\hline Lecture Hall* & $7.1(15)$ & $531(1125)$ & $5.3(1.05)$ & $3262(1812)$ & 0.03 \\
\hline \multicolumn{6}{|c|}{ * Under intermittent occupancy provision of Standard 62-2001 } \\
\hline \multicolumn{6}{|c|}{ Addendum 62n } \\
\hline & \multirow{2}{*}{$\begin{array}{l}\text { Outdoor air requirement } \\
\mathrm{L} / \mathrm{s}(\mathrm{cfm}) \text { per person/ } \\
\mathrm{L} / \mathrm{s}^{\bullet} \mathrm{m}^{2}\left(\mathrm{cfm} / \mathrm{ft}^{2}\right)\end{array}$} & \multicolumn{2}{|c|}{ Outdoor air intake } & \multicolumn{2}{|c|}{$\begin{array}{l}\text { Steady-state } \\
\text { concentration }\end{array}$} \\
\hline Space type & & $\mathrm{L} / \mathrm{s}(\mathrm{cfm})$ & $\begin{array}{c}\mathrm{L} / \mathrm{s} \bullet \mathrm{m}^{2} \\
\left(\mathrm{cfm} / \mathrm{ft}^{2}\right)\end{array}$ & $\begin{array}{c}\mathrm{CO}_{2} \mathrm{mg} / \mathrm{m}^{3} \\
(\mathrm{ppm}(\mathrm{v}))\end{array}$ & $\begin{array}{l}\mathrm{VOC} \\
\mathrm{mg} / \mathrm{m}^{3}\end{array}$ \\
\hline Office & $2.4 / 0.3(5.0 / 0.06)$ & $470(996)$ & $0.5(0.09)$ & $2061(1145)$ & 0.30 \\
\hline Conference Room & $2.4 / 0.3(5.0 / 0.06)$ & $149(315)$ & $1.5(0.29)$ & $3740(2078)$ & 0.09 \\
\hline Lecture Hall & $3.5 / 0.3(7.5 / 0.06)$ & $562(1190)$ & $5.6(1.11)$ & $3123(1735)$ & 0.03 \\
\hline Classroom & $4.7 / 0.6(10 / 0.12)$ & $226(479)$ & $2.2(0.44)$ & $2113(1174)$ & 0.06 \\
\hline Portable classroom & $4.7 / 0.6(10 / 0.12)$ & $149(315)$ & $1.7(0.33)$ & $1494(830)$ & 0.08 \\
\hline Fast food restaurant & $3.5 / 0.9(7.5 / 0.18)$ & $362(767)$ & $2.9(0.57)$ & $2461(1367)$ & 0.05 \\
\hline \multicolumn{6}{|c|}{ Title 24} \\
\hline & & \multicolumn{2}{|c|}{ Outdoor air intake } & \multicolumn{2}{|c|}{$\begin{array}{l}\text { Steady-state } \\
\text { concentration }\end{array}$} \\
\hline Space type & Outdoor air requirement & L/s (cfm) & $\begin{array}{l}\mathrm{L} / \mathrm{s} \bullet \mathrm{m}^{2} \\
\left(\mathrm{cfm} / \mathrm{ft}^{2}\right)\end{array}$ & $\begin{array}{l}\mathrm{CO}_{2} \mathrm{mg} / \mathrm{m}^{3} \\
(\mathrm{ppm}(\mathrm{v}))\end{array}$ & $\begin{array}{r}\mathrm{VOC} \\
\mathrm{mg} / \mathrm{m}^{3}\end{array}$ \\
\hline Office & $0.76 \mathrm{~L} / \mathrm{s} \cdot \mathrm{m}^{2}\left(0.15 \mathrm{cfm} / \mathrm{ft}^{2}\right)$ & $762(1614)$ & $0.75(0.15)$ & $1546(859)$ & 0.18 \\
\hline Conference Room & $7.1 \mathrm{~L} / \mathrm{s}(15 \mathrm{cfm})$ per person & $354(750)$ & $3.5(0.70)$ & $1991(1106)$ & 0.04 \\
\hline Lecture Hall & $7.1 \mathrm{~L} / \mathrm{s}(15 \mathrm{cfm})$ per person & $1062(2250)$ & $10.6(2.09)$ & $1991(1106)$ & 0.01 \\
\hline Classroom & $7.1 \mathrm{~L} / \mathrm{s}(15 \mathrm{cfm})$ per person & $248(525)$ & $2.5(0.49)$ & $1991(1106)$ & 0.06 \\
\hline Portable classroom & $7.1 \mathrm{~L} / \mathrm{s}(15 \mathrm{cfm})$ per person & $170(360)$ & $1.9(0.38)$ & $1399(777)$ & 0.07 \\
\hline Fast food restaurant & $7.1 \mathrm{~L} / \mathrm{s}(15 \mathrm{cfm})$ per person & $495(1050)$ & $4.0(0.78)$ & $1991(1106)$ & 0.04 \\
\hline
\end{tabular}

Table 2 Design Ventilation Rates and Steady-State Contaminant Levels during Occupancy

Seven ventilation control scenarios were simulated in the six spaces, with one additional scenario applied to two of them. The first three scenarios, based on ASHRAE Standard 62, serve as reference cases for comparing the DCV options. They are:

62/2001: Constant outdoor air intake rates based on ASHRAE Standard 62-2001 and the design occupancy values in Table 1.

62tracking: Outdoor air intake rates that track occupancy (as depicted in Figure 1) perfectly using the ASHRAE Standard 62-2001 rates, i.e., the intake rate always equals the number of occupants times the per person ventilation requirement.

62/Int: Outdoor air intake rate based on $50 \%$ of peak occupancy using the intermittent occupancy approach in the standard (only applied to the Conference Room and Lecture Hall). 
Two cases employing $\mathrm{CO}_{2}$ DCV using the Standard 62-2001 rates were also studied:

C-ZeroMin: Maximum ventilation rate based on ASHRAE Standard 62-2001; minimum ventilation rate equal to zero.

C-25\%Min: Maximum ventilation rate based on ASHRAE Standard 62-2001; minimum ventilation rate equal to $25 \%$ of the maximum.

In addition, two cases were studied based on the revision of the Ventilation Rate Procedure in the standard, so-called addendum 62n:

62n: Constant outdoor air intake rates based on addendum $62 \mathrm{n}$ and the design occupancy values from Table 1.

C-62nAreaMin: $\mathrm{CO}_{2}$ DCV control with the maximum ventilation rate based on the design occupancy and the requirements in addendum 62n; minimum ventilation rate equal to the "area" requirement times the floor area of the space.

Finally, one case followed the requirements of California's Title 24:

C-T24: $\mathrm{CO}_{2} \mathrm{DCV}$ control with the maximum ventilation rate based on the requirement for $7.1 \mathrm{~L} / \mathrm{s}(15 \mathrm{cfm})$ person in these spaces, using the larger of the design occupancy or $50 \%$ of the UBC exiting density. The minimum ventilation rate is based on $0.76 \mathrm{~L} / \mathrm{s}^{\bullet} \mathrm{m}^{2}\left(0.15 \mathrm{cfm} / \mathrm{ft}^{2}\right)$. In the case of the office, the ventilation rate is constant at this minimum level because the per person requirement results in a ventilation rate that is lower than this value.

For the reference cases and the $62 \mathrm{n}$ case, it was not necessary to model outdoor air intake controls. In the simulations, the ventilation system was simply scheduled to turn on and off per the operating schedules described earlier. In the case of 62tracking, in which the outdoor air intake rate was "controlled" to track occupancy perfectly, the fan was set to follow the same schedule as the occupancy. For the cases in which $\mathrm{CO}_{2}$ control was implemented, the control simulation capabilities of CONTAMW were employed. A proportional control algorithm based on previously published descriptions was used (Schell, et al. 1998, Schell and Int-Hout 2001). The proportional controllers were specified to modulate the ventilation rate between the minimum and maximum rates with a linear response to $\mathrm{CO}_{2}$ concentration based on the output $O$ described below. The lower limit of this range was selected to be $90 \mathrm{mg} / \mathrm{m}^{3}$ (50 ppm(v)) higher than the outdoor level, and the upper $\mathrm{CO}_{2}$ limit was set at the equilibrium concentration corresponding to the design occupancy and design ventilation rate under steady conditions $\mathrm{C}_{\mathrm{eq}}$. For the Title 24 case, the upper $\mathrm{CO}_{2}$ limit was set to $1440 \mathrm{mg} / \mathrm{m}^{3}(800 \mathrm{ppm}(\mathrm{v}))$ for all cases, with constant flow at the maximum ventilation rate delivered at all concentrations above this level. The CONTAMW proportional control algorithm calculates the output $O$ according to the following relationship,

$$
O=I \times K_{p}
$$

where $\mathrm{I}$ is the controller input and $\mathrm{K}_{\mathrm{p}}$ is a constant. In this control strategy the controller input is the indoor $\mathrm{CO}_{2}$ concentration minus $810 \mathrm{mg} / \mathrm{m}^{3}$ (450 ppm(v)), and $\mathrm{K}_{\mathrm{p}}$ defined as,

$$
K_{p}=1 /\left[C_{e q}-450 \operatorname{ppm}(v)\right]
$$

Other control algorithms have been proposed and employed for $\mathrm{CO}_{2} \mathrm{DCV}$, such as proportionalintegral control. 


\subsection{Airflow and contaminant analysis}

Each of the cases was simulated in the six spaces for a period of 7 days. The simulations were performed using a 5 min time step and yielded a $\mathrm{CO}_{2}$ and VOC concentration at each time step. In the case of the DCV systems, the simulations also yielded a ventilation rate. These ventilation data were analyzed to yield the average ventilation rate during the occupancy period. The $\mathrm{CO}_{2}$ concentration data were analyzed to yield the average concentration over the occupancy period and the peak hourly average during occupancy. The VOC data were also analyzed to determine the average concentration during occupancy, plus the peak concentration. Plots of $\mathrm{CO}_{2}$ and $\mathrm{VOC}$ concentrations during the simulation period are presented in the results section.

\subsection{Energy analysis}

In order to compare the energy consumption associated with the different ventilation control cases, a simplified approach was used to estimate the heating and cooling loads associated with conditioning the ventilation air to the indoor conditions based on the sensible and latent heat capacity of the outdoor air relative to the indoor air. Therefore, the energy analysis accounts for only the load due to ventilation air, and not the energy required to meet that load, which depends on the type of system used to meet that load. Economizer operation is, however, taken into account by not including any cooling energy consumed when operating in this mode. Also, no energy consumption is assessed when the outdoor air temperature is between the heating balance point and the space temperature

\section{Determination of heating balance point temperature}

The balance point temperature was estimated using a simplified steady-state energy balance in which the heat transferred out of the structure equals the heat transferred in via airflows and internal gains:

$$
\left(\square U A+Q C_{p}\right) T_{o}+q=\left(\square U A+Q C_{p}\right) T_{i}
$$

where,

$$
\begin{aligned}
& \square U A=\text { building envelope thermal conductance } \\
& Q=\text { mass flow rate of ventilation air } \\
& C_{p}=\text { specific heat of air } \\
& T_{o}=\text { outdoor temperature } \\
& T_{i}=\text { indoor temperature } \\
& q=\text { internal heat gains }
\end{aligned}
$$

The heating balance point temperature is the outdoor temperature at which internal heat gains are equal to the heat loss rate at a given ventilation rate and indoor temperature, $T_{i}$. Heating is required below this temperature, and internal gains maintain the building at the heating setpoint above this temperature. The heating balance point, $T_{h b p}$, can be defined as:

$$
T_{h b p}=T_{i}-q /\left(\square U A+Q C_{p}\right)
$$

The thermal conductance term $(\square U A)$ is often much smaller than the ventilation flow term in equation (4) for commercial buildings, and is sometimes neglected. However, since some of the airflow control strategies allowed the airflow to occasionally go to zero, it was maintained for this analysis. However, the accuracy of the thermal conductance term is not critical, since the $Q C_{p}$ term is usually much larger than the $U A$ term. The value of $\square U A$ was estimated based on 
ASHRAE Standard 90.1 envelope requirements (ANSI/ASHRAE/IESNA 1999). During the few times when the ventilation flow rate does approach zero, the heating balance point is so low that it was not reached in any of the climates investigated.

Table 3 shows the internal heat gain used for each space, which were estimated using data published for nonresidential cooling and heating load calculations by ASHRAE (2001b).

Occupant heat gains were based on the average modeled occupancy during the occupied period and assumed occupant activity levels. Heat gain from lighting was estimated using the installed lighting load from ASHRAE Standard 90.1 (ANSI/ASHRAE/IESNA 1999), adjusted for usage and allowance factors. Heat gain from 80 computers was included for the office.

\begin{tabular}{|l|c|c|c|c|}
\hline & Occupants & Lighting & Computers & Total \\
\hline Space & $\mathrm{W} / \mathrm{m}^{2}$ & $\mathrm{~W} / \mathrm{m}^{2}$ & $\mathrm{~W} / \mathrm{m}^{2}$ & $\mathrm{~W} / \mathrm{m}^{2}$ \\
\hline Office & 4.9 & 12.1 & 10.0 & 27.0 \\
\hline Conference Room & 9.8 & 6.4 & 0.0 & 16.2 \\
\hline Lecture Hall & 42.0 & 9.3 & 0.0 & 51.3 \\
\hline Classroom & 16.1 & 9.3 & 0.0 & 25.4 \\
\hline Portable Classroom & 7.8 & 9.3 & 0.0 & 17.1 \\
\hline Fast Food Restaurant & 17.3 & 20.1 & 0.0 & 37.3 \\
\hline
\end{tabular}

Table 3 Internal Heat Gains Used to Estimate Balance Point

The weekly CONTAM simulations, repeated for an entire year, were used to determine the ventilation mass flow rate in equation (4). And because the heating balance point depends on this flow rate, it was calculated individually for each hour of the year.

$\underline{\text { Heating load }}$

Based on the estimated heating balance point temperature, the heating load associated with ventilation was calculated for each hour in which the outdoor temperature was below the heating balance point using the relationship:

$$
q_{\text {heating }}=Q C_{p}\left(T_{i}-T_{o}\right)
$$

where,

$$
\begin{aligned}
& q_{\text {heating }}=\text { heating load } \\
& Q=\text { mass flow rate of ventilation air } \\
& C_{p}=\text { specific heat of air } \\
& T_{o}=\text { outdoor temperature } \\
& T_{i}=\text { indoor temperature (assumed } 22^{\circ} \mathrm{C} \text { year round) }
\end{aligned}
$$

\section{Cooling load}

When the outdoor temperature is greater than the indoor temperature, the additional sensible cooling load $q_{\text {cooling }}$ associated with the ventilation air can be calculated from the relationship:

$$
q_{\text {cooling }}=Q C_{p}\left(T_{o}-T_{i}\right)
$$

Whether or not a latent cooling load exists depends, to some extent, on the latent loads as well as the degree of humidity control that can be achieved by the means of thermal conditioning in the space. For this simplified model, it was assumed that the thermal control strategy was capable of maintaining a maximum indoor relative humidity of $60 \%$. Therefore, when the outdoor humidity ratio exceeds this humidity ratio upper limit, a latent load associated with ventilation is assessed:

$$
q_{\text {latent }}=Q h_{f g}\left(W_{o}-W_{\text {limit }}\right)
$$


where,

$q_{\text {latent }}=$ latent cooling load

$Q=$ mass flow rate of ventilation air

$h_{f g}=$ latent heat capacity of moist air

$W_{o}=$ outdoor humidity ratio

$W_{\text {limit }}=$ indoor humidity ratio (defined at $60 \%$ relative humidity at $22{ }^{\circ} \mathrm{C}$ )

The energy calculations assume that each space operates with a return air temperature economizer that uses outdoor air for cooling. Under this strategy the system provides $100 \%$ outdoor air when the outdoor dry bulb temperature is between the supply air temperature and the indoor temperature. Some mechanical cooling will be required under these conditions, but it will be less than would be needed if indoor air was recirculated. When the outdoor temperature is above the heating balance point but below the system supply temperature, the economizer strategy mixes return air with a volume of outdoor air greater than that needed for ventilation, and neither cooling nor heating is required. In both of these cases, thermal conditioning and control, not the ventilation control strategy, dictate the amount of outdoor air supplied to the spaces. Since our approach is intended to determine the heating and cooling loads associated with ventilation, cooling energy consumed in this mode is not included in the reported values.

The heating, cooling, and latent loads associated with ventilation were calculated for every hour during which the ventilation system was assumed to be operating. These were then summed for each case over an entire year of weather data for the six cities identified below.

\section{Climates analyzed}

Based on the methodology outlined above, the energy consumption was estimated for four California climates (Bakersfield, Los Angeles, Sacramento, and San Francisco) selected to cover a range of coastal and inland climates. As points of reference, Miami (hot and humid) and Minneapolis (cold) were also analyzed. These energy estimates employed TMY2 weather data (Marion and Urban 1995), except for Sacramento and Miami for which WYEC data (ASHRAE 1997) was used. Table 3 summarizes the weather data for these six climates.

\begin{tabular}{|l|c|c|}
\hline \multicolumn{1}{|c|}{ City } & Heating degree days ${ }^{\circ} \mathbf{C}\left({ }^{\circ} \mathbf{F}\right)$ & Cooling degree days ${ }^{\circ} \mathbf{C}\left({ }^{\circ} \mathbf{F}\right)$ \\
\hline Bakersfield & $1213(2183)$ & $1210(2178)$ \\
\hline Los Angeles & $1010(1816)$ & $341(614)$ \\
\hline Sacramento & $1579(2842)$ & $643(1157)$ \\
\hline San Francisco & $1690(3042)$ & $60(108)$ \\
\hline Miami & $114(205)$ & $2243(4037)$ \\
\hline Minneapolis & $4532(8158)$ & $325(585)$ \\
\hline
\end{tabular}

Table 4 Summary of Six Climates Analyzed (Knapp et al. 1980) 


\section{RESULTS}

This section presents the results of the simulations for the six space types, seven ventilation control approaches and six climates. These results are presented separately for the ventilation rates, $\mathrm{CO}_{2}$ and VOC contaminant concentrations, and energy loads.

\subsection{Ventilation Rates}

The ventilation rates for the different space types and control strategies are summarized in Table 5. Note that these rates are inputs to the contaminant simulations for three of the cases $(62 / 2001$, 62 tracking and 62n), as well as 62/Int when relevant, but are calculated during the simulations for the four DCV cases (C-ZeroMin, C-25\%Min, C-62nMinArea and C-T24). Also note that the intermittent occupancy case is only applied to the Conference Room and Lecture Hall. Also, while the Title 24 case is thought of as DCV, in the case of the Office it is in fact a constant ventilation rate based on the minimum outdoor air requirement of $0.76 \mathrm{~L} / \mathrm{s} \bullet \mathrm{m}^{2}\left(0.15 \mathrm{cfm} / \mathrm{ft}^{2}\right)$.

For each space and control strategy, Table 5 contains the average, minimum and maximum outdoor air intake during occupancy in units of airflow rate per person $\mathrm{L} / \mathrm{s} \bullet$ person $(\mathrm{cfm} /$ person). Also, in the first column, the table presents the per person design value for outdoor air intake for Standard 62-2001, addendum 62n and Title 24. The calculations were initially performed in IP units and converted to SI units. Therefore, some of the SI values are slightly different from those that appear in Standard 62, addendum 62n and Title 24. The last column of the table contains the minimum and maximum per person outdoor air intake during periods of time when the space is at its maximum occupancy level. For some spaces (e.g., Office) the space is at maximum occupancy for many hours, while for other spaces (e.g., Fast Food) maximum occupancy occurs for only short periods of time. Note that the Conference Room is never at its design occupancy of 50 people, but rather has a maximum occupancy of 40 .

The maximum rates during occupancy in Table 5, for all but the 62 tracking case, are well above the relevant requirements of Standard 62,62n or Title24. This is particularly true for cases $62 / 2001$ and $62 \mathrm{n}$ in which the design outdoor air intake is in effect whenever the system operates, which results in high per person rates when the occupancy is low. For the 62 tracking case, the averages, minimums and maximums are all equal to the Standard 62 requirement as expected, except in the Portable Classroom because the 62tracking case is actually based on the $\mathrm{CO}_{2}$ generation rates of the occupants. (Since different $\mathrm{CO}_{2}$ generation rates are used for the adults and children in that space, there is some variation in the per person rates based on whether the space is occupied by only the adults or by the whole class.) The minimum per person rate for the case of C-ZeroMin is always zero, since the intake is at its minimum position (zero intake) until the $\mathrm{CO}_{2}$ levels build-up after the space has been occupied for some time. The other $\mathrm{CO}_{2}$ DCV cases also have minimum per person rates below the rate required by the standard, as the indoor $\mathrm{CO}_{2}$ levels are too low at the start of occupancy for the $\mathrm{CO}_{2}$ controls to induce outdoor air intake. However, these low rates are temporary and not unexpected.

Figures 2 through 7 are plots of the total ventilation rates, including infiltration, for each of the spaces and ventilation control approaches over a period of one or two days. The one-day plots all contain data for a Friday, to capture the impact of any $\mathrm{CO}_{2}$ buildup over the week in cases where the assumed infiltration rate of $0.1 \mathrm{~h}^{-1}$ is not sufficient to bring the indoor $\mathrm{CO}_{2}$ level down to the outdoor level overnight. For the $\mathrm{CO}_{2}$ control cases, this residual $\mathrm{CO}_{2}$ leads to a low level of ventilation early in the morning. For the spaces with occupancy patterns that vary by day of the week, two days are presented in the corresponding figure. Specifically, Figure 3 presents the ventilation rates for Wednesday and Thursday in the Conference Room, and Figure 6 presents 
Friday and Saturday for the Fast Food Restaurant. In all the figures, the 62-2001 and 62n cases are horizontal lines indicating constant ventilation rates when the system operates. The Title 24 case C-T24 results in a constant intake rate for the office space as discussed earlier. The intermittent occupancy cases (62-Int) in the Conference Room and the Lecture Hall, Figures 3 and 4 respectively, also exhibit constant ventilation rates. The 62tracking case appears as a solid black line in all the figures, with the ventilation rate corresponding to the occupancy schedule of the given space. The four control cases (C-ZeroMin, C25\%Min, C-62nAreaMin and C-T24) exhibit more variation as the controls respond to the indoor $\mathrm{CO}_{2}$ level. They generally start each day low relative to the constant ventilation rate cases, with the ventilation rates increasing as the indoor $\mathrm{CO}_{2}$ levels increase.

Referring to Table 5, the results for the Office exhibit a number of trends that are also reflected in most of the other spaces. The average per-person outdoor air intake rate is the second highest for the $62 / 2001$ case in which the intake rate is always equal to $9.4 \mathrm{~L} / \mathrm{s}(20 \mathrm{cfm})$ times the maximum number of occupants. Under low occupancy, the constant intake rate is divided by a relatively small number of people, yielding per person ventilation rates with a maximum value of $94 \mathrm{~L} / \mathrm{s}(200 \mathrm{cfm})$. The lowest average intake rate is for 62tracking, in which the system always brings in $9.4 \mathrm{~L} / \mathrm{s}(20 \mathrm{cfm})$ per person times the number of people in the space. The $62 \mathrm{n}$ rate is also constant during system operation, but at a lower value than 62/2001, resulting in a lower average ventilation rate but still yielding high maximum values when occupancy is low. The CT24 case has the highest rates in the Office based on the minimum requirement. Other than 62 tracking, all the ventilation strategies have high per person intake rates at low occupancy relative to the design values. The control approaches based on the Standard 62 rates (C-ZeroMin and $\mathrm{C}-25 \% \mathrm{Min}$ ) both have average ventilation rates higher than 62 tracking. Therefore, while these $\mathrm{CO}_{2}$ control strategies may have lower ventilation rates during periods of the day, overall they provide more ventilation air than a "perfect" control system, presumably a desirable and conservative outcome from an indoor air quality perspective.

Figure 2 is a plot of the total outdoor air ventilation rate (intake plus infiltration) for a single day in the Office. Note that the two $\mathrm{CO}_{2}$ control strategies using the Standard 62 rates, $\mathrm{C}-25 \% \mathrm{Min}$ and C-ZeroMin, track the idealized case of 62 tracking fairly well, with some "underventilation" early in the day and some "overventilation" after occupancy has peaked and towards the end of the day. However, one could argue that one would desire overventilation at these times to "flush out" residual contaminants and that one could tolerate some underventilation early in the day before contaminants have built up. However, overventilation late in the workday can have an energy penalty in hot weather. The use of the terms underventilation and overventilation are only relative to the rates required by the standard or addendum (design values). The $\mathrm{C}-25 \% \mathrm{Min}$ case is more conservative, in that it starts the day with higher ventilation rates relative to the 62tracking and 62-ZeroMin cases. The C-62nAreaMin case is even more conservative in the early part of the day, based on its higher minimum ventilation rate, but it does not provide as much ventilation later in the day as the other DCV cases. 


\begin{tabular}{|c|c|c|c|c|c|}
\hline & \multicolumn{5}{|c|}{ Outdoor Air Intake Rate (neglecting infiltration) L/s•person (cfm/person) } \\
\hline & \multirow{2}{*}{$\begin{array}{l}\text { Design } \\
\text { value }\end{array}$} & \multicolumn{3}{|c|}{ During Occupancy } & \multirow{2}{*}{$\begin{array}{c}\text { Min/Max at } \\
\text { maximum occupancy }\end{array}$} \\
\hline & & Average & Minimum & Maximum & \\
\hline \multicolumn{6}{|l|}{ Office } \\
\hline $62 / 2001$ & $9.4(20.0)$ & $24.0(50.9)$ & $9.4(20.0)$ & $94.0(200.0)$ & $9.4 / 9.4(20.0 / 20.0)$ \\
\hline 62tracking & -- & $9.4(20.0)$ & $9.4(20.0)$ & $9.4(20.0)$ & $9.4 / 9.4(20.0 / 20.0)$ \\
\hline C-ZeroMin & -- & $12.1(25.7)$ & $0(0)$ & $65.0(137.8)$ & $6.1 / 8.9(12.9 / 18.8)$ \\
\hline $\mathrm{C}-25 \% \mathrm{Min}$ & -- & $14.7(31.2)$ & $5.0(10.5)$ & $70.9(150.3)$ & $6.6 / 9.0(13.9 / 19.0)$ \\
\hline $62 n$ & $6.8(14.4)$ & $16.3(34.6)$ & $6.4(13.6)$ & $64.1(135.7)$ & $6.4 / 6.4(13.6 / 13.6)$ \\
\hline C-62nAreaMin & -- & $13.2(27.9)$ & $5.1(10.7)$ & $56.9(120.6)$ & $5.1 / 6.2(10.7 / 13.1)$ \\
\hline $\mathrm{C}-\mathrm{T} 24$ & $10.8(23.1)$ & $27.8(58.8)$ & $10.9(23.1)$ & $108.9(230.8)$ & $10.9 / 10.9(23.1 / 23.1)$ \\
\hline \multicolumn{6}{|c|}{ Conference Room } \\
\hline $62 / 2001$ & $9.4(20.0)$ & $49.4(104.7)$ & $11.8(25.0)$ & $188.9(400.1)$ & $11.8 / 11.8(25.0 / 25.0)$ \\
\hline 62tracking & -- & $9.4(20.0)$ & $9.4(20.0)$ & $9.4(20.0)$ & $9.4 / 9.4(20.0 / 20.0)$ \\
\hline $62 /$ Int & -- & $24.7(52.4)$ & $5.9(12.5)$ & $94(200.0)$ & $5.9 / 5.9(12.5 / 12.5)$ \\
\hline C-ZeroMin & -- & $13.2(28.0)$ & $0(0)$ & $26.3(55.8)$ & $2.0 / 10.4(4.2 / 22.1)$ \\
\hline $\mathrm{C}-25 \% \mathrm{Min}$ & -- & $19.7(41.7)$ & $3.7(7.9)$ & $53.4(113.1)$ & $3.7 / 10.6(7.9 / 22.5)$ \\
\hline $62 n$ & $3.9(8.2)$ & $15.3(32.5)$ & $3.7(7.8)$ & $58.5(124.0)$ & $3.7 / 3.7(7.8 / 7.8)$ \\
\hline C-62nAreaMin & -- & $5.2(11.0)$ & $1.4(3.0)$ & $13.4(28.3)$ & $1.6 / 3.1(3.4 / 6.5)$ \\
\hline C-T24 & $7.1(15.0)$ & $17.0(36.0)$ & $3.1(6.6)$ & $42.7(90.5)$ & $3.2 / 8.9(6.8 / 18.8)$ \\
\hline \multicolumn{6}{|l|}{ Lecture Hall } \\
\hline $62 / 2001$ & $7.1(15.0)$ & $14.7(31.1)$ & $7.1(15.0)$ & $35.4(75.0)$ & $7.1 / 7.1(15 / 15)$ \\
\hline 62tracking & -- & $7.1(15.0)$ & $7.1(15.0)$ & $7.1(15.0)$ & $7.1 / 7.1(15 / 15)$ \\
\hline 62/Int & -- & $7.4(15.6)$ & $3.5(7.5)$ & $17.7(37.5)$ & $3.5 / 3.5(7.5 / 7.5)$ \\
\hline C-ZeroMin & -- & $10.1(21.4)$ & $0(0)$ & $31.6(67.0)$ & $0.8 / 7.1(1.8 / 15.0)$ \\
\hline $\mathrm{C}-25 \% \mathrm{Min}$ & -- & $10.8(22.9)$ & $2.0(4.3)$ & $32.1(68.1)$ & $2.0 / 7.1(4.3 / 15.0)$ \\
\hline $62 n$ & $3.8(8.0)$ & $7.8(16.6)$ & $3.8(8.0)$ & $18.9(40.0)$ & $3.8 / 3.8(8.0 / 8.0)$ \\
\hline C-62nAreaMin & -- & $5.3(11.2)$ & $0.3(0.7)$ & $16.5(35.0)$ & $0.9 / 3.8(1.9 / 8.0)$ \\
\hline $\mathrm{C}-\mathrm{T} 24$ & $7.1(15.0)$ & $12.8(27.1)$ & $0.8(1.8)$ & $35.4(75.0)$ & $1.3 / 7.1(2.7 / 15.0)$ \\
\hline \multicolumn{6}{|l|}{ Classroom } \\
\hline $62 / 2001$ & $7.1(15.0)$ & $35.9(76.1)$ & $7.0(14.9)$ & $140.3(297.2)$ & $7.0 / 7.0(14.9 / 14.9)$ \\
\hline 62tracking & & $7.0(14.9)$ & $7.0(14.9)$ & $7.0(14.9)$ & $7.0 / 7.0(14.9 / 14.9)$ \\
\hline C-ZeroMin & & $12.1(25.6)$ & $0(0)$ & $71.4(151.2)$ & $0.2 / 6.9(0.4 / 14.7)$ \\
\hline $\mathrm{C}-25 \% \mathrm{Min}$ & & $17.1(36.3)$ & $1.8(3.8)$ & $84.9(179.8)$ & $1.8 / 6.9(3.8 / 14.7)$ \\
\hline $62 n$ & $6.7(14.2)$ & $32.1(68.1)$ & $6.3(13.3)$ & $125.6(266.1)$ & $6.3 / 6.3(13.3 / 13.3)$ \\
\hline C-62nAreaMin & & $15.6(33.0)$ & $1.6(3.4)$ & $77.9(165.0)$ & $1.6 / 6.2(3.4 / 13.1)$ \\
\hline $\mathrm{C}-\mathrm{T} 24$ & $7.1(15.0)$ & $20.2(42.7)$ & $2.2(4.6)$ & $111.6(236.5)$ & $2.2 / 7.0(4.6 / 14.9)$ \\
\hline \multicolumn{6}{|c|}{ Portable Classroom } \\
\hline $62 / 2001$ & $7.1(15.0)$ & $21.2(44.9)$ & $7.0(14.9)$ & $70.1(148.6)$ & $7.0 / 7.0(14.9 / 14.9)$ \\
\hline 62tracking & & $7.9(16.7)$ & $7.0(14.9)$ & $10.9(23.1)$ & $7.0 / 7.0(14.9 / 14.9)$ \\
\hline C-ZeroMin & & $9.7(20.6)$ & $0(0)$ & $43.2(91.6)$ & $0.5 / 6.9(1.0 / 14.6)$ \\
\hline $\mathrm{C}-25 \% \mathrm{Min}$ & & $12.0(25.4)$ & $1.9(4.1)$ & $48.4(102.5)$ & $1.9 / 6.9(4.1 / 14.6)$ \\
\hline $62 n$ & $7.7(16.2)$ & $21.7(45.9)$ & $7.2(15.2)$ & $71.7(152.1)$ & $7.2 / 7.2(15.2 / 15.2)$ \\
\hline C-62nAreaMin & & $13.3(28.1)$ & $2.6(5.6)$ & $51.6(109.4)$ & $2.6 / 7.1(5.6 / 15.0)$ \\
\hline $\mathrm{C}-\mathrm{T} 24$ & $8.5(18.0)$ & $16.0(33.9)$ & $3.6(7.6)$ & $60.4(127.9)$ & $3.6 / 8.4(7.6 / 17.7)$ \\
\hline \multicolumn{6}{|l|}{ Fast Food } \\
\hline $62 / 2001$ & $9.4(20.0)$ & $65.2(138.1)$ & $9.4(20.0)$ & $944.0(2000.0)$ & $9.4 / 9.4(20.0 / 20.0)$ \\
\hline 62tracking & & $9.4(20.0)$ & $9.4(20.0)$ & $9.4(20.0)$ & $9.4 / 9.4(20.0 / 20.0)$ \\
\hline C-ZeroMin & & $16.4(34.8)$ & $0(0)$ & $87.0(184.4)$ & $9.2 / 9.3(19.5 / 19.8)$ \\
\hline $\mathrm{C}-25 \% \mathrm{Min}$ & & $26.2(55.5)$ & $9.0(19.0)$ & $236.1(500.1)$ & $9.2 / 9.3(19.5 / 19.8)$ \\
\hline $62 \mathrm{n}$ & $5.1(10.8)$ & $35.3(74.7)$ & $5.1(10.8)$ & $510.7(1082.0)$ & $5.1 / 5.1(10.8 / 10.8)$ \\
\hline C-62nAreaMin & & $15.9(33.6)$ & $4.5(9.6)$ & $151.8(321.6)$ & $4.8 / 5.0(10.1 / 10.5)$ \\
\hline C-T24 & $7.1(15.0)$ & $21.5(45.5)$ & $7.1(15.0)$ & $136.2(288.5)$ & $7.1 / 7.1(15.0 / 15.0)$ \\
\hline
\end{tabular}

Table 5 Summary of Ventilation Rates 
The Conference Room ventilation results are also presented in Table 5, with the additional case of 62/Int, which implements the intermittent occupancy provision of Standard 62-2001. The highest average intake rate is for $62 / 2001$. Note that the conference room is never occupied at its design value of 50 occupants; the maximum is 40 in these simulations, and this value only occurs for a few hours on Mondays and Wednesdays. Based on the lower and more variable occupancy pattern relative to the Office, the maximum ventilation rates for the $\mathrm{CO}_{2}$ control approaches are not as high relative to 62-2001 as in the Office. In the Office control cases, the ventilation rates continue to increase over several hours of high occupancy. However, in the Conference Room the occupancy drops before the $\mathrm{CO}_{2}$ levels get as high, and the ventilation rates are lower on average. Figure 3 presents the Conference Room ventilation rates for Wednesday and Thursday of the simulation period. The most significant difference from the Office results in Figure 2 is seen for the $\mathrm{CO}_{2}$ control cases that "overshoot" the 62tracking case. This "overshooting" occurs during the short periods of elevated occupancy because these peak occupancy levels are below the design value and the maximum ventilation rate in the $\mathrm{CO}_{2}$ control algorithm is based on the design occupancy. The Conference Room in fact never achieves the design occupancy, and therefore this overshoot occurs for all the occupancy peaks.

The Lecture Hall results in Table 5 are similar to those for the Conference Room except all the rates are lower given the lower design ventilation rates. Also, the Lecture Hall does attain its design occupancy level, even if only briefly. The Lecture Hall ventilation rates are plotted in Figure 4 and also exhibit the "overshoot" relative to the 62 tracking case that is seen in the Conference Room. However, the occupancy peak that occurs after lunch is at the design occupancy level and therefore no overshoot is seen here.

The results for the Classroom and Portable Classroom are similar, with some differences seen due to the lower occupancy density and lower average $\mathrm{CO}_{2}$ generation rate in the Portable Classroom. These differences generally result in lower per person ventilation rates. The ventilation rates plotted in Figures 5 and 6 for the two spaces exhibit very similar patterns, with the values lower in the Portable Classroom. Note that the C-T24 case has the highest ventilation rates of the control cases in both classrooms, notably so in the Portable Classroom.

The Fast Food Restaurant has an extremely variable occupancy pattern in which the design occupancy pattern is only achieved briefly once during each day. Therefore, the ratio of the average and maximum per person ventilation rates to the design value for the $62 / 2001$ and $62 n$ case are highest for this space. The ventilation rates for Friday and Saturday in this space are plotted in Figure 7. 


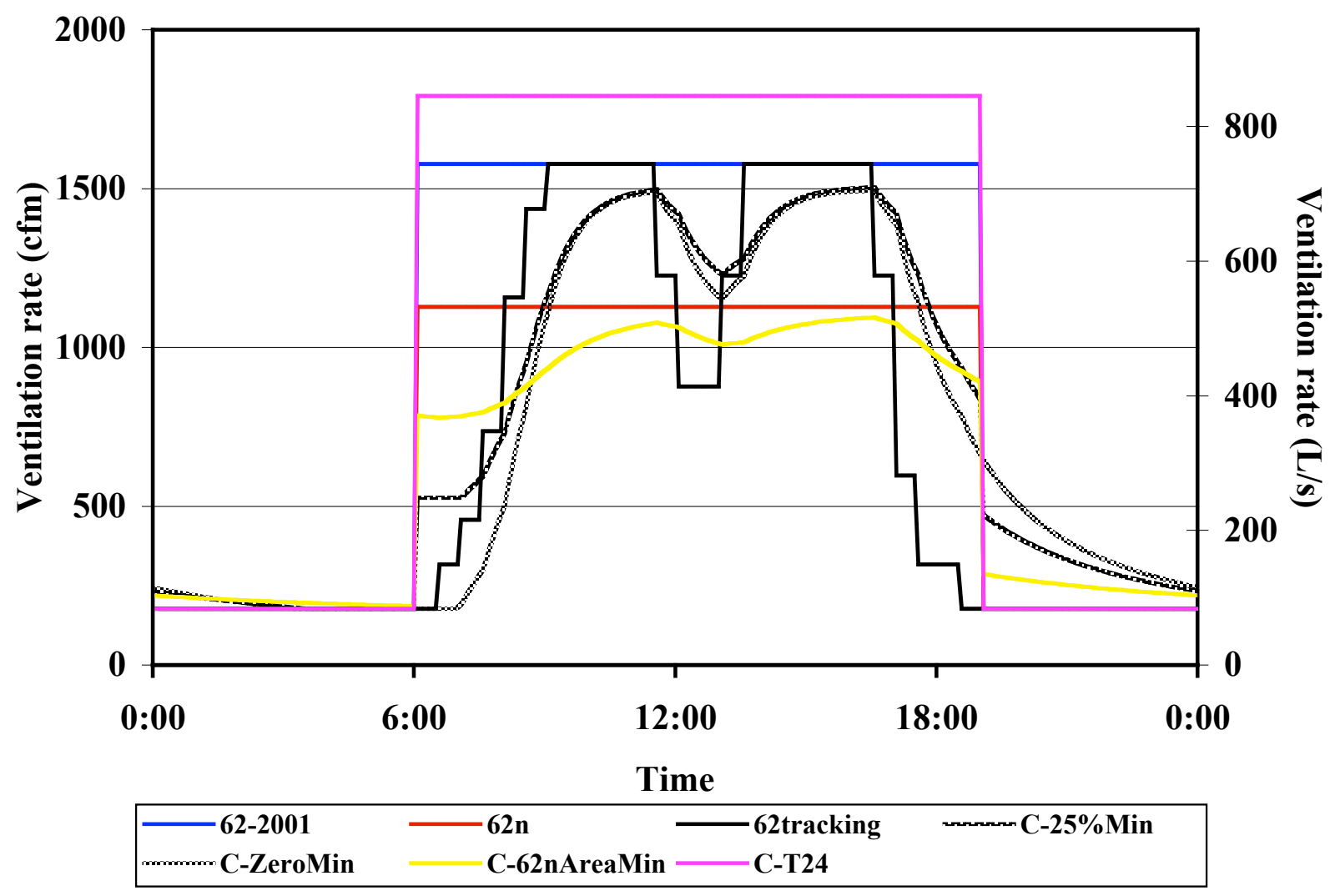

Figure 2 Office Ventilation Rates during Weekday (Friday)

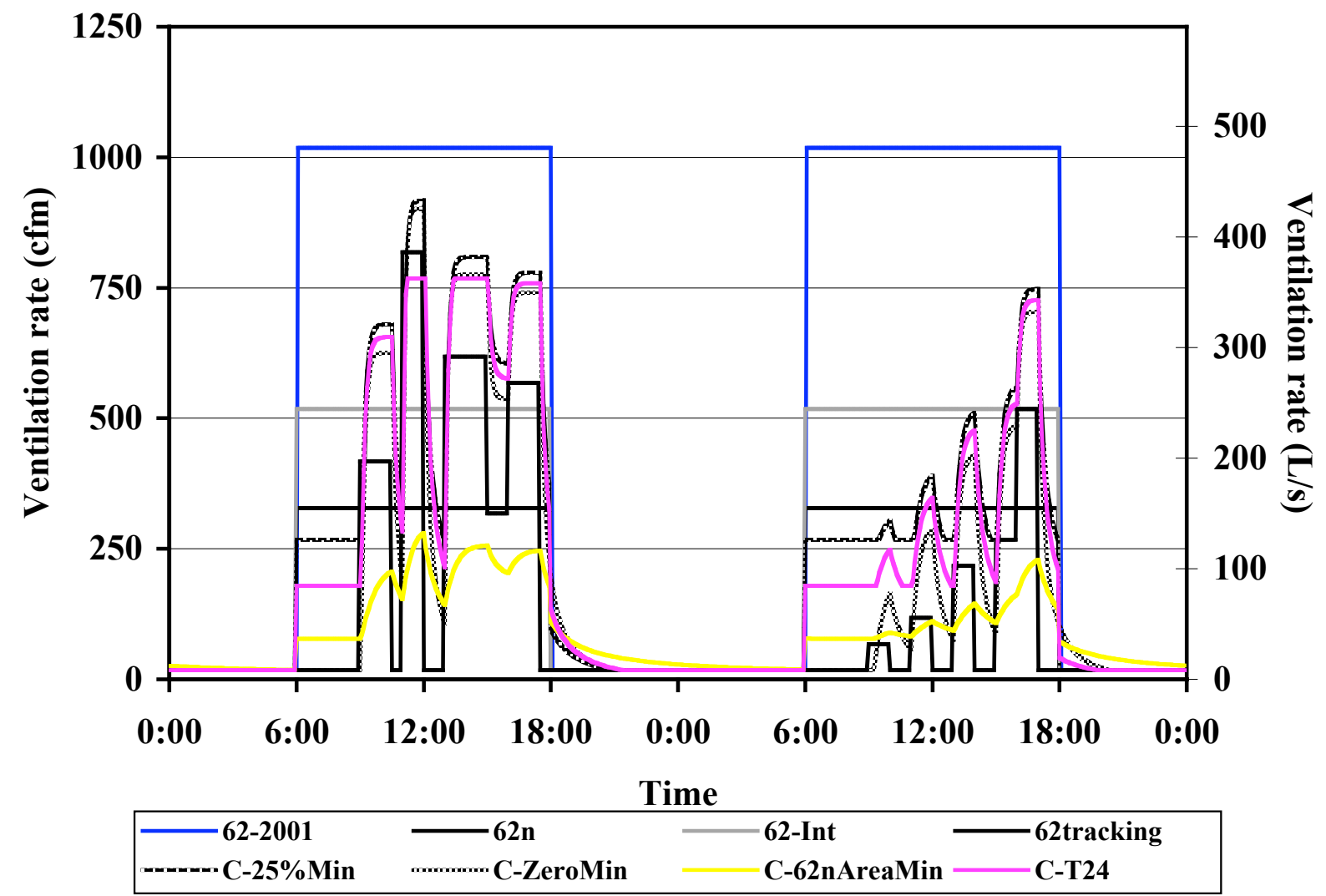

Figure 3 Conference Room Ventilation Rates during Week (Wednesday and Thursday) 


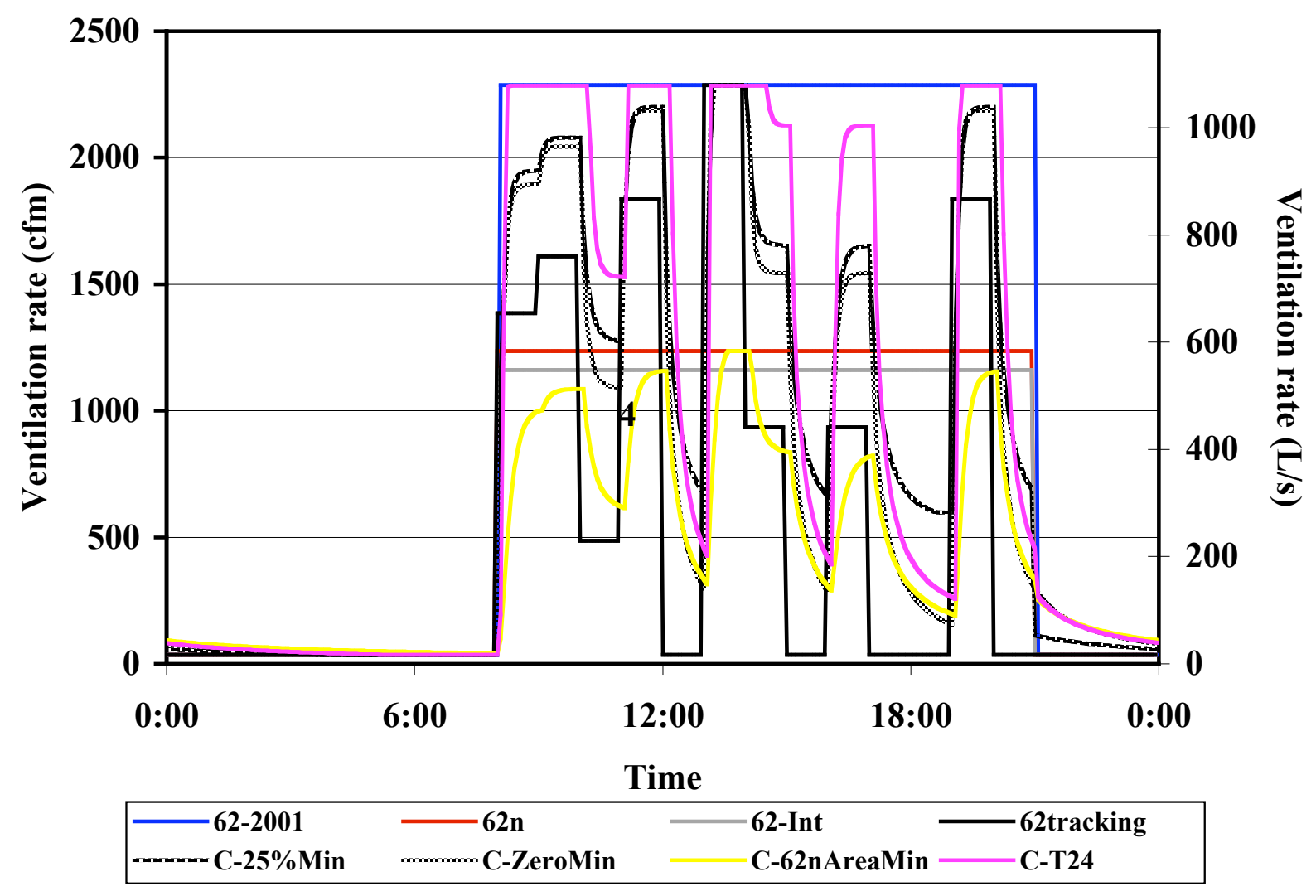

Figure 4 Lecture Hall Ventilation Rates during Week (Friday)

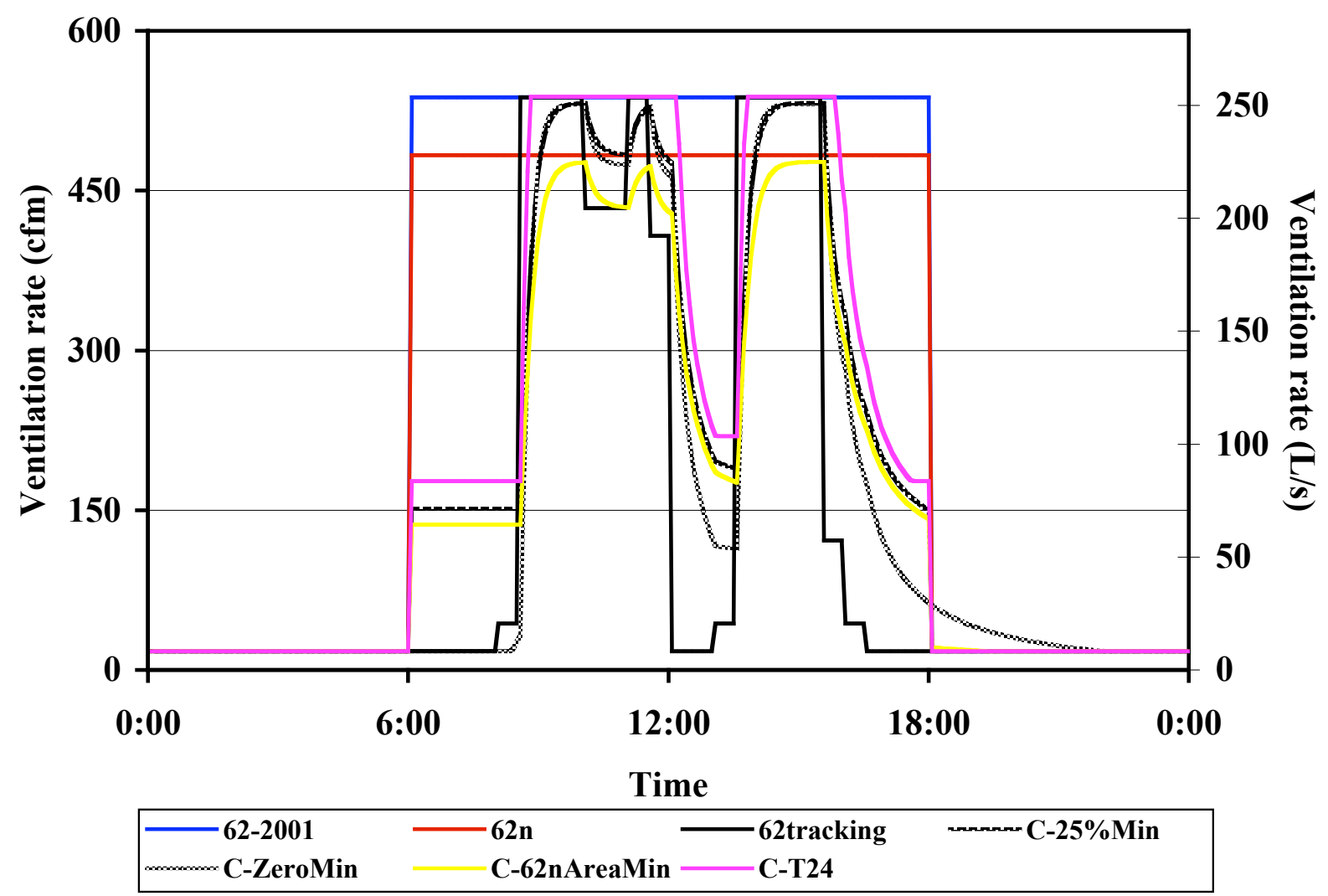

Figure 5 Classroom Ventilation Rates during Week (Friday) 


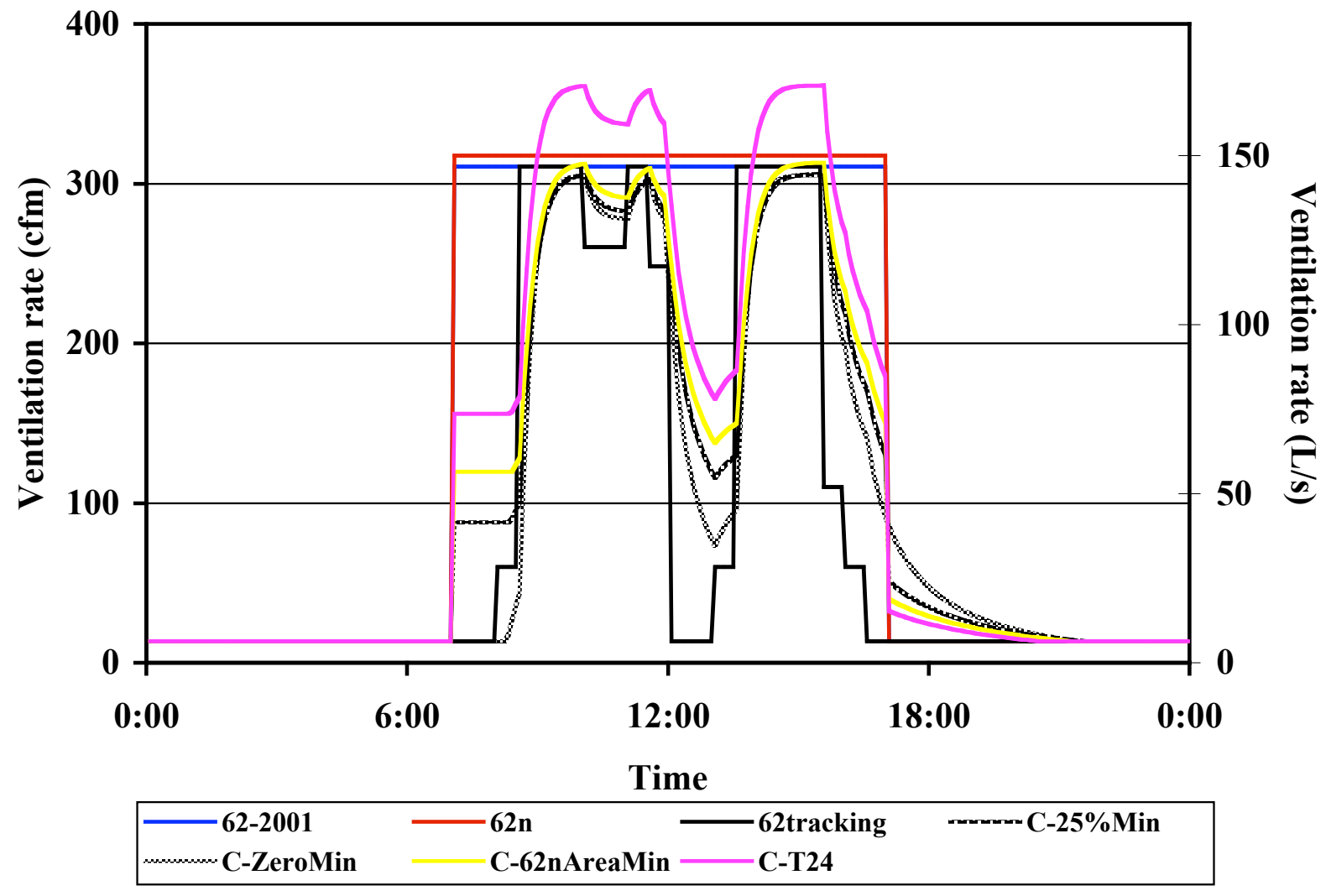

Figure 6 Portable Classroom Ventilation Rates during Week (Friday)

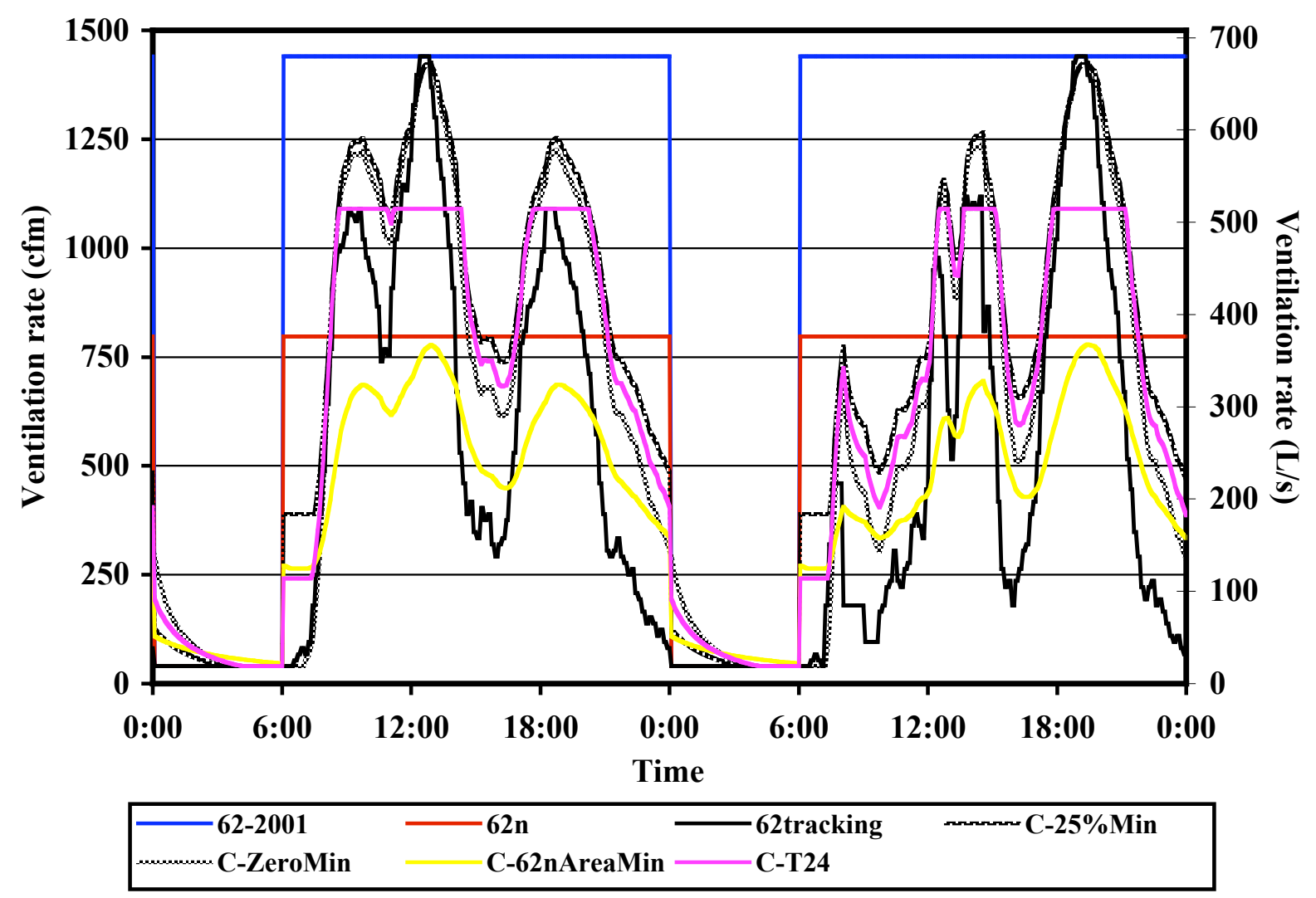

Figure 7 Fast Food Restaurant Ventilation Rates over Friday and Saturday 


\subsection{Carbon Dioxide Concentration}

Table 6 summarizes the indoor $\mathrm{CO}_{2}$ concentrations for the ventilation strategies and spaces in terms of the average and maximum concentration during occupancy. The first column of the table also presents the steady-state $\mathrm{CO}_{2}$ concentration for the $62 / 2001,62 \mathrm{n}$ and Title 24 cases, as well as the 62/Int case when relevant, based on the values in Table 2.

In all spaces, the average and maximum $\mathrm{CO}_{2}$ concentrations are lower for the 62/2001 cases than for the other cases, except for C-T24 in the Office. This result is expected due to 62/2001 having the highest ventilation rates compared to the 62 tracking and the $\mathrm{CO}_{2}$ control cases. And while 62tracking and the $\mathrm{CO}_{2}$ control cases have higher average and maximum $\mathrm{CO}_{2}$ concentrations relative to the $62 / 2001$ case, they are almost always within about $200 \mathrm{mg} / \mathrm{m}^{3}$ (about 100 parts per million by volume (ppm(v)) ) of the $62 / 2001$ values. Also, the $\mathrm{CO}_{2}$ control cases almost always have average and maximum concentrations below the idealized 62tracking case, which indicates good control of occupant-generated contaminants. In all cases the maximum $\mathrm{CO}_{2}$ concentration during occupancy is less than the steady-state concentration based on the design value in the first column. These differences are generally on the order of $200 \mathrm{mg} / \mathrm{m}^{3}$ (roughly $100 \mathrm{ppm}(\mathrm{v})$ ) except for the Conference Room where the design occupancy is never achieved. The 62/Int case, applicable to only the Conference Room and Lecture Hall, has higher $\mathrm{CO}_{2}$ concentrations than the other 62-based cases as expected. However, the average concentrations during occupancy are still only about $200 \mathrm{mg} / \mathrm{m}^{3}$ (roughly $100 \mathrm{ppm}(\mathrm{v})$ ) above the 62 tracking case.

Figures 8 through 13 present the $\mathrm{CO}_{2}$ concentrations in each of the spaces over one day (two days in selected cases) for the different ventilation strategies. The $\mathrm{CO}_{2}$ concentrations in the Office in Figure 3 are fairly similar for the six different ventilation strategies. The 62tracking case is higher during unoccupied periods as the ventilation rate during those periods includes only infiltration, and therefore the post-occupancy $\mathrm{CO}_{2}$ concentration is elevated relative to the other strategies. This residual concentration builds up during the week, and the biggest differences are seen in this plot for Friday. The two 62n cases, 62n and C-62nAreaMin, have higher concentrations than the other cases during occupancy based on the lower design ventilation rates. The Title $24 \mathrm{DCV}$ case has the lowest $\mathrm{CO}_{2}$ levels in the Office as expected since it has the highest, and in fact constant, ventilation rates during occupancy. In the other spaces, the 62-2001 case has the lowest $\mathrm{CO}_{2}$ levels due its having the highest ventilation rates.

There is more variation in $\mathrm{CO}_{2}$ levels among the ventilation strategies for the Conference Room as seen in Figure 9. The two 62n-based cases, 62n and C-62nAreaMin, have lower per person ventilation rates relative to Standard 62 , and therefore the $\mathrm{CO}_{2}$ concentrations are significantly higher. The 62 tracking case again has elevated concentrations during unoccupied periods based on only infiltration occurring during these times. The Lecture Hall in Figure 10 shows the same features as the Conference Room, higher concentrations for the $62 \mathrm{n}$-based cases and elevated concentrations for 62 tracking during unoccupied periods. The different ventilation strategies have fairly similar $\mathrm{CO}_{2}$ concentrations in the two classroom cases (Figures 11 and 12). Finally, the Fast Food Restaurant in Figure 13 also exhibits elevated concentrations for the 62n-based cases and elevated concentrations for 62 tracking.

From the concentrations in Table 6 and the figures, one sees that the $\mathrm{CO}_{2}$ control cases result in $\mathrm{CO}_{2}$ concentrations that are not very different from those in the cases without $\mathrm{CO}_{2}$ control. While the $\mathrm{CO}_{2}$ control cases have higher concentrations, the differences are generally on the order of $200 \mathrm{mg} / \mathrm{m}^{3}$ (100 ppm(v)). 


\begin{tabular}{|c|c|c|c|c|}
\hline & \multicolumn{4}{|c|}{ Indoor $\mathrm{CO}_{2}$ concentrations during occupancy } \\
\hline & \multicolumn{2}{|c|}{$\mathrm{mg} / \mathrm{m}^{3} \stackrel{\text { Average }}{(\mathrm{ppm}(\mathrm{v}))}$} & \multicolumn{2}{|c|}{ Maximum } \\
\hline \multicolumn{5}{|l|}{ Office } \\
\hline $62 / 2001\left(1674 \mathrm{mg} / \mathrm{m}^{3}, 930 \mathrm{ppm}(\mathrm{v})\right)^{*}$ & 1305 & 725 & 1555 & 864 \\
\hline 62 tracking & 1427 & 793 & 1571 & 873 \\
\hline C-ZeroMin & 1413 & 785 & 1620 & 900 \\
\hline $\mathrm{C}-25 \% \mathrm{Min}$ & 1393 & 774 & 1613 & 896 \\
\hline $62 \mathrm{n}\left(2061 \mathrm{mg} / \mathrm{m}^{3}, 1145 \mathrm{ppm}(\mathrm{v})\right)^{*}$ & 1512 & 840 & 1854 & 1030 \\
\hline C-62nAreaMin & 1573 & 874 & 1908 & 1060 \\
\hline C-T24 $\left(1546 \mathrm{mg} / \mathrm{m}^{3}, 859 \mathrm{ppm}(\mathrm{v})\right)^{*}$ & 1231 & 684 & 1447 & 804 \\
\hline \multicolumn{5}{|l|}{ Conference Room } \\
\hline $62 / 2001\left(1674 \mathrm{mg} / \mathrm{m}^{3}, 930 \mathrm{ppm}(\mathrm{v})\right)^{*}$ & 1037 & 576 & 1471 & 817 \\
\hline 62 tracking & 1467 & 815 & 1661 & 923 \\
\hline 62/Int $\left(2626 \mathrm{mg} / \mathrm{m}^{3}, 1459 \mathrm{ppm}(\mathrm{v})\right)^{*}$ & 1291 & 717 & 2106 & 1170 \\
\hline C-ZeroMin & 1244 & 691 & 1575 & 875 \\
\hline $\mathrm{C}-25 \% \mathrm{Min}$ & 1183 & 657 & 1561 & 867 \\
\hline $62 \mathrm{n}\left(3740 \mathrm{mg} / \mathrm{m}^{3}, 2078 \mathrm{ppm}(\mathrm{v})\right)^{*}$ & 1553 & 863 & 2736 & 1520 \\
\hline C-62nAreaMin & 1962 & 1090 & 3240 & 1800 \\
\hline C-T24 (1991 mg/m $\left.\mathrm{m}^{3}, 1106 \mathrm{ppm}(\mathrm{v})\right)^{*}$ & 1202 & 668 & 1694 & 941 \\
\hline \multicolumn{5}{|l|}{ Lecture Hall } \\
\hline 62/2001 (1991 mg/m $\left.\mathrm{m}^{3}, 1106 \mathrm{ppm}(\mathrm{v})\right)^{*}$ & 1436 & 798 & 1980 & 1100 \\
\hline 62 tracking & 1926 & 1070 & 1980 & 1100 \\
\hline $62 / \mathrm{Int}\left(3262 \mathrm{mg} / \mathrm{m}^{3}, 1812 \mathrm{ppm}(\mathrm{v})\right)^{*}$ & 2032 & 1129 & 3078 & 1710 \\
\hline C-ZeroMin & 1606 & 892 & 1980 & 1100 \\
\hline $\mathrm{C}-25 \% \mathrm{Min}$ & 1568 & 871 & 1980 & 1100 \\
\hline $62 \mathrm{n}\left(3123 \mathrm{mg} / \mathrm{m}^{3}, 1735 \mathrm{ppm}(\mathrm{v})\right)^{*}$ & 1962 & 1090 & 2952 & 1640 \\
\hline C-62nAreaMin & 2299 & 1277 & 3024 & 1680 \\
\hline C-T24 (1991 mg/m $\left.\mathrm{m}^{3}, 1106 \mathrm{ppm}(\mathrm{v})\right)^{*}$ & 1469 & 816 & 1962 & 1090 \\
\hline \multicolumn{5}{|l|}{ Classroom } \\
\hline $62 / 2001\left(1991 \mathrm{mg} / \mathrm{m}^{3}, 1106 \mathrm{ppm}(\mathrm{v})\right)^{*}$ & 1559 & 866 & 1962 & 1090 \\
\hline 62 tracking & 1827 & 1015 & 1962 & 1090 \\
\hline C-ZeroMin & 1688 & 938 & 1980 & 1100 \\
\hline $\mathrm{C}-25 \% \mathrm{Min}$ & 1656 & 920 & 1980 & 1100 \\
\hline $62 \mathrm{n}\left(2113 \mathrm{mg} / \mathrm{m}^{3}, 1174 \mathrm{ppm}(\mathrm{v})\right)^{*}$ & 1647 & 915 & 2088 & 1160 \\
\hline C-62nAreaMin & 1760 & 978 & 2124 & 1180 \\
\hline C-T24 (1991 mg/m $\left.\mathrm{m}^{3}, 1106 \mathrm{ppm}(\mathrm{v})\right)^{*}$ & 1573 & 874 & 1944 & 1080 \\
\hline \multicolumn{5}{|l|}{ Portable Classroom } \\
\hline $62 / 2001\left(1532 \mathrm{mg} / \mathrm{m}^{3}, 851 \mathrm{ppm}(\mathrm{v})\right)^{*}$ & 1262 & 701 & 1496 & 831 \\
\hline 62 tracking & 1418 & 788 & 1505 & 836 \\
\hline C-ZeroMin & 1352 & 751 & 1519 & 844 \\
\hline $\mathrm{C}-25 \% \mathrm{Min}$ & 1332 & 740 & 1517 & 843 \\
\hline $62 \mathrm{n}\left(1494 \mathrm{mg} / \mathrm{m}^{3}, 830 \mathrm{ppm}(\mathrm{v})\right)^{*}$ & 1251 & 695 & 1480 & 822 \\
\hline C-62nAreaMin & 1310 & 728 & 1499 & 833 \\
\hline C-T24 (1399 mg/m³, $777 \mathrm{ppm}(\mathrm{v}))^{*}$ & 1222 & 679 & 1384 & 769 \\
\hline \multicolumn{5}{|l|}{ Fast Food Restaurant } \\
\hline $62 / 2001\left(1674 \mathrm{mg} / \mathrm{m}^{3}, 930 \mathrm{ppm}(\mathrm{v})\right)^{*}$ & 1132 & 629 & 1640 & 911 \\
\hline 62tracking & 1566 & 870 & 1656 & 920 \\
\hline C-ZeroMin & 1314 & 730 & 1667 & 926 \\
\hline $\mathrm{C}-25 \% \mathrm{Min}$ & 1246 & 692 & 1636 & 909 \\
\hline $62 \mathrm{n}\left(2461 \mathrm{mg} / \mathrm{m}^{3}, 1367 \mathrm{ppm}(\mathrm{v})\right)^{*}$ & 1463 & 813 & 2322 & 1290 \\
\hline C-62nAreaMin & 1687 & 937 & 2412 & 1340 \\
\hline C-T24 (1991 mg/m $\left.\mathrm{m}^{3}, 1106 \mathrm{ppm}(\mathrm{v})\right)^{*}$ & 1318 & 732 & 1908 & 1060 \\
\hline
\end{tabular}

* Steady-state $\mathrm{CO}_{2}$ concentration based on the design ventilation rate from Table 2.

Table 6 Summary of Carbon Dioxide Concentrations 


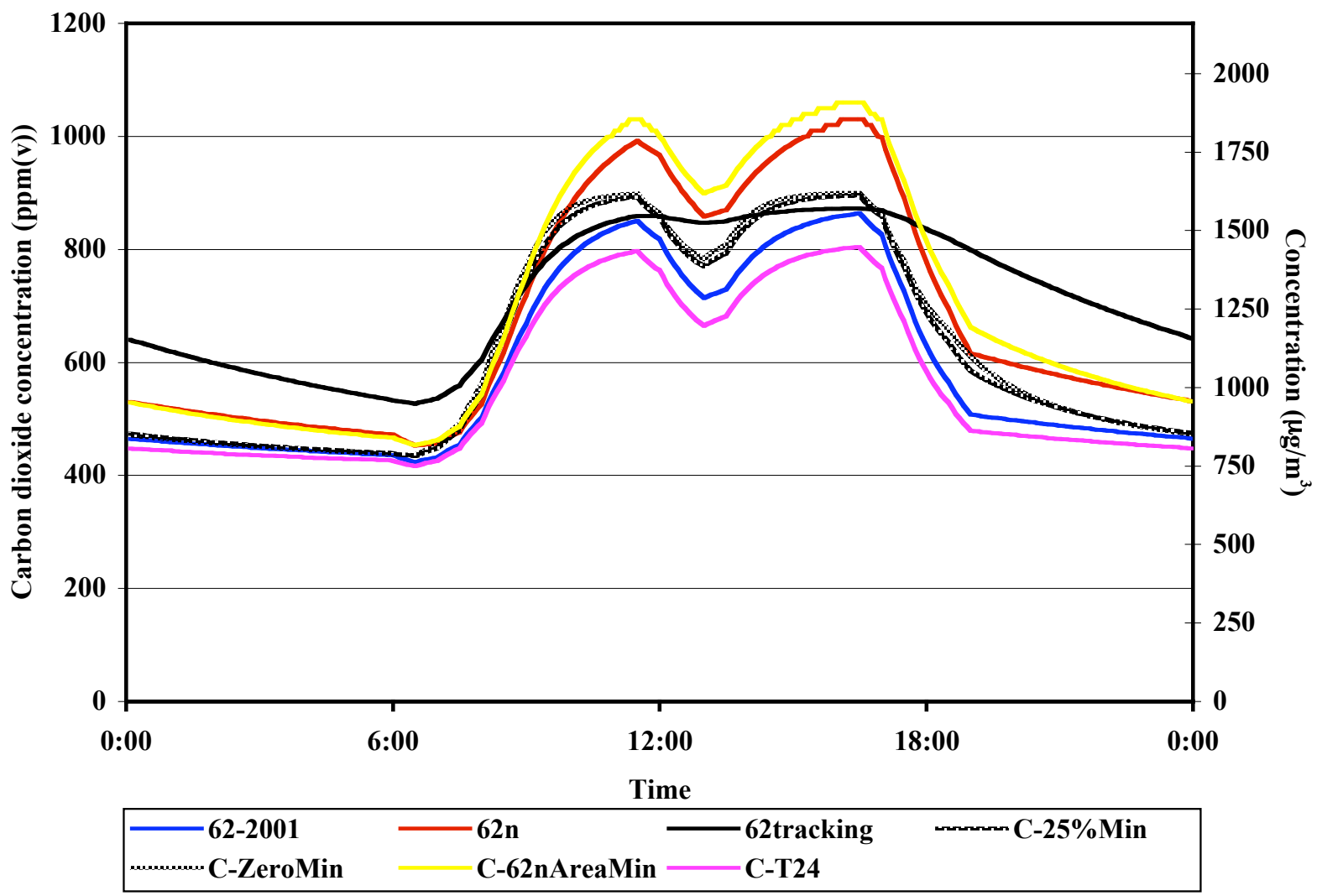

Figure 8 Office $\mathrm{CO}_{2}$ Concentrations during Weekday (Friday)

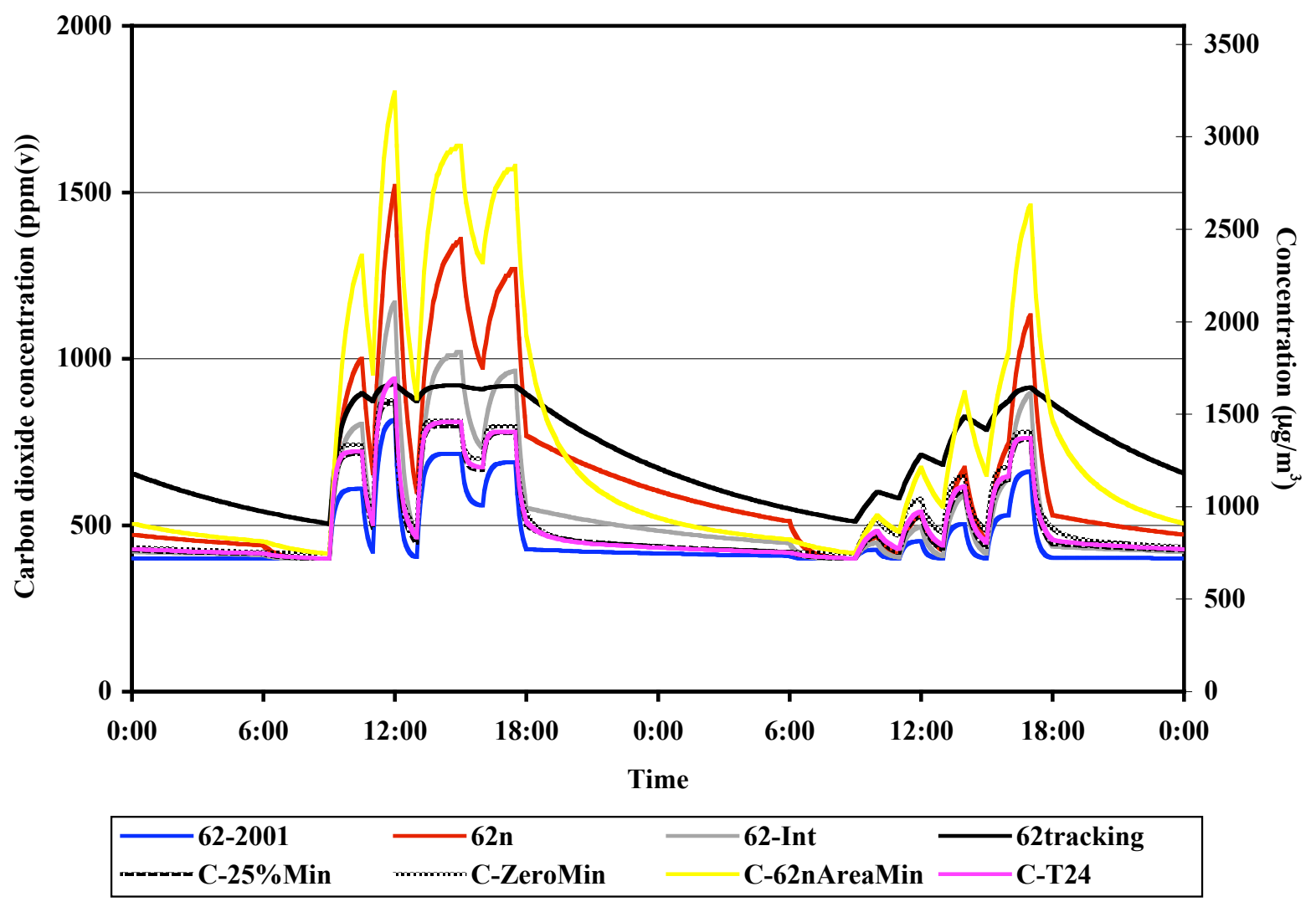

Figure 9 Conference Room $\mathrm{CO}_{2}$ Concentrations during Week (Wednesday and Thursday) 


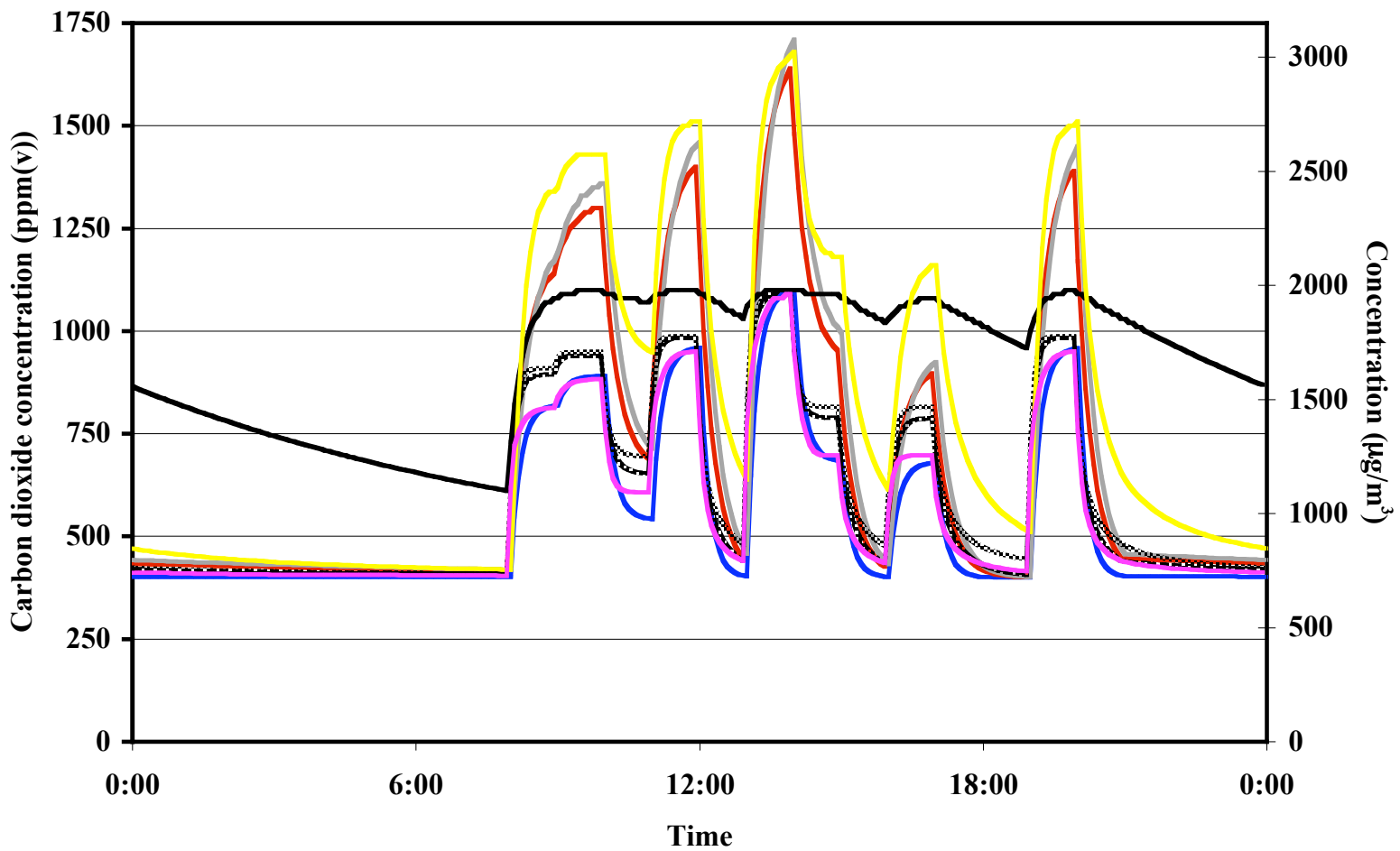

\begin{tabular}{|c|c|c|}
\hline $\begin{array}{l}62-2001 \\
\text { C-25\%Min }\end{array}$ & $\begin{array}{l}-62 n \\
\text {. } \\
\text { C-Zeromeromin }\end{array}$ & $\begin{array}{ll}\text { 62-Int } & \text { 62tracking } \\
\text { C-62nAreaMin } & \text { C-T24 }\end{array}$ \\
\hline
\end{tabular}

Figure 10 Lecture Hall $\mathrm{CO}_{2}$ Concentrations during Week (Friday)

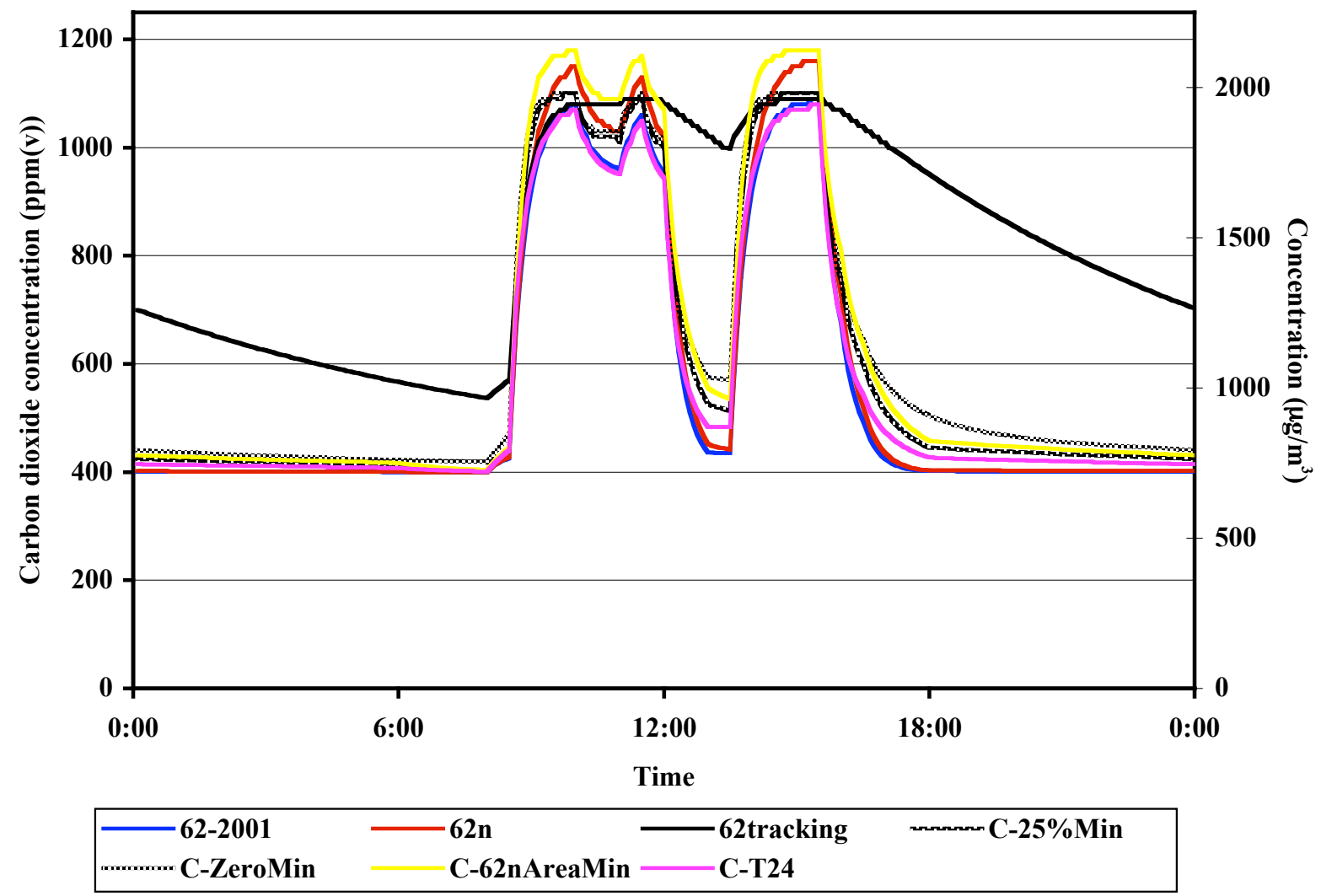

Figure 11 Classroom $\mathrm{CO}_{2}$ Concentrations during Week (Friday) 


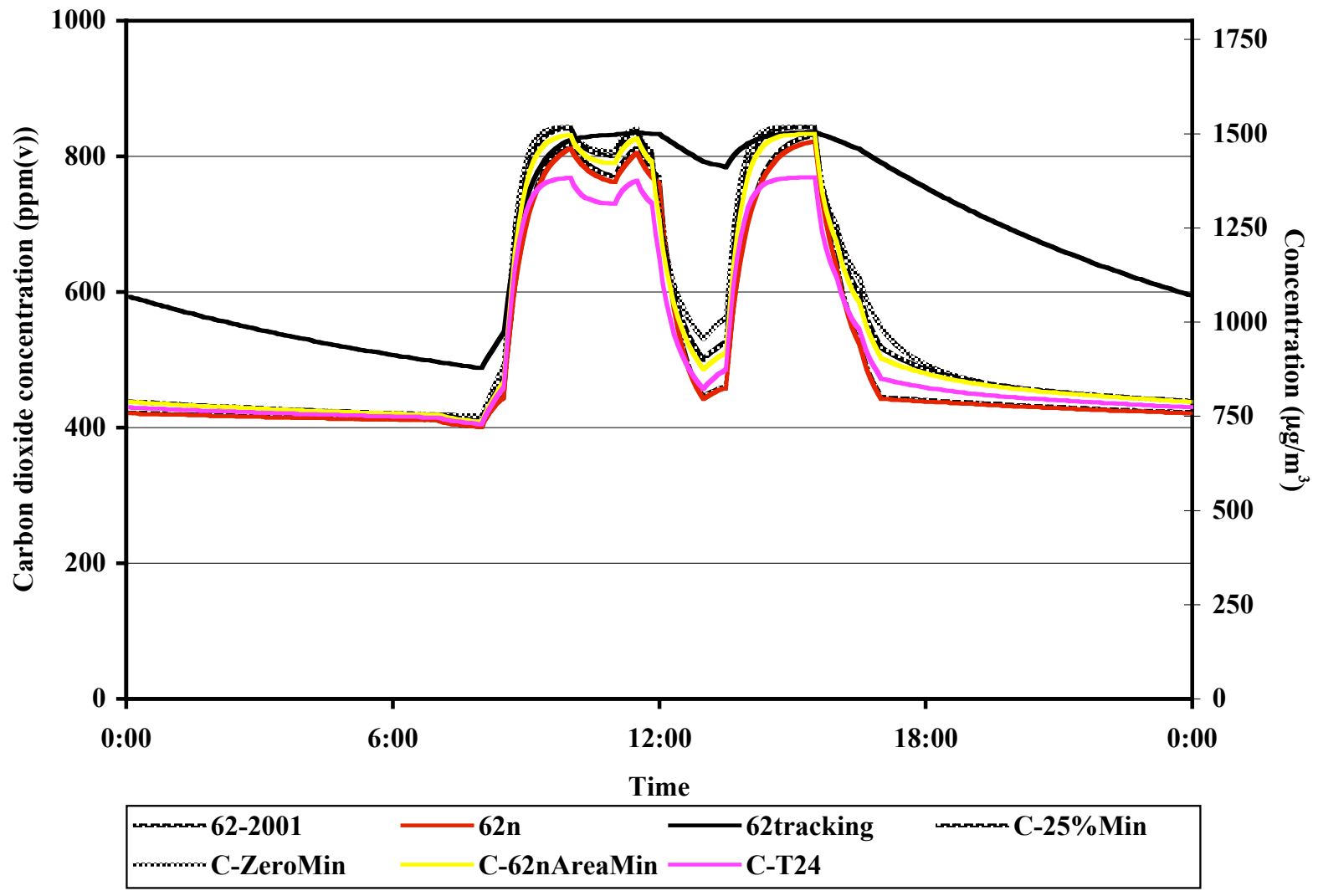

Figure 12 Portable Classroom $\mathrm{CO}_{2}$ Concentrations during Week (Friday)

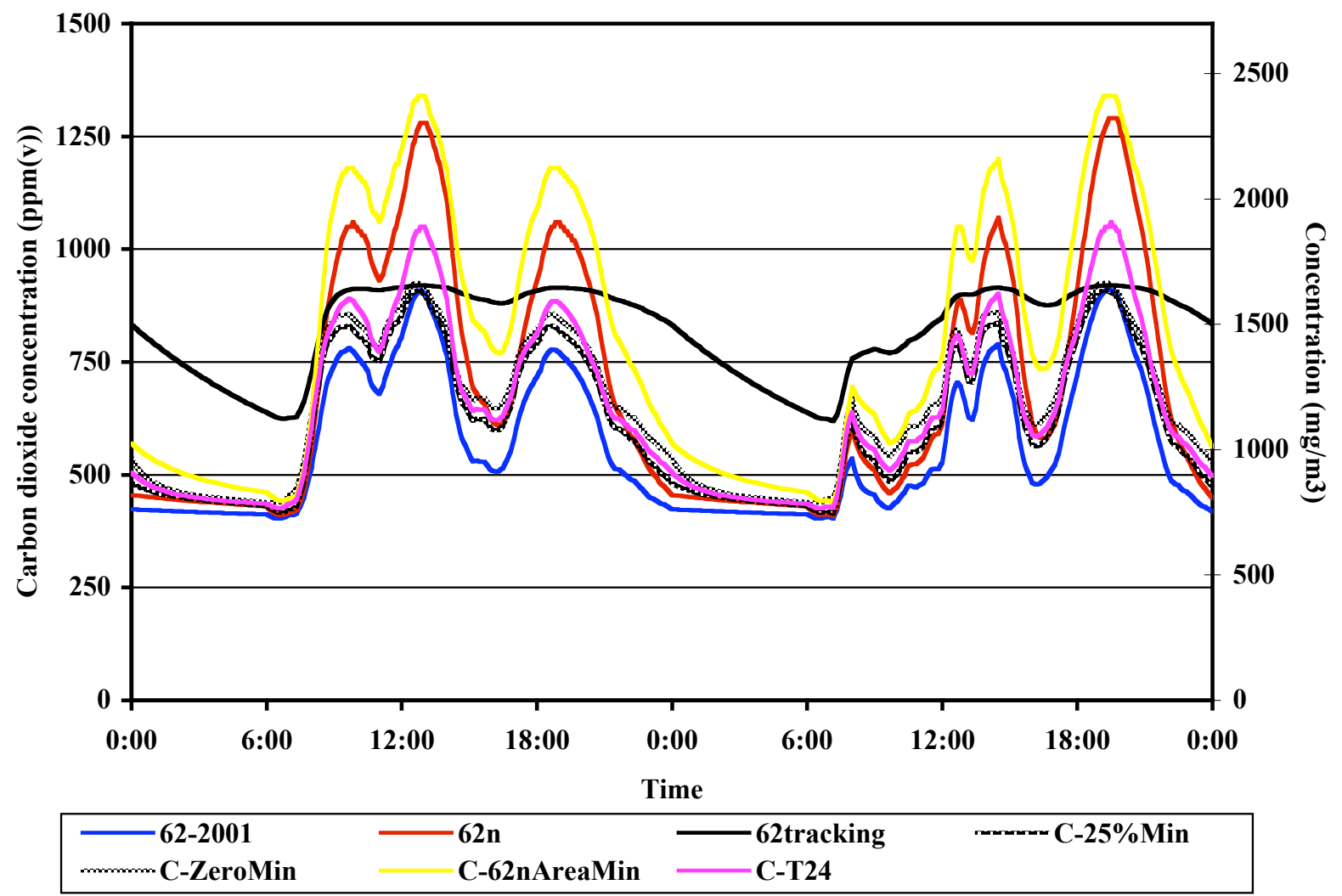

Figure 13 Fast Food Restaurant $\mathrm{CO}_{2}$ Concentrations over Friday and Saturday 


\subsection{VOC Concentration}

Table 7 summarizes the indoor VOC concentrations for the ventilation strategies in each of the spaces in terms of the average and maximum concentrations during occupancy. The first column of the table also presents the steady-state VOC concentration for the various cases based on the design ventilation rates from Table 2. Figures 14 through 19 present the VOC concentrations in each of the spaces over one day (two in selected cases). Note that the averages in Table 7 are less than $0.4 \mathrm{mg} / \mathrm{m}^{3}$ in all cases and less than $0.1 \mathrm{mg} / \mathrm{m}^{3}$ in most cases. While these concentrations are on the low end of those measured in the field, they are dependent on the assumed source strengths during occupied and unoccupied periods and on the assumed infiltration rate during the unoccupied periods. The maximum concentrations are closer to, and in several cases above, $1 \mathrm{mg} / \mathrm{m}^{3}$ as a result of increases in concentration over unoccupied periods as discussed below.

In all spaces, the average and maximum VOC concentrations are lower for the 62/2001 case than for the other cases, except C-T24 in the Office, as expected. And while the 62 tracking and $\mathrm{CO}_{2}$ control cases have higher average concentrations than the 62/2001 case, these averages are generally only two to three times higher and always below $0.4 \mathrm{mg} / \mathrm{m}^{3}$. Also, the $\mathrm{CO}_{2}$ control cases almost always have average concentrations that are close to or even below the 62 tracking case. If one is willing to assume that 62 tracking, which is clearly in compliance with the standard, provides adequate control of building-related contaminants, then the $\mathrm{CO}_{2} \mathrm{DCV}$ cases also control these contaminants on average. The $62 \mathrm{n}$-based $\mathrm{CO}_{2}$ control case (C-62nAreaMin) also has an average VOC concentration that is generally within a factor of two of the $62 \mathrm{n}$ case, again indicating reasonable control of building-related contaminants. The only exception is in the Conference Room where the initial VOC concentration for C-62nAreaMin is elevated at the start of the day. It is worth noting that the average VOC level in non-office spaces with $\mathrm{CO}_{2}$ control is almost always lower than the VOC level in the Office with the Standard 62-2001 ventilation rate. Therefore, if the VOC level in the Office based on Standard 62 is acceptable, then the level in the other spaces is also acceptable. Of course, this conclusion is based on the same VOC emission rates per unit floor area in all the spaces, which may not always be a good assumption.

The maximum VOC concentrations during occupancy are generally greater than the steady-state VOC concentrations from Table 2 by a factor of two or three, but in some cases by more than an order of magnitude. These maximum concentrations are so much higher due to the increase in VOC concentrations over unoccupied periods when the spaces have an infiltration rate of only $0.1 \mathrm{~h}^{-1}$. Note that the steady-state concentrations are based on the design ventilation rates and are not impacted by the elevated initial concentrations that may exist early in the morning. The maximum concentrations are strongly dependent on the unoccupied infiltration rate and the relative values of the source strength during occupied and unoccupied periods, and therefore the relative values of the different cases are more informative than the absolute values. The highest maximum concentrations are seen for 62 tracking or the $\mathrm{CO}_{2}$ control cases where there is very little ventilation in the early part of occupancy. The maximum concentrations confirm the observation above that if the 62tracking case is considered to control IAQ acceptably then the DCV cases should also be considered acceptable as the maximum concentrations for the DCV cases are near or below the 62 tracking cases in all situations.

Figure 14 presents the VOC concentrations in the Office space. The patterns are similar for the different ventilation cases with the exception of the elevated concentrations early in the day for 62 tracking and C-ZeroMin, where the VOC source increases as soon as the system comes on but the ventilation rate does not increase until later in the morning. A slight increase in concentration is seen at mid-day for the 62 tracking and the $\mathrm{CO}_{2}$ control cases when the ventilation rate is 
reduced in response to the lower occupancy. After the system is turned off at 1900, the VOC concentration increases steadily and reaches its maximum value just before the system comes back on the next morning. Figures 15 and 16 shows similar trends for the Conference Room and Lecture Hall, with dramatic increases in concentration at system startup for 62 tracking and CZeroMin. Once the ventilation rates increase, the concentrations reduce by a factor of 5 to 10 . The increases in VOC concentrations during periods of low occupancy are more evident in these spaces than in the Office. The two classrooms show similar results in Figures 17 and 18, as does the Fast Rood Restaurant in Figure 19.

The average and maximum VOC concentrations in Table 7 are both heavily influenced by the elevated concentrations at the start of occupancy. The figures reveal that once the early morning transients die out, the differences between the various ventilation strategies become less significant. Looking at the concentrations in the late afternoon, the ratio of maximum to minimum VOC concentrations for the various cases, neglecting the idealized 62tracking case, is about 1.5 in the Office, at most 3 or 4 in the Conference Room, Lecture Hall and classrooms, and around 2 in the fast food restaurant. 


\begin{tabular}{|c|c|c|}
\hline & \multicolumn{2}{|c|}{$\begin{array}{c}\text { Indoor VOC concentrations during } \\
\text { occupancy }\left(\mathrm{mg} / \mathrm{m}^{3}\right)\end{array}$} \\
\hline & Average & Maximum \\
\hline \multicolumn{3}{|l|}{ Office } \\
\hline $62 / 2001\left(0.21 \mathrm{mg} / \mathrm{m}^{3}\right)^{*}$ & 0.22 & 0.58 \\
\hline 62tracking & 0.34 & 0.89 \\
\hline C-ZeroMin & 0.37 & 0.96 \\
\hline C-25\%Min & 0.32 & 0.80 \\
\hline $62 \mathrm{n}\left(0.03 \mathrm{mg} / \mathrm{m}^{3}\right)^{*}$ & 0.31 & 0.67 \\
\hline C-62nAreaMin & 0.35 & 0.74 \\
\hline C-T24 $\left(0.18 \mathrm{mg} / \mathrm{m}^{3}\right)^{*}$ & 0.19 & 0.55 \\
\hline \multicolumn{3}{|l|}{ Conference Room } \\
\hline $62 / 2001\left(0.03 \mathrm{mg} / \mathrm{m}^{3}\right)^{*}$ & 0.03 & 0.03 \\
\hline 62tracking & 0.30 & 0.90 \\
\hline $62 /$ Int $\left(0.06 \mathrm{mg} / \mathrm{m}^{3}\right)^{*}$ & 0.06 & 0.06 \\
\hline C-ZeroMin & 0.22 & 1.06 \\
\hline C-25\%Min & 0.07 & 0.12 \\
\hline $62 \mathrm{n}\left(0.09 \mathrm{mg} / \mathrm{m}^{3}\right)^{*}$ & 0.09 & 0.09 \\
\hline C-62nAreaMin & 0.25 & 0.50 \\
\hline C-T24 $\left(0.04 \mathrm{mg} / \mathrm{m}^{3}\right)^{*}$ & 0.09 & 0.20 \\
\hline \multicolumn{3}{|l|}{ Lecture Hall } \\
\hline $62 / 2001\left(0.01 \mathrm{mg} / \mathrm{m}^{3}\right)^{*}$ & 0.02 & 0.28 \\
\hline 62tracking & 0.04 & 0.32 \\
\hline $62 / \operatorname{Int}\left(0.03 \mathrm{mg} / \mathrm{m}^{3}\right)^{*}$ & 0.04 & 0.34 \\
\hline C-ZeroMin & 0.03 & 0.42 \\
\hline C-25\%Min & 0.03 & 0.37 \\
\hline $62 \mathrm{n}\left(0.03 \mathrm{mg} / \mathrm{m}^{3}\right) *$ & 0.03 & 0.33 \\
\hline C-62nAreaMin & 0.06 & 0.42 \\
\hline C-T24 $\left(0.01 \mathrm{mg} / \mathrm{m}^{3}\right)^{*}$ & 0.03 & 0.41 \\
\hline \multicolumn{3}{|l|}{ Classroom } \\
\hline $62 / 2001\left(0.06 \mathrm{mg} / \mathrm{m}^{3}\right)^{*}$ & 0.06 & 0.06 \\
\hline 62tracking & 0.18 & 0.99 \\
\hline C-ZeroMin & 0.19 & 1.03 \\
\hline $\mathrm{C}-25 \% \mathrm{Min}$ & 0.10 & 0.31 \\
\hline $62 \mathrm{n}\left(0.06 \mathrm{mg} / \mathrm{m}^{3}\right)^{*}$ & 0.06 & 0.07 \\
\hline C-62nAreaMin & 0.11 & 0.35 \\
\hline C-T24 $\left(0.06 \mathrm{mg} / \mathrm{m}^{3}\right)^{*}$ & 0.08 & 0.26 \\
\hline \multicolumn{3}{|l|}{ Portable Classroom } \\
\hline $62 / 2001\left(0.09 \mathrm{mg} / \mathrm{m}^{3}\right)^{*}$ & 0.09 & 0.18 \\
\hline 62tracking & 0.22 & 1.04 \\
\hline C-ZeroMin & 0.24 & 1.10 \\
\hline C-25\%Min & 0.17 & 0.64 \\
\hline $62 \mathrm{n}\left(0.08 \mathrm{mg} / \mathrm{m}^{3}\right)^{*}$ & 0.09 & 0.17 \\
\hline C-62nAreaMin & 0.15 & 0.52 \\
\hline C-T24 $\left(0.07 \mathrm{mg} / \mathrm{m}^{3}\right)^{*}$ & 0.12 & 0.41 \\
\hline \multicolumn{3}{|l|}{ Fast Food } \\
\hline $62 / 2001\left(0.03 \mathrm{mg} / \mathrm{m}^{3}\right)^{*}$ & 0.03 & 0.06 \\
\hline 62tracking & 0.10 & 0.36 \\
\hline C-ZeroMin & 0.07 & 0.31 \\
\hline C-25\%Min & 0.05 & 0.18 \\
\hline $62 \mathrm{n}\left(0.05 \mathrm{mg} / \mathrm{m}^{3}\right)^{*}$ & 0.05 & 0.11 \\
\hline C-62nAreaMin & 0.08 & 0.20 \\
\hline C-T24 $\left(0.04 \mathrm{mg} / \mathrm{m}^{3}\right)^{*}$ & 0.06 & 0.21 \\
\hline
\end{tabular}

* Steady-state VOC concentration based on the design ventilation rate from Table 2.

Table 7 Summary of VOC Concentrations 


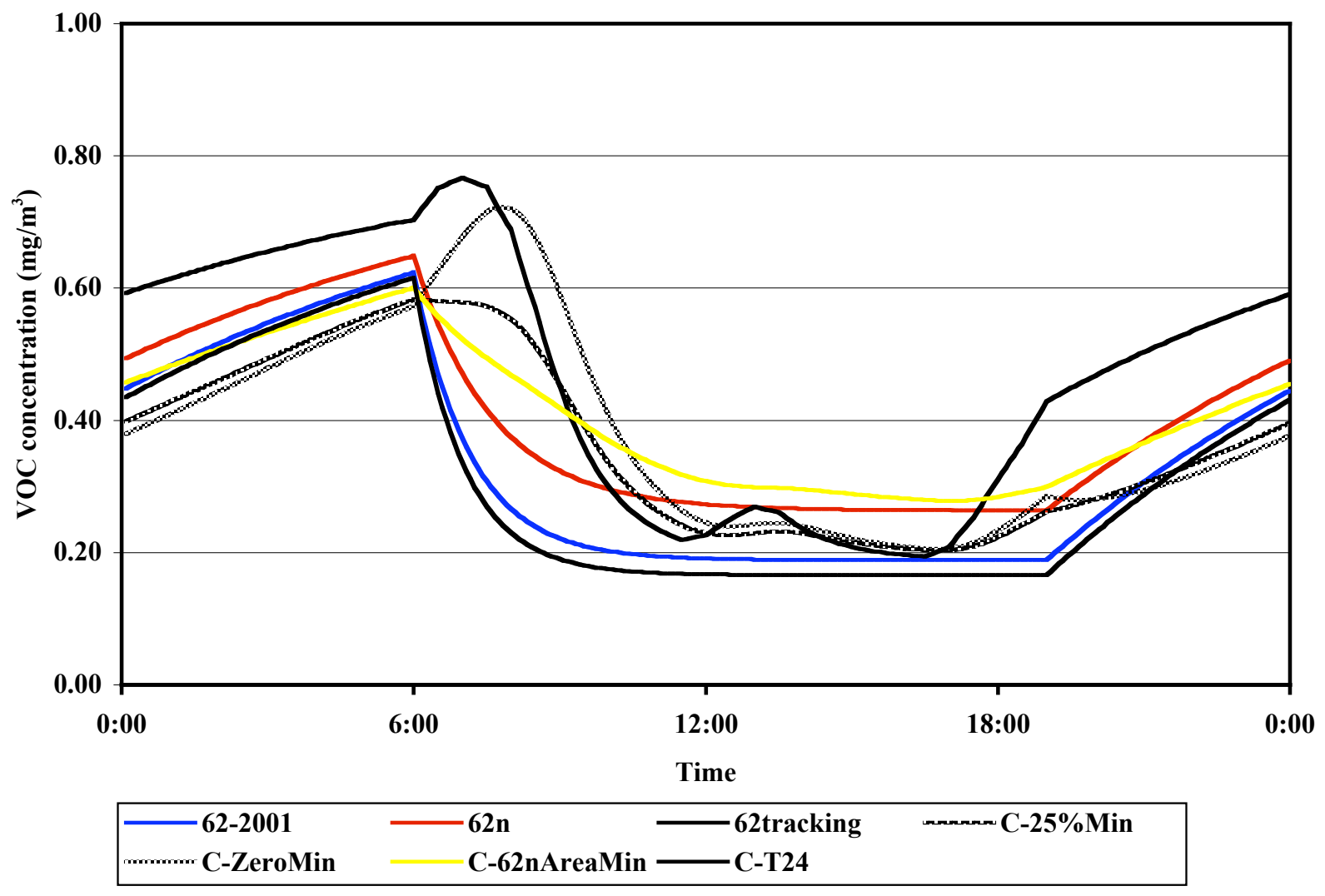

Figure 14 Office VOC Concentrations during Weekday (Friday)

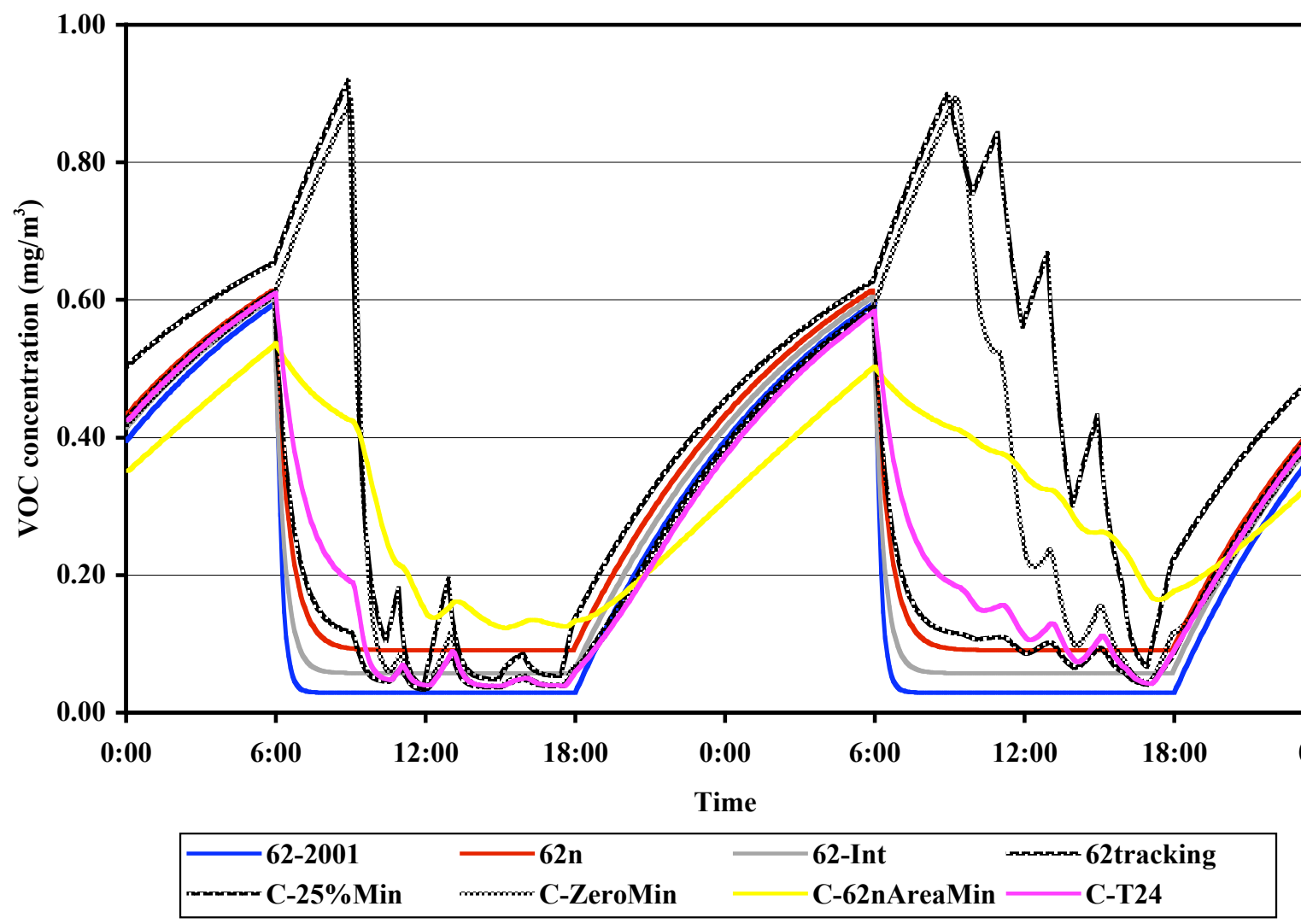

Figure 15 Conference Room VOC Concentrations during Week (Wednesday and Thursday) 


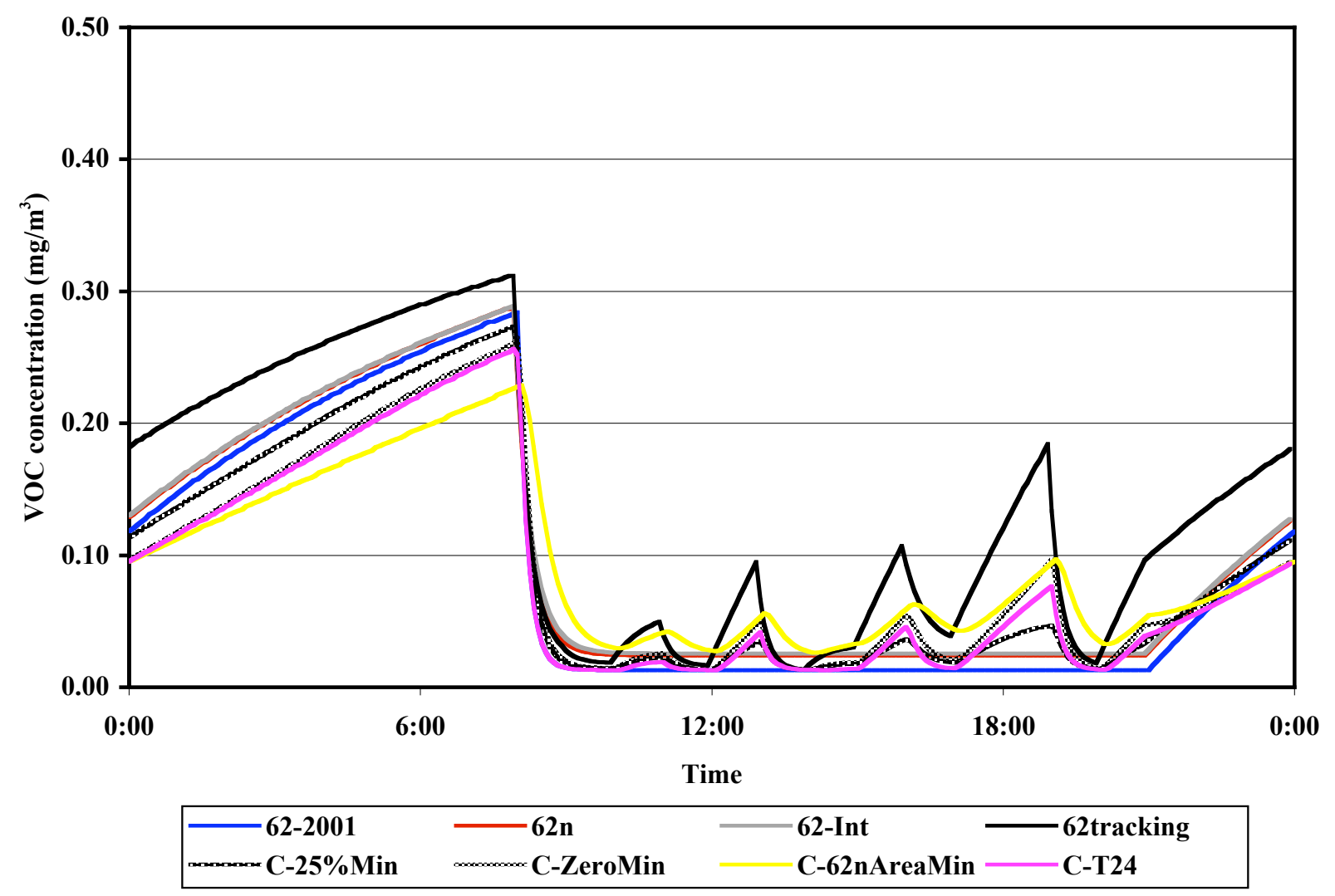

Figure 16 Lecture Hall VOC Concentrations during Week (Friday)

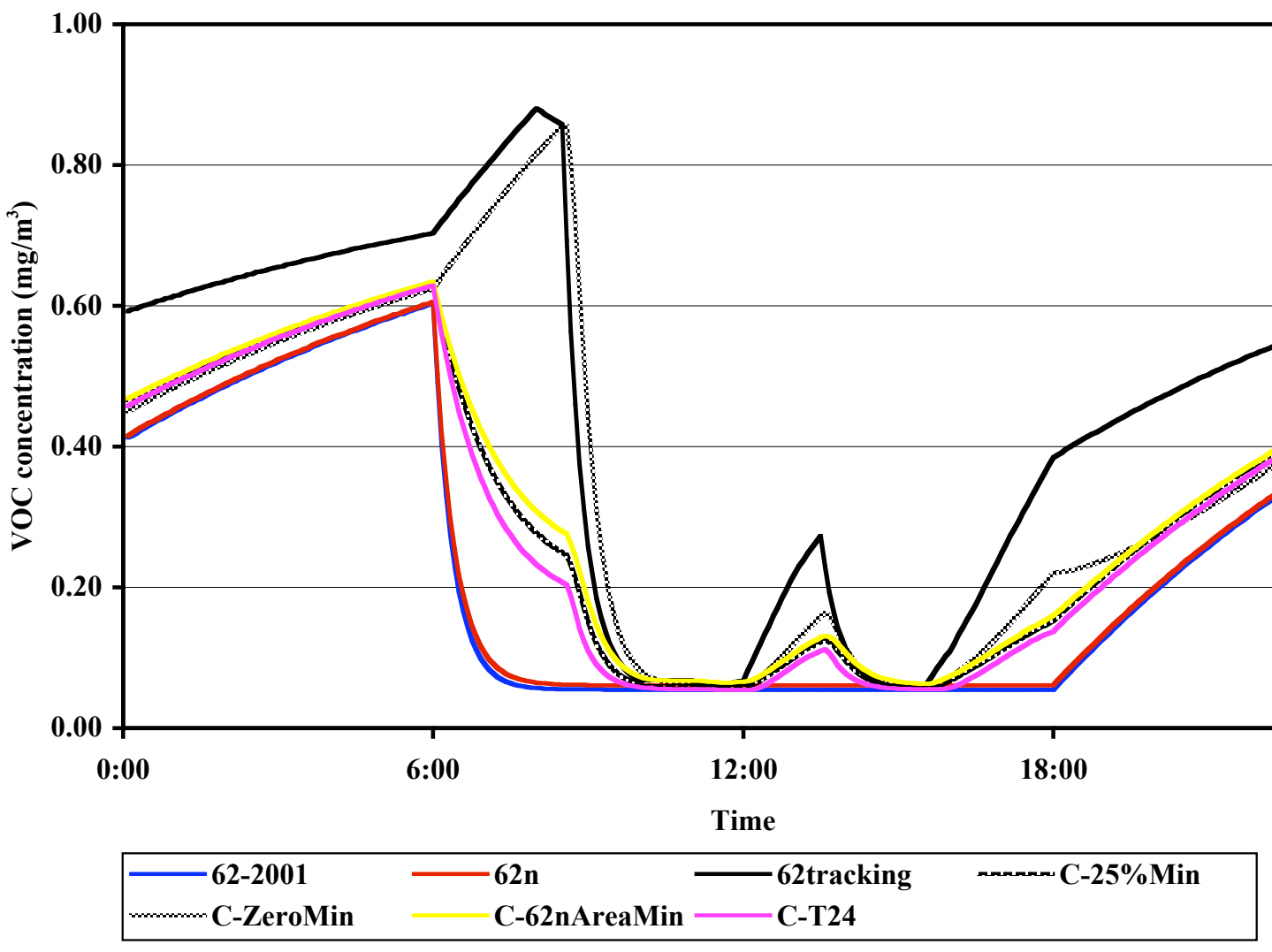

Figure 17 Classroom VOC Concentrations during Week (Friday) 


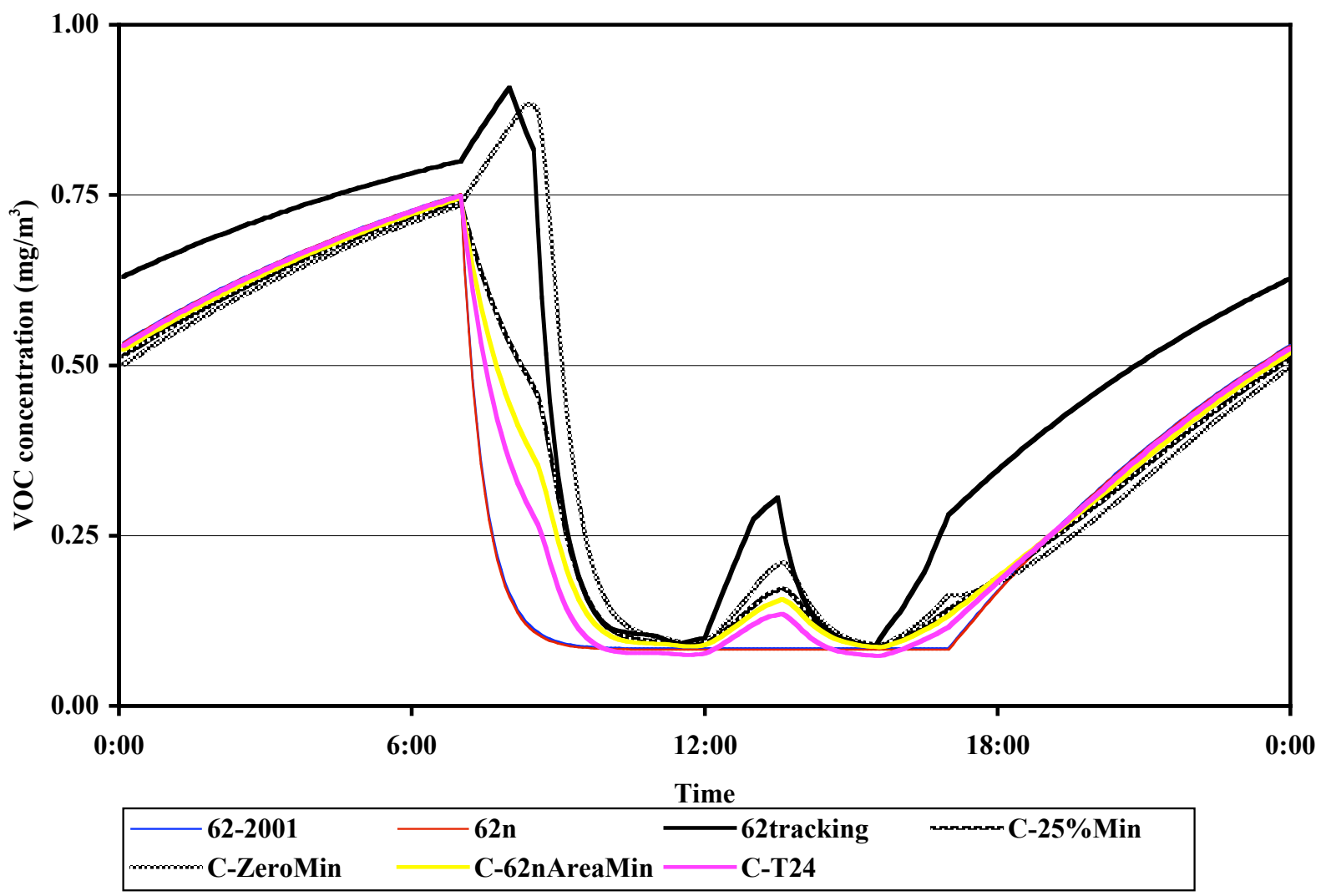

Figure 18 Portable Classroom VOC Concentrations during Week (Friday)

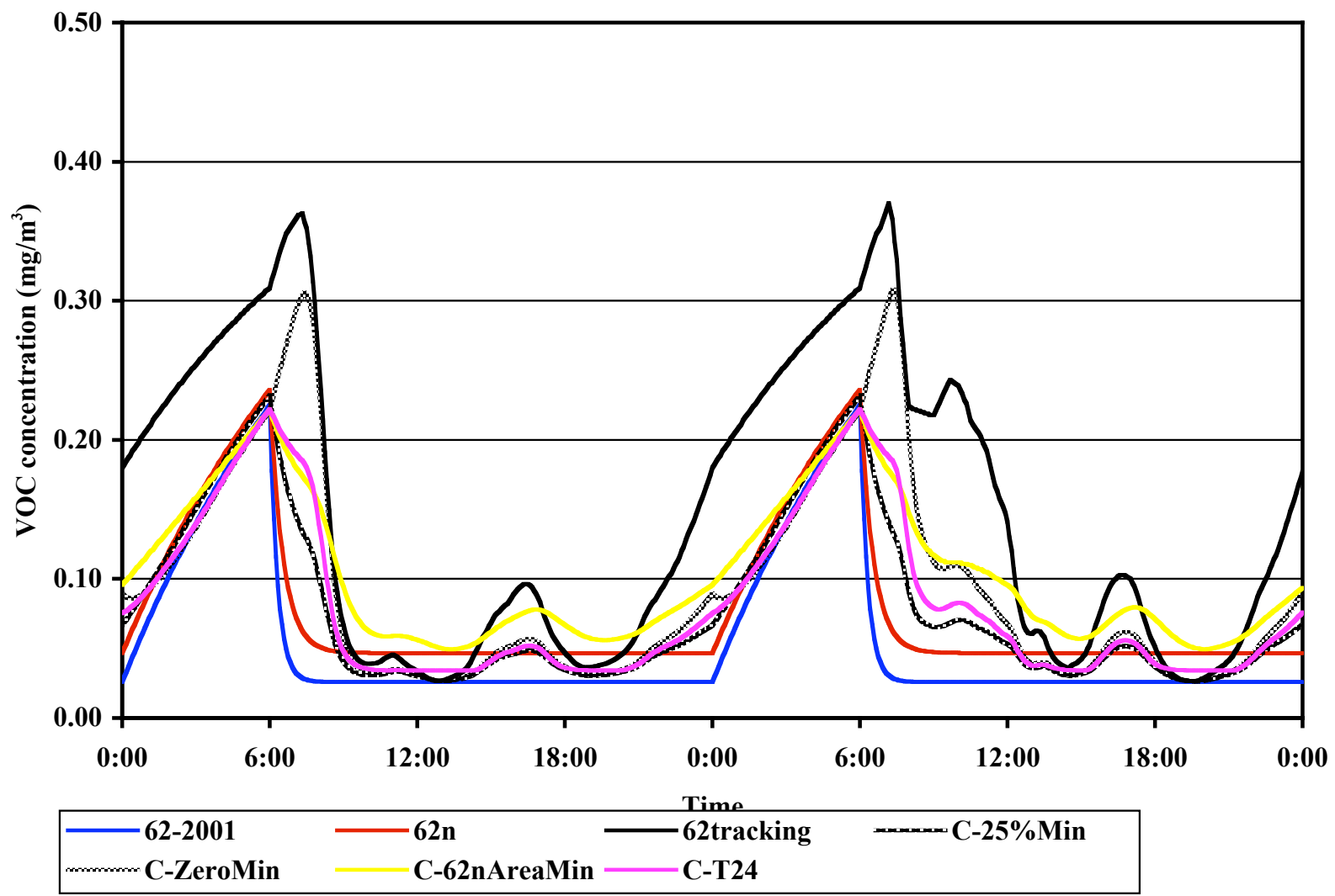

Figure 19 Fast Food Restaurant VOC Concentrations over Friday and Saturday 


\subsection{Energy Loads}

Table 8 summarizes the estimated energy loads associated with ventilation for each of the spaces. For each city, this table presents the annual energy load associated with ventilation for each ventilation strategy in units of $\mathrm{MJ} / \mathrm{m}^{2}$ to account for differences in the sizes of the spaces. Appendix A contains more details on the energy loads, including the heating, sensible cooling and latent cooling for each case. In general, the $\mathrm{CO}_{2}$ control cases use less energy than the constant ventilation rate cases, and the $62 \mathrm{n}$ case uses less than 62/2001 except in the Portable Classroom where the $62 \mathrm{n}$ ventilation rate is higher. The magnitude of these reductions in a particular city and space combination is a fairly complex function of climate (relative amounts of heating and cooling), ventilation rate per unit floor area as shown in Table 2 (which also impacts the heating load via the balance point), internal heat loads shown in Table 3 (which also impacts balance point) and occupancy patterns.

In the Office space, 62tracking and the two 62-based $\mathrm{CO}_{2}$ control cases have energy loads that are roughly $20 \%$ lower than the straight 62-2001 case. (The loads in San Francisco are so low in the Office space that the reductions are not discussed.) Compared to 62/2001, the addendum 62n rates decrease the ventilation-induced energy load by $30 \%$ to $60 \%$ depending on the city, with the largest reduction in the heating-dominated Minneapolis climate. Implementing $\mathrm{CO}_{2}$ control under $62 \mathrm{n}$ leads to further variable reductions in the energy loads among the different cities, ranging from around $10 \%$ to $30 \%$. For the Office space, the biggest reductions in energy under $\mathrm{CO}_{2}$ control occur in Minneapolis, which is a heating dominated climate. These reductions are larger under heating due to the combined impact of lower ventilation rates under $\mathrm{CO}_{2}$ control and decreased balance point temperatures due to these lower rates. Another reason for larger reductions under heating is that the ventilation rates tend to be lower early in the day when the outdoor temperature is lower. The energy load increases in the Office under C-T24, but as noted earlier that is not really a DCV case in the Office and in fact has a higher ventilation rate than required by Standard 62-2001.

The reductions in energy load for the $\mathrm{CO}_{2}$ control cases, including C-T24, are much larger in the Conference Room and Lecture Hall given the higher design ventilation rates per unit floor area and impact of these rates on balance point temperature. The reduction in energy load from the $62 / 2001$ to $62 \mathrm{n}$ cases is also much larger than in the Office, more than $50 \%$ in all cases and as high as $80 \%$. Implementing $\mathrm{CO}_{2}$ control under 62 n leads to further reductions in energy load. The results for the classrooms are similar in relative magnitude to the changes seen in the other cases, with the exception of the difference between 62n and 62/2001. As noted earlier, the ventilation rate under $62 \mathrm{n}$ in the Portable Classroom is actually higher than under 62/2001, leading to a slight increase in the energy load. Otherwise, implementing $\mathrm{CO}_{2}$ control under Standard 62, Title 24 or $62 \mathrm{n}$ results in energy reductions from around $30 \%$ to $50 \%$ depending on the city. Implementing $\mathrm{CO}_{2}$ control under Standard 62 or Title 24 in the Fast Food Restaurant reduces the energy load by around $40 \%$ to as high as $75 \%$, again depending on the city. The lower rates under addendum $62 \mathrm{n}$ reduce the energy load by around $50 \%$ relative to $62 / 2001$, with an $86 \%$ reduction in Los Angeles due to a greater relative reduction in the heating load compared to the other cities.

The energy reductions for C-62nAreaMin relative to $62 / 2001$ are as high as $80 \%$ to $90 \%$ in many cases based on the lower rates in addendum $62 \mathrm{n}$. Also, the percent reductions in the spaces studies are much greater in the mild climates than the more extreme climates. 


\begin{tabular}{|c|c|c|c|c|c|c|}
\hline & \multicolumn{6}{|c|}{ Annual Energy Load due to Ventilation $\left(\mathrm{MJ} / \mathrm{m}^{2}\right)$} \\
\hline & Bakersfield & $\begin{array}{c}\text { Los } \\
\text { Angeles }\end{array}$ & Sacramento & $\begin{array}{c}\text { San } \\
\text { Francisco }\end{array}$ & Miami & Minneapolis \\
\hline \multicolumn{7}{|l|}{ Office } \\
\hline $62 / 2001$ & 30 & 6 & 18 & 1 & 117 & 63 \\
\hline 62 tracking & 24 & 5 & 15 & 1 & 85 & 34 \\
\hline C-ZeroMin & 26 & 5 & 17 & 1 & 87 & 35 \\
\hline C-25\%Min & 27 & 5 & 17 & 1 & 93 & 37 \\
\hline $62 n$ & 20 & 4 & 12 & 1 & 79 & 18 \\
\hline C-62nAreaMin & 19 & 4 & 12 & 1 & 71 & 13 \\
\hline C-Title24 & 35 & 7 & 21 & 1 & 135 & 94 \\
\hline \multicolumn{7}{|c|}{ Conference Room } \\
\hline $62 / 2001$ & 357 & 173 & 348 & 298 & 670 & 727 \\
\hline 62tracking & 71 & 25 & 66 & 44 & 147 & 148 \\
\hline $62 /$ Int & 169 & 63 & 162 & 127 & 332 & 356 \\
\hline C-ZeroMin & 111 & 41 & 104 & 73 & 228 & 233 \\
\hline C-25\%Min & 151 & 56 & 145 & 106 & 303 & 320 \\
\hline $62 n$ & 93 & 22 & 89 & 53 & 205 & 213 \\
\hline C-62nAreaMin & 30 & 4 & 22 & 4 & 87 & 71 \\
\hline C-Title24 & 129 & 48 & 122 & 85 & 248 & 280 \\
\hline \multicolumn{7}{|l|}{ Lecture Hall } \\
\hline $62 / 2001$ & 1049 & 528 & 1010 & 931 & 1943 & 2168 \\
\hline 62 tracking & 383 & 142 & 362 & 292 & 790 & 841 \\
\hline $62 /$ Int & 464 & 127 & 437 & 322 & 962 & 1041 \\
\hline C-ZeroMin & 568 & 219 & 537 & 428 & 1143 & 1231 \\
\hline C-25\%Min & 645 & 248 & 614 & 502 & 1278 & 1395 \\
\hline $62 n$ & 508 & 157 & 479 & 372 & 1025 & 1117 \\
\hline C-62nAreaMin & 242 & 40 & 215 & 95 & 620 & 618 \\
\hline C-Title24 & 714 & 302 & 687 & 585 & 140 & 1521 \\
\hline \multicolumn{7}{|l|}{ Classroom } \\
\hline $62 / 2001$ & 197 & 56 & 194 & 132 & 406 & 446 \\
\hline 62tracking & 81 & 16 & 74 & 34 & 203 & 202 \\
\hline C-ZeroMin & 97 & 19 & 87 & 43 & 236 & 228 \\
\hline $\mathrm{C}-25 \% \mathrm{Min}$ & 105 & 21 & 93 & 45 & 271 & 264 \\
\hline $62 n$ & 168 & 43 & 166 & 105 & 364 & 397 \\
\hline C-62nAreaMin & 88 & 16 & 80 & 33 & 242 & 230 \\
\hline C-Title24 & 119 & 23 & 108 & 53 & 300 & 303 \\
\hline \multicolumn{7}{|c|}{ Portable Classroom } \\
\hline $62 / 2001$ & 108 & 36 & 106 & 79 & 219 & 236 \\
\hline 62 tracking & 62 & 17 & 57 & 35 & 135 & 138 \\
\hline C-ZeroMin & 64 & 17 & 61 & 37 & 143 & 146 \\
\hline C-25\%Min & 71 & 17 & 65 & 40 & 157 & 163 \\
\hline $62 n$ & 110 & 38 & 109 & 81 & 222 & 240 \\
\hline C-62nAreaMin & 76 & 17 & 72 & 44 & 166 & 175 \\
\hline C-Title24 & 94 & 27 & 92 & 63 & 199 & 212 \\
\hline \multicolumn{7}{|l|}{ Fast Food } \\
\hline $62 / 2001$ & 1021 & 514 & 1041 & 1018 & 1875 & 2171 \\
\hline 62tracking & 362 & 94 & 326 & 229 & 833 & 847 \\
\hline C-ZeroMin & 516 & 158 & 489 & 381 & 1109 & 1204 \\
\hline C-25\%Min & 574 & 180 & 550 & 442 & 1228 & 1357 \\
\hline $62 n$ & 435 & 74 & 421 & 254 & 995 & 1106 \\
\hline C-62nAreaMin & 222 & 29 & 174 & 50 & 679 & 672 \\
\hline C-Title24 & 490 & 125 & 465 & 345 & 1090 & 1178 \\
\hline
\end{tabular}

Table 8 Summary of Energy Loads 


\section{DISCUSSION}

The objective of this study was to examine the ventilation, indoor air quality and energy impacts of $\mathrm{CO}_{2}$ demand controlled ventilation in a number of different space types and climates based on the project goal of developing application guidance for potential users of $\mathrm{CO}_{2} \mathrm{DCV}$. The results indicate that these impacts are dependent on the details of the spaces including occupancy patterns, ventilation rate requirements and ventilation system operating schedule as well as the assumptions used in the analysis, including contaminant source strengths and system-off infiltration rates. The results and conclusions presented in this report are therefore specific to the cases studied; however, some general conclusions can be reasonably made and the methodology can be extended to other cases and even used in the design process as discussed below.

In terms of the ventilation rates, the simulations results yield the expected result that basing design ventilation rates on design occupancy levels results in "overventilation" for potentially many hours depending on the occupancy schedule. While ventilating at the design rate, even under low occupancy, may have indoor air quality benefits in terms of better dilution of indoor contaminant sources, there is an energy penalty. The $\mathrm{CO}_{2}$ control cases help avoid such periods of overventilation, but generally result in relatively low ventilation rates early in the day when occupancy is low. These low rates result in contaminant buildup, particularly of those contaminants associated with the building, including potential exposure to contaminants that may have built up overnight when the system was off. The extent of such contaminant buildup is highly dependent on the source strengths in the unoccupied building, for which only very limited data is available, and fan off infiltration rates, which are highly building specific and weather dependent. Therefore it is very hard to generalize about early occupancy exposure, other than stating that $\mathrm{CO}_{2}$ control strategies with a nonzero base ventilation rate, such as $\mathrm{C}-25 \% \mathrm{Min}, \mathrm{C}$ 62nAreaMin and C-T24, will help to temper such exposure. Pre-occupancy "flush out" strategies (a requirement of Title 24, but not Standard 62-2001) may also be helpful in lessening such exposure, but need to be considered for the given space and climate, as early morning ventilation can have energy implications that depend on temperature and humidity variations over the day.

As expected, the $62 \mathrm{n}$ rates are significantly lower than the $62 / 2001$ rates for all but the two classroom spaces. While this reduction has generated some questions based on potential IAQ concerns, the $\mathrm{CO}_{2}$ and VOC simulations provide some insight into this question.

While $\mathrm{CO}_{2}$ is not a contaminant of concern at typical indoor levels, it has become viewed as an indicator of occupant-generated contaminants and is useful in this respect if the limitations are understood. In particular, it provides information on the acceptability of the space in terms of odor from human bioeffluents and perhaps the level of other occupant generated contaminants, but is not a comprehensive indicator of overall indoor air quality. Many have come to view an indoor $\mathrm{CO}_{2}$ concentration of $1800 \mathrm{mg} / \mathrm{m}^{3}(1000 \mathrm{ppm}(\mathrm{v}))$ as a threshold separating good and bad indoor air quality, but in reality $1800 \mathrm{mg} / \mathrm{m}^{3}(1000 \mathrm{ppm}(\mathrm{v})) \mathrm{CO}_{2}$ has no significance from a health or comfort perspective (ASTM 2002) and is only of interest based on it being the expected steady-state concentration at ventilation rates of about $8 \mathrm{~L} / \mathrm{s}(17 \mathrm{cfm})$ per person and an outdoor concentration of $540 \mathrm{mg} / \mathrm{m}^{3}(300 \mathrm{ppm}(\mathrm{v}))$. Nonetheless, the average and maximum indoor $\mathrm{CO}_{2}$ concentrations serve as metrics for comparing the different cases.

As expected, ventilating at the Standard 62-2001 rate whenever the system is operating results in the lowest $\mathrm{CO}_{2}$ concentrations, except for the offices where Title 24 results in lower concentrations. However, the $\mathrm{CO}_{2}$ control cases increase the average and maximum $\mathrm{CO}_{2}$ concentrations during occupancy by only about $180 \mathrm{mg} / \mathrm{m}^{3}(100 \mathrm{ppm}(\mathrm{v}))$. In terms of the impact on bioeffluent perception, $180 \mathrm{mg} / \mathrm{m}^{3}(100 \mathrm{ppm}(\mathrm{v}))$ is not very significant. Specifically, based on 
the relationship between percent of occupants dissatisfied with human bioeffluents and $\mathrm{CO}_{2}$ concentration (ECA 1992), a change of $180 \mathrm{mg} / \mathrm{m}^{3}$ (100 ppm(v)) corresponds to an increase in the percent dissatisfied of only about $2 \%$.

The use of ventilation rates based on addendum $62 \mathrm{n}$ resulted in more significant increases in indoor $\mathrm{CO}_{2}$ levels. The average concentrations increased from $180 \mathrm{mg} / \mathrm{m}^{3}(100 \mathrm{ppm}(\mathrm{v}))$ or less to about $540 \mathrm{mg} / \mathrm{m}^{3}(300 \mathrm{ppm}(\mathrm{v}))$ in the Conference Room. The increases in the maximum concentration were larger, up to $900 \mathrm{mg} / \mathrm{m}^{3}$ (500 ppm(v)) in the Lecture Hall and $1260 \mathrm{mg} / \mathrm{m}^{3}$ (700 ppm(v)) in the Conference Room. These increases in the maximum concentrations are more significant but still below any level of concern based on health (ASTM 2002). None of the maximum concentrations exceeded $3060 \mathrm{mg} / \mathrm{m}^{3}(1700 \mathrm{ppm}(\mathrm{v}))$, which corresponds to about $35 \%$ dissatisfaction with odor from human bioeffluents on the part of unadapted visitors to a space and about $12 \%$ dissatisfaction on the part of adapted occupants (ECA 1992). The term adapted refers to the fact that people become accustomed to body odors relatively quickly, in less than a minute, and therefore express lower levels of dissatisfaction at the same level of body odor $\left(\right.$ or $\mathrm{CO}_{2}$ ) than individuals who have not yet become adapted to these odors.

For some of the $\mathrm{CO}_{2}$ control scenarios, the indoor $\mathrm{CO}_{2}$ level built-up during the week, but this was due to the value assumed for infiltration when the system was off. Note that while there is not a great deal of data on commercial building infiltration rates, the value used in these simulations is likely conservatively low for most building-climate combinations. In fact, a low value was selected intentionally to highlight the impact of contaminant build-up during unoccupied periods. The magnitude of the build-up depended on the details of the control algorithm, but was rarely more than about $180 \mathrm{mg} / \mathrm{m}^{3}$ (100 ppm(v)).

Indoor VOC concentrations were calculated to assess the impact of $\mathrm{CO}_{2}$ control on non-occupant generated contaminants, for example those emitted by building materials and furnishings. Based on the assumed emission rates, which were not particularly low relative to the limited data from field studies, the average indoor VOC levels during occupancy were always less than $0.4 \mathrm{mg} / \mathrm{m}^{3}$ and less than $0.1 \mathrm{mg} / \mathrm{m}^{3}$ in most cases. While the lack of definitiveness of the VOC emission rate values limits the reliability of the predicted VOC levels in absolute terms, the relative comparison between cases is far more reliable. Using the 62 tracking case, which complies with Standard 62-2001, as a baseline, all the other cases have average VOC concentrations that are close to or below this idealized case. If one is willing to accept that 62tracking provides adequate control of building-related contaminants, then the $\mathrm{CO}_{2}$ DCV cases also control these contaminants on average. The $\mathrm{CO}_{2}$ control cases had higher VOC concentrations than the reference cases based on Standard 62-2001 and addendum 62n, with the greatest increase in the Conference Room based on its low occupancy early in the day. The average concentrations, and more so the maximum concentrations, were heavily influenced by the build-up in concentration during unoccupied hours, which in turn depend on the values, assumed for the fan-off infiltration rate and VOC emission rate. As discussed earlier, these elevated concentrations early in the day can be tempered by a nonzero minimum ventilation rate under $\mathrm{CO}_{2}$ control (as with $\mathrm{C}-25 \% \mathrm{Min}$, C-62nAreaMin and C-Title24) or with an early morning flush-out. That latter strategy was not evaluated as part of this project, but this simulation approach could be used to investigate its potential benefits. Note that while the VOC results are dependent on the assumed emission rates, they can be scaled up or down linearly for other emission rates as long as the two-to-one ratio of occupied to unoccupied emission rate is maintained.

The annual energy load reductions due to the use of $\mathrm{CO}_{2}$ control were significant in most of the cases, ranging from $10 \%$ to $80 \%$ depending on the space type, climate and ventilation strategy. For the Office, the reductions are generally around $20 \%$, given the relatively stable occupancy 
pattern in that space relative to some of the others. Spaces with more variability in occupancy, such as the Conference Room and Lecture Hall, exhibit larger energy reductions. The energy load reductions associated with the use of addendum $62 \mathrm{n}$ relative to the ventilation requirements in Standard 62-2001 are as large as 30\% to $50 \%$ in the spaces where the $62 \mathrm{n}$ rates are lower. However, in the two classroom spaces, the $62 \mathrm{n}$ rates are similar to those based on Standard 622001 and therefore no significant difference is seen. The most significant reductions are seen for the $62 \mathrm{n}$ DCV case relative to the Standard 62 baseline case.

Taking a closer look at the California climates, these results indicate that $\mathrm{CO}_{2}$ DCV is not likely to provide much energy benefit in offices in the milder climates (Los Angeles and San Francisco) for the relatively stable occupancy patterns used in this study. However in the more "severe" climates of Bakersfield and Sacramento, the savings in the Office were more significant. The spaces with more variable occupancy (Conference Room, Lecture Hall and Fast Food Restaurant) resulted in significant energy savings in all the climates studied. The energy savings in the classroom spaces are strongly dependent on the system operating schedule versus the occupancy schedule, and while significant load reductions were seen in this study, application of $\mathrm{CO}_{2} \mathrm{DCV}$ in classrooms may require more careful consideration.

This study has employed an approach to assessing ventilation, IAQ and energy impacts of different ventilation strategies using the control simulation capabilities of the CONTAMW program. As noted above, this methodology can be applied to other spaces, climates and ventilation strategies to investigate a number of other issues of interest. In particular, the impacts of different VOC source strengths in different spaces and variable emissions patterns over the day would be of interest. Also, the impacts of occupancy levels both lower and greater than those assumed in the design, which does occur in practice, would be worth considering. 


\section{ACKNOWLEDGEMENTS}

This report was supported by the California Energy Commission through the Architectural Energy Corporation. The authors acknowledge the contributions of Vern Smith of the Architectural Energy Corporation and Steven Taylor of Taylor Engineering.

\section{REFERENCES}

Anderson, K, JV Bakke, O Bjørseth, C-G Bornehag, G Clausen, JK Hongslo, M Kjellman, S Kjærgaard, F Levy, L Mølhave, S Skerfving and J Sundell. 1997. TVOC and Health in NonIndustrial Indoor Environments. Report from a Nordic Scientific Consensus Meeting at Långholmen in Stockholm, 1996. Indoor Air, Vol 7:78-91.

ANSI/ASHRAE/IESNA. 1999. ANSI/ASHRAE/IESNA Standard 90.1-1999: Energy Standard for Buildings Except Low-Rise Residential Buildings. American Society of Heating, Refrigerating, and Air Conditioning Engineers and Illuminating Engineering Society of North America.

ASHRAE. 1997. WYEC2: Weather Year for Energy Calculations 2. American Society of Heating, Refrigerating and Air-Conditioning Engineers.

ASHRAE. 2001a. ANSI/ASHRAE Standard 62-2001, Ventilation for Acceptable Indoor Air Quality. American Society of Heating, Refrigerating and Air-Conditioning Engineers.

ASHRAE 2001b. ASHRAE Handbook of Fundamentals. American Society of Heating, Refrigerating, and Air Conditioning Engineers.

ASTM. 2002. D6245-98 (2002) Standard Guide for Using Indoor Carbon Dioxide Concentrations to Evaluate Indoor Air Quality and Ventilation. American Society for Testing and Materials.

Brandemuehl, MJ and JE Braun. 1999. The Impact of Demand-Controlled and Economizer Ventilation Strategies on Energy Use in Buildings. ASHRAE Transactions 105 (2): 39-50.

Brown, S, MR Sim, MJ Abramson and CN Gray. 1994. Concentrations of Volatile Organic Compounds in Indoor Air - A Review, p. 123-134. Indoor Air, Vol. 4.

Carpenter, SC. 1996. Energy and IAQ Impacts of CO2-Based Demand Controlled Ventilation. ASHRAE Transactions, Vol. 102 (2): 1183-1197.

CEC. 2001. Energy Efficiency Standards for Residential and Nonresidential Buildings. California Energy Commission, P400-01-024.

Daisey, JM, AT Hodgson, WJ Fisk, MJ Mendell, and J Ten Brinks. 1994. Volatile Organic Compounds in Twelve California Office Buildings: Classes, Concentrations, and Sources, p. 3557-3562. In Atmospheric Environment. Vol. 28, No. 22.

Dols, WS and GN Walton. 2002. CONTAMW 2.0 User Manual. National Institute of Standards and Technology, NISTIR 6921.

ECA (European Collaborative Action). 1992. Guidelines for Ventilation Requirements in Buildings, Report No. 11, EUR1449EN. Luxembourg Office for Official Publications of the European Communities. 
Emmerich, SJ, JW Mitchell and WA Beckman. 1994. Demand-Controlled Ventilation in a MultiZone Office Building. Indoor Environment, Vol. 3: 331-340.

Emmerich, SJ and AK Persily. 2001. State-of-the-Art Review of $\mathrm{CO}_{2}$ Demand Controlled Ventilation Technology and Application. National Institute of Standards and Technology, NISTIR 6729.

Enermodal. 1995. An Evaluation of the Effect of CO2-Based Demand-Controlled Ventilation Strategies on Energy Use and Occupant-Source Contaminant Concentrations. ASHRAE Research Project 740-TRP. Enermodal Engineering Limited.

EPA. 1999. Exposure Factors Handbook. U.S. Environmental Protection Agency, EPA/600/C$99 / 001$.

Hadwen, GE, JF McCarthy, SE Womble, JR Girman and HS Brightman. 1997. Volatile Organic Compound Concentrations in 41 Office Buildings in the Continental United States. In Proceedings of Healthy Buildings/IAQ'97. Volume 2: 465-470.

Knapp, CL, TL Stoffel and SD Whitaker. 1980. Insolation Data Manual. Solar Energy Research Institute, SERISP-755-789.

Levin, H. 1995. Emissions Testing Data and Indoor Air Quality. Second International Conference on Indoor Air Quality, Ventilation and Energy Conservation in Buildings, 1: 465482.

Marion W and K Urban. 1995. User's Manual for TMY2s, Typical Meteorological Years, Derived from the 1961-1990 National Solar Radiation Data Base. National Renewable Energy Laboratory, NREL/SP-463-7668, E95004064.

Persily, AK. 2001. Addendum 62n: Revising the Ventilation Rate Procedure. ASHRAE Journal 43 (9): 12-13.

Schell, MB, SC Turner and RO Shim. 1998. Application of $\mathrm{CO}_{2}$-Based Demand-Controlled Ventilation Using ASHRAE Standard 62: Optimizing Energy Use and Ventilation. ASHRAE Transactions 104 (2): 1213-1225.

Schell, MB and D Int-Hout. 2001. Demand Control Ventilation Using $\mathrm{CO}_{2}$. ASHRAE Journal 43 (2): 18-29.

Sowa J. 2002. $\mathrm{CO}_{2}$-Based Occupancy Detection for On-Line Demand Controlled Ventilation Systems. Proceedings of Indoor Air 2002, Vol. 3: 334-339.

Wolkoff, P. 1995. Volatile Organic Compounds - Sources, Measurements, Emissions, and The Impact on Indoor Air Quality. Indoor Air. Supplement No. 3/95. 


\section{Appendix A: Details of Energy Simulation Results}

This appendix presents the energy simulation results for the six space types for each ventilation control strategy in each city. The tables that follow break down the total energy presented in the body of the report into heating energy and sensible and latent cooling. A separate table is included for each of the six cities. 


\begin{tabular}{|c|c|c|c|c|c|c|}
\hline & $\begin{array}{c}\text { Heating } \\
(\mathrm{MJ})\end{array}$ & $\begin{array}{c}\text { Sensible } \\
\text { cooling } \\
(\mathrm{MJ})\end{array}$ & $\begin{array}{c}\text { Latent } \\
\text { cooling } \\
(\mathrm{MJ}) \\
\end{array}$ & $\begin{array}{c}\text { Total } \\
\text { cooling } \\
(\mathbf{M J}) \\
\end{array}$ & $\begin{array}{c}\text { Total } \\
\text { heating \& } \\
\text { cooling } \\
(\mathrm{MJ}) \\
\end{array}$ & $\begin{array}{c}\text { Total } \\
\text { heating \& } \\
\text { cooling } \\
\left(\mathrm{MJ} / \mathbf{m}^{2}\right)\end{array}$ \\
\hline \multicolumn{7}{|l|}{ Office } \\
\hline $62 / 2001$ & 0 & 29.800 & 200 & 30.000 & 30.000 & 30 \\
\hline 62 tracking & 0 & 23.600 & 100 & 23.700 & 23.700 & 24 \\
\hline C-ZeroMin & 0 & 25.600 & 100 & 25.700 & 25.700 & 26 \\
\hline C- $25 \%$ Min & 0 & 26.300 & 200 & 26.500 & 26.500 & 27 \\
\hline $62 n$ & 0 & 20.200 & 100 & 20.300 & 20.300 & 20 \\
\hline C-62nAreaMin & 0 & 19.000 & 100 & 19.100 & 19.100 & 19 \\
\hline C-Title24 & 0 & 34.400 & 200 & 34.600 & 34.600 & 35 \\
\hline \multicolumn{7}{|c|}{ Conference Room } \\
\hline $62 / 2001$ & 17.200 & 18.400 & 100 & 18.500 & 35.700 & 357 \\
\hline 62 tracking & 2.400 & 4.700 & 0 & 4.700 & 7.100 & 71 \\
\hline $62 /$ Int & 7.600 & 9.200 & 100 & 9.300 & 16.900 & 169 \\
\hline C-ZeroMin & 3.900 & 7.200 & 0 & 7.200 & 11.100 & 111 \\
\hline $\mathrm{C}-25 \% \mathrm{Min}$ & 6.000 & 9.000 & 100 & 9.100 & 15.100 & 151 \\
\hline $62 n$ & 3.600 & 5.700 & 0 & 5.700 & 9.300 & 93 \\
\hline C-62nAreaMin & 300 & 2.700 & 0 & 2.700 & 3.000 & 30 \\
\hline C-Title24 & 4.700 & 8.200 & 0 & 8.200 & 12.900 & 129 \\
\hline \multicolumn{7}{|l|}{ Lecture Hall } \\
\hline $62 / 2001$ & 51.800 & 52.800 & 300 & 53.100 & 104.900 & 1049 \\
\hline 62tracking & 18.200 & 20.000 & 100 & 20.100 & 38.300 & 383 \\
\hline $62 /$ Int & 19.800 & 26.400 & 200 & 26.600 & 46.400 & 464 \\
\hline C-ZeroMin & 26.500 & 30.100 & 200 & 30.300 & 56.800 & 568 \\
\hline C- $25 \%$ Min & 30.300 & 34.000 & 200 & 34.200 & 64.500 & 645 \\
\hline $62 n$ & 22.400 & 28.200 & 200 & 28.400 & 50.800 & 508 \\
\hline C-62nAreaMin & 7.300 & 16.800 & 100 & 16.900 & 24.200 & 242 \\
\hline C-Title24 & 34,400 & 36,800 & 200 & 37.000 & 71.400 & 714 \\
\hline \multicolumn{7}{|l|}{ Classroom } \\
\hline $62 / 2001$ & 9.600 & 10.000 & 100 & 10,100 & 19.700 & 197 \\
\hline 62 tracking & 2.600 & 5.400 & 0 & 5.500 & 8.100 & 81 \\
\hline C-ZeroMin & 3.100 & 6.600 & 0 & 6.600 & 9.700 & 97 \\
\hline $\mathrm{C}-25 \% \mathrm{Min}$ & 3.200 & 7.300 & 0 & 7.300 & 10.500 & 105 \\
\hline $62 n$ & 7.800 & 8.900 & 100 & 9.000 & 16,800 & 168 \\
\hline C-62nAreaMin & 2.300 & 6.500 & 0 & 6.500 & 8.800 & 88 \\
\hline C-Title24 & 3,900 & 8.000 & 0 & 8.000 & 11.900 & 119 \\
\hline \multicolumn{7}{|c|}{ Portable Classroom } \\
\hline $62 / 2001$ & 4.700 & 4.900 & 0 & 4.900 & 9.600 & 108 \\
\hline 62tracking & 2.300 & 3.200 & 0 & 3.200 & 5.500 & 62 \\
\hline C-ZeroMin & 2.200 & 3.500 & 0 & 3.500 & 5.700 & 64 \\
\hline C- $25 \%$ Min & 2.500 & 3.800 & 0 & 3.800 & 6.300 & 71 \\
\hline $62 n$ & 4.800 & 5.000 & 0 & 5.000 & 9.800 & 110 \\
\hline C-62nAreaMin & 2.800 & 4.000 & 0 & 4.000 & 6.800 & 76 \\
\hline C-Title24 & 3.700 & 4.700 & 0 & 4.700 & 8.400 & 94 \\
\hline \multicolumn{7}{|l|}{ Fast Food } \\
\hline $62 / 2001$ & 74.200 & 53.000 & 400 & 53,400 & 127.600 & 1021 \\
\hline 62tracking & 18.600 & 26.400 & 200 & 26.600 & 45.200 & 362 \\
\hline C-ZeroMin & 29.400 & 34.900 & 200 & 35.100 & 64.500 & 516 \\
\hline C-25\%Min & 34.000 & 37.500 & 300 & 37.800 & 71.800 & 574 \\
\hline $62 n$ & 25.600 & 28.600 & 200 & 28.800 & 54.400 & 435 \\
\hline C-62nAreaMin & 6.600 & 20.900 & 200 & 21.100 & 27.700 & 222 \\
\hline C-Title24 & 27.500 & 33.500 & 200 & 33.700 & 61.200 & 490 \\
\hline
\end{tabular}

Table A1 Detailed Energy Loads for Bakersfield 


\begin{tabular}{|c|c|c|c|c|c|c|}
\hline & $\begin{array}{c}\text { Heating } \\
\text { (MJ) }\end{array}$ & $\begin{array}{c}\text { Sensible } \\
\text { cooling } \\
(\mathbf{M J})\end{array}$ & $\begin{array}{c}\text { Latent } \\
\text { cooling } \\
(\mathrm{MJ})\end{array}$ & $\begin{array}{c}\text { Total } \\
\text { cooling } \\
\text { (MJ) }\end{array}$ & $\begin{array}{c}\text { Total } \\
\text { heating \& } \\
\text { cooling } \\
(\mathrm{MJ}) \\
\end{array}$ & $\begin{array}{c}\text { Total } \\
\text { heating } \& \\
\text { cooling } \\
\left(\mathbf{M J} / \mathbf{m}^{2}\right)\end{array}$ \\
\hline \multicolumn{7}{|l|}{ Office } \\
\hline $62 / 2001$ & 0 & 2.700 & 3.100 & 5.800 & 5.800 & 6 \\
\hline 62 tracking & 0 & 2.300 & 2.400 & 4.700 & 4.700 & 5 \\
\hline C-ZeroMin & 0 & 2.300 & 2.300 & 4.600 & 4.600 & 5 \\
\hline C- $25 \%$ Min & 0 & 2.400 & 2.500 & 4.900 & 4.900 & 5 \\
\hline $62 n$ & 0 & 1.800 & 2.100 & 3.900 & 3.900 & 4 \\
\hline C-62nAreaMin & 0 & 1.700 & 1.900 & 3.600 & 3.600 & 4 \\
\hline C-Title24 & 0 & 3.100 & 3.600 & 6.700 & 6.700 & 7 \\
\hline \multicolumn{7}{|c|}{ Conference Room } \\
\hline $62 / 2001$ & 13.600 & 1.900 & 1.800 & 3.700 & 17.300 & 173 \\
\hline 62tracking & 1.700 & 400 & 400 & 800 & 2.500 & 25 \\
\hline 62/Int & 4.500 & 900 & 900 & 1.800 & 6.300 & 63 \\
\hline C-ZeroMin & 2.900 & 600 & 600 & 1.200 & 4.100 & 41 \\
\hline $\mathrm{C}-25 \% \mathrm{Min}$ & 3.900 & 900 & 800 & 1.700 & 5.600 & 56 \\
\hline $62 n$ & 1.000 & 600 & 600 & 1.200 & 2.200 & 22 \\
\hline C-62nAreaMin & 0 & 200 & 200 & 400 & 400 & 4 \\
\hline \multirow{2}{*}{\multicolumn{7}{|c|}{ Lecture Hall }} \\
\hline & & & & & & \\
\hline $62 / 2001$ & 43.900 & 4.200 & 4.700 & 8.900 & 52.800 & 528 \\
\hline 62tracking & 10.200 & 2.000 & 2.000 & 4.000 & 14.200 & 142 \\
\hline 62/Int & 8.200 & 2.100 & 2.400 & 4.500 & 12.700 & 127 \\
\hline C-ZeroMin & 16,100 & 2.800 & 3.000 & 5.800 & 21.900 & 219 \\
\hline C- $25 \%$ Min & 18.400 & 3.100 & 3.300 & 6.400 & 24.800 & 248 \\
\hline $62 n$ & 10,900 & 2.300 & 2.500 & 4.800 & 15.700 & 157 \\
\hline C-62nAreaMin & 900 & 1.500 & 1.600 & 3.100 & 4.000 & 40 \\
\hline C-Title24 & 23,200 & 3.400 & 3.600 & 7.000 & 30.200 & 302 \\
\hline \multicolumn{7}{|l|}{ Classroom } \\
\hline $62 / 2001$ & 3.500 & 1000 & 1.100 & 2.100 & 5.600 & 56 \\
\hline 62tracking & 400 & 600 & 600 & 1.200 & 1.600 & 16 \\
\hline C-ZeroMin & 500 & 700 & 700 & 1.400 & 1.900 & 19 \\
\hline C- $25 \%$ Min & 600 & 700 & 800 & 1.500 & 2.100 & 21 \\
\hline $62 n$ & 2.400 & 900 & 1000 & 1.900 & 4.300 & 43 \\
\hline C-62nAreaMin & 200 & 700 & 700 & 1.400 & 1.600 & 16 \\
\hline C-Title24 & 700 & 800 & 800 & 1.600 & 2.300 & 23 \\
\hline \multicolumn{7}{|c|}{ Portable Classroom } \\
\hline $62 / 2001$ & 2.100 & 500 & 600 & 1.100 & 3.200 & 36 \\
\hline 62tracking & 700 & 400 & 400 & 800 & 1.500 & 17 \\
\hline C-ZeroMin & 700 & 400 & 400 & 800 & 1.500 & 17 \\
\hline C- $25 \%$ Min & 700 & 400 & 400 & 800 & 1.500 & 17 \\
\hline $62 n$ & 2.200 & 600 & 600 & 1.200 & 3.400 & 38 \\
\hline C-62nAreaMin & 700 & 400 & 400 & 800 & 1.500 & 17 \\
\hline C-Title24 & 1.400 & 500 & 500 & 1,000 & 2,400 & 27 \\
\hline \multicolumn{7}{|l|}{ Fast Food } \\
\hline $62 / 2001$ & 55.100 & 4.100 & 5.100 & 9.200 & 64,300 & 514 \\
\hline 62 tracking & 7.200 & 2.200 & 2.400 & 4.600 & 11.800 & 94 \\
\hline C-ZeroMin & 13.900 & 2.800 & 3.100 & 5.900 & 19.800 & 158 \\
\hline C- $25 \% \mathrm{Min}$ & 16.100 & 3.000 & 3.400 & 6.400 & 22.500 & 180 \\
\hline $62 n$ & 4.200 & 2.200 & 2.800 & 5.000 & 9.200 & 74 \\
\hline C-62nAreaMin & 100 & 1.600 & 1.900 & 3.500 & 3.600 & 29 \\
\hline C-Title24 & 10,000 & 2.600 & 3.000 & 5.600 & 15.600 & 125 \\
\hline
\end{tabular}

Table A2 Detailed Energy Loads for Los Angeles 


\begin{tabular}{|c|c|c|c|c|c|c|}
\hline & $\begin{array}{c}\text { Heating } \\
\text { (MJ) }\end{array}$ & $\begin{array}{c}\text { Sensible } \\
\text { cooling } \\
(\mathbf{M J})\end{array}$ & $\begin{array}{c}\text { Latent } \\
\text { cooling } \\
(\mathrm{MJ})\end{array}$ & $\begin{array}{c}\text { Total } \\
\text { cooling } \\
\text { (MJ) }\end{array}$ & $\begin{array}{c}\text { Total } \\
\text { heating \& } \\
\text { cooling } \\
(\mathrm{MJ}) \\
\end{array}$ & $\begin{array}{c}\text { Total } \\
\text { heating } \& \\
\text { cooling } \\
\left(\mathbf{M J} / \mathbf{m}^{2}\right)\end{array}$ \\
\hline \multicolumn{7}{|l|}{ Office } \\
\hline $62 / 2001$ & 0 & 18,100 & 100 & 18.200 & 18.200 & 18 \\
\hline 62tracking & 0 & 14.900 & 100 & 15.000 & 15.000 & 15 \\
\hline C-ZeroMin & 0 & 16.400 & 100 & 16.500 & 16.500 & 17 \\
\hline C- $25 \%$ Min & 0 & 16.600 & 100 & 16.700 & 16.700 & 17 \\
\hline $62 n$ & 0 & 12.200 & 100 & 12.300 & 12.300 & 12 \\
\hline C-62nAreaMin & 0 & 11.700 & 100 & 11.800 & 11.800 & 12 \\
\hline C-Title24 & 0 & 20,800 & 100 & 20.900 & 20.900 & 21 \\
\hline \multicolumn{7}{|c|}{ Conference Room } \\
\hline $62 / 2001$ & 22.900 & 11.800 & 100 & 11.900 & 34.800 & 348 \\
\hline 62tracking & 3.600 & 3.000 & 0 & 3.000 & 6.600 & 66 \\
\hline 62/Int & 10.300 & 5.900 & 0 & 5.900 & 16.200 & 162 \\
\hline C-ZeroMin & 5.700 & 4.700 & 0 & 4.700 & 10.400 & 104 \\
\hline $\mathrm{C}-25 \% \mathrm{Min}$ & 8.700 & 5,800 & 0 & 5.800 & 14.500 & 145 \\
\hline $62 n$ & 5.200 & 3.700 & 0 & 3.700 & 8.900 & 89 \\
\hline C-62nAreaMin & 500 & 1.700 & 0 & 1.700 & 2.200 & 22 \\
\hline C-Title24 & 6.900 & 5.300 & 0 & 5.300 & 12.200 & 122 \\
\hline \multicolumn{7}{|l|}{ Lecture Hall } \\
\hline $62 / 2001$ & 70.000 & 30.800 & 200 & 31.000 & 101.000 & 1010 \\
\hline 62tracking & 24.600 & 11.500 & 100 & 11.600 & 36.200 & 362 \\
\hline 62/Int & 28.200 & 15.400 & 100 & 15.500 & 43.700 & 437 \\
\hline C-ZeroMin & 35.900 & 17.700 & 100 & 17.800 & 53.700 & 537 \\
\hline C- $25 \%$ Min & 41.300 & 20.000 & 100 & 20.100 & 61.400 & 614 \\
\hline $62 n$ & 31.400 & 16,400 & 100 & 16.500 & 47.900 & 479 \\
\hline C-62nAreaMin & 11.400 & 10.000 & 100 & 10.100 & 21.500 & 215 \\
\hline C-Title24 & 46,800 & 21,800 & 100 & 21.900 & 68.700 & 687 \\
\hline \multicolumn{7}{|l|}{ Classroom } \\
\hline $62 / 2001$ & 13.200 & 6.200 & 0 & 6.200 & 19.400 & 194 \\
\hline 62tracking & 3.900 & 3.500 & 0 & 3.500 & 7.400 & 74 \\
\hline C-ZeroMin & 4.400 & 4.300 & 0 & 4.300 & 8.700 & 87 \\
\hline C- $25 \%$ Min & 4.700 & 4.600 & 0 & 4.600 & 9.300 & 93 \\
\hline $62 n$ & 11,100 & 5,500 & 0 & 5,500 & 16.600 & 166 \\
\hline C-62nAreaMin & 3.800 & 4.200 & 0 & 4.200 & 8.000 & 80 \\
\hline C-Title24 & 5.700 & 5,100 & 0 & 5,100 & 10,800 & 108 \\
\hline \multicolumn{7}{|c|}{ Portable Classroom } \\
\hline $62 / 2001$ & 6.300 & 3.100 & 0 & 3,100 & 9.400 & 106 \\
\hline 62tracking & 3.100 & 2.000 & 0 & 2.000 & 5.100 & 57 \\
\hline C-ZeroMin & 3.100 & 2.300 & 0 & 2.300 & 5.400 & 61 \\
\hline C- $25 \%$ Min & 3.400 & 2.400 & 0 & 2.400 & 5.800 & 65 \\
\hline $62 n$ & 6.500 & 3.100 & 0 & 3.200 & 9.700 & 109 \\
\hline C-62nAreaMin & 3.900 & 2.500 & 0 & 2.500 & 6.400 & 72 \\
\hline C-Title24 & 5.200 & 3,000 & 0 & 3.000 & 8,200 & 92 \\
\hline \multicolumn{7}{|l|}{ Fast Food } \\
\hline $62 / 2001$ & 102.500 & 27.500 & 100 & 27.600 & 130.100 & 1041 \\
\hline 62 tracking & 26.500 & 14.100 & 100 & 14.200 & 40.700 & 326 \\
\hline C-ZeroMin & 42.400 & 18.600 & 100 & 18.700 & 61.100 & 489 \\
\hline C- $25 \% \mathrm{Min}$ & 48.700 & 19.900 & 100 & 20.000 & 68.700 & 550 \\
\hline $62 n$ & 37.700 & 14.800 & 100 & 14.900 & 52.600 & 421 \\
\hline C-62nAreaMin & 10.600 & 11.100 & 100 & 11.200 & 21.800 & 174 \\
\hline C-Title24 & 40.200 & 17.800 & 100 & 17,900 & 58.100 & 465 \\
\hline
\end{tabular}

Table A3 Detailed Energy Loads for Sacramento 


\begin{tabular}{|c|c|c|c|c|c|c|}
\hline & $\begin{array}{c}\text { Heating } \\
\text { (MJ) }\end{array}$ & $\begin{array}{c}\text { Sensible } \\
\text { cooling } \\
(\mathbf{M J})\end{array}$ & $\begin{array}{c}\text { Latent } \\
\text { cooling } \\
\text { (MJ) }\end{array}$ & $\begin{array}{c}\text { Total } \\
\text { cooling } \\
\text { (MJ) }\end{array}$ & $\begin{array}{c}\text { Total } \\
\text { heating \& } \\
\text { cooling } \\
(\mathrm{MJ}) \\
\end{array}$ & $\begin{array}{c}\text { Total } \\
\text { heating } \& \\
\text { cooling } \\
\left(\mathbf{M J} / \mathbf{m}^{2}\right)\end{array}$ \\
\hline \multicolumn{7}{|l|}{ Office } \\
\hline $62 / 2001$ & 0 & 1.200 & 0 & 1.200 & 1.200 & 1 \\
\hline 62 tracking & 0 & 1.000 & 0 & 1.000 & 1.000 & 1 \\
\hline C-ZeroMin & 0 & 1.100 & 0 & 1.100 & 1.100 & 1 \\
\hline C- $25 \%$ Min & 0 & 1.100 & 0 & 1.100 & 1.100 & 1 \\
\hline $62 n$ & 0 & 800 & 0 & 800 & 800 & 1 \\
\hline C-62nAreaMin & 0 & 800 & 0 & 800 & 800 & 1 \\
\hline C-Title24 & 0 & 1.400 & 0 & 1.400 & 1.400 & 1 \\
\hline \multicolumn{7}{|c|}{ Conference Room } \\
\hline $62 / 2001$ & 29.000 & 800 & 0 & 800 & 29.800 & 298 \\
\hline 62tracking & 4.200 & 200 & 0 & 200 & 4.400 & 44 \\
\hline 62/Int & 12.300 & 400 & 0 & 400 & 12.700 & 127 \\
\hline C-ZeroMin & 7.000 & 300 & 0 & 300 & 7.300 & 73 \\
\hline C-25\%Min & 10.200 & 400 & 0 & 400 & 10.600 & 106 \\
\hline $62 n$ & 5.000 & 300 & 0 & 300 & 5.300 & 53 \\
\hline C-62nAreaMin & 300 & 100 & 0 & 100 & 400 & 4 \\
\hline \multirow{2}{*}{\multicolumn{7}{|c|}{ Lecture Hall }} \\
\hline & & & & & & \\
\hline $62 / 2001$ & 91.200 & 1.900 & 0 & 1.900 & 93.100 & 931 \\
\hline 62tracking & 28.300 & 900 & 0 & 900 & 29.200 & 292 \\
\hline 62/Int & 31.200 & 1.000 & 0 & 1.000 & 32.200 & 322 \\
\hline C-ZeroMin & 41.600 & 1.200 & 0 & 1.200 & 42.800 & 428 \\
\hline C- $25 \%$ Min & 48.800 & 1.400 & 0 & 1.400 & 50.200 & 502 \\
\hline $62 n$ & 36,200 & 1.000 & 0 & 1.000 & 37.200 & 372 \\
\hline C-62nAreaMin & 8.800 & 700 & 0 & 700 & 9.500 & 95 \\
\hline C-Title24 & 57.000 & 1.500 & 0 & 1.500 & 58.500 & 585 \\
\hline \multicolumn{7}{|l|}{ Classroom } \\
\hline $62 / 2001$ & 12.800 & 400 & 0 & 400 & 13.200 & 132 \\
\hline 62tracking & 3.200 & 200 & 0 & 200 & 3.400 & 34 \\
\hline C-ZeroMin & 4.100 & 300 & 0 & 300 & 4.400 & 44 \\
\hline C- $25 \%$ Min & 4.200 & 300 & 0 & 300 & 4.500 & 45 \\
\hline $62 n$ & 10,100 & 400 & 0 & 400 & 10.500 & 105 \\
\hline C-62nAreaMin & 3.000 & 300 & 0 & 300 & 3.300 & 33 \\
\hline C-Title24 & 4.900 & 400 & 0 & 400 & 5,300 & 53 \\
\hline \multicolumn{7}{|c|}{ Portable Classroom } \\
\hline $62 / 2001$ & 6.800 & 200 & 0 & 200 & 7.000 & 79 \\
\hline 62tracking & 3.000 & 100 & 0 & 100 & 3.100 & 35 \\
\hline C-ZeroMin & 3.100 & 200 & 0 & 200 & 3,300 & 37 \\
\hline C- $25 \%$ Min & 3.400 & 200 & 0 & 200 & 3.600 & 40 \\
\hline $62 n$ & 7.000 & 200 & 0 & 200 & 7.200 & 81 \\
\hline C-62nAreaMin & 3.700 & 200 & 0 & 200 & 3.900 & 44 \\
\hline C-Title24 & 5.400 & 200 & 0 & 200 & 5.600 & 63 \\
\hline \multicolumn{7}{|l|}{ Fast Food } \\
\hline $62 / 2001$ & 125.500 & 1.800 & 0 & 1.800 & 127.300 & 1018 \\
\hline 62 tracking & 27.600 & 1.000 & 0 & 1.000 & 28.600 & 229 \\
\hline C-ZeroMin & 46.300 & 1.300 & 0 & 1.300 & 47.600 & 381 \\
\hline C- $25 \% \mathrm{Min}$ & 53.800 & 1.400 & 0 & 1.400 & 55.200 & 442 \\
\hline $62 n$ & 30.700 & 1.000 & 0 & 1.000 & 31.700 & 254 \\
\hline C-62nAreaMin & 5.500 & 800 & 0 & 800 & 6.300 & 50 \\
\hline C-Title24 & 41.900 & 1.200 & 0 & 1.200 & 43.100 & 345 \\
\hline
\end{tabular}

Table A4 Detailed Energy Loads for San Francisco 


\begin{tabular}{|c|c|c|c|c|c|c|}
\hline & $\begin{array}{c}\text { Heating } \\
(\mathrm{MJ})\end{array}$ & $\begin{array}{c}\text { Sensible } \\
\text { cooling } \\
(\mathbf{M J})\end{array}$ & $\begin{array}{c}\text { Latent } \\
\text { cooling } \\
\text { (MJ) }\end{array}$ & $\begin{array}{c}\text { Total } \\
\text { cooling } \\
\text { (MJ) }\end{array}$ & $\begin{array}{c}\text { Total } \\
\text { heating \& } \\
\text { cooling } \\
(\mathrm{MJ}) \\
\end{array}$ & $\begin{array}{c}\text { Total } \\
\text { heating } \& \\
\text { cooling } \\
\left(\mathbf{M J} / \mathbf{m}^{2}\right)\end{array}$ \\
\hline \multicolumn{7}{|l|}{ Office } \\
\hline $62 / 2001$ & 0 & 37.500 & 79.200 & 116.700 & 116.700 & 117 \\
\hline 62 tracking & 0 & 29.200 & 56.100 & 85.300 & 85.300 & 85 \\
\hline C-ZeroMin & 0 & 30.400 & 56.900 & 87.300 & 87.300 & 87 \\
\hline C- $25 \%$ Min & 0 & 31.700 & 61.500 & 93.200 & 93.200 & 93 \\
\hline $62 n$ & 0 & 25.500 & 53.800 & 79.300 & 79.300 & 79 \\
\hline C-62nAreaMin & 0 & 23.300 & 47.300 & 70.600 & 70.600 & 71 \\
\hline C-Title24 & 0 & 43.300 & 91.400 & 134.700 & 134.700 & 135 \\
\hline \multicolumn{7}{|c|}{ Conference Room } \\
\hline $62 / 2001$ & 1.600 & 22,800 & 42.600 & 65.400 & 67.000 & 670 \\
\hline 62tracking & 100 & 5.200 & 9.400 & 14.600 & 14.700 & 147 \\
\hline 62/Int & 500 & 11.400 & 21.300 & 32.700 & 33.200 & 332 \\
\hline C-ZeroMin & 200 & 8.100 & 14.500 & 22.600 & 22.800 & 228 \\
\hline $\mathrm{C}-25 \% \mathrm{Min}$ & 300 & 10,600 & 19.400 & 30.000 & 30,300 & 303 \\
\hline $62 n$ & 200 & 7.100 & 13.200 & 20.300 & 20.500 & 205 \\
\hline C-62nAreaMin & 0 & 3.100 & 5.600 & 8.700 & 8.700 & 87 \\
\hline \multirow{2}{*}{\multicolumn{7}{|c|}{ Lecture Hall }} \\
\hline & & & & & & \\
\hline $62 / 2001$ & 4.300 & 62.300 & 127.700 & 190.000 & 194.300 & 1943 \\
\hline 62tracking & 1.400 & 25.500 & 52.100 & 77.600 & 79.000 & 790 \\
\hline 62/Int & 1.200 & 31.200 & 63.800 & 95.000 & 96.200 & 962 \\
\hline C-ZeroMin & 2.000 & 37.400 & 74.900 & 112.300 & 114.300 & 1143 \\
\hline C- $25 \%$ Min & 2.300 & 41.600 & 83.900 & 125.500 & 127.800 & 1278 \\
\hline $62 n$ & 1.200 & 33.200 & 68,100 & 101,300 & 102.500 & 1025 \\
\hline C-62nAreaMin & 300 & 20.600 & 41.100 & 61.700 & 62.000 & 620 \\
\hline C-Title24 & 2.800 & 45.500 & 91.400 & 136.900 & 139.700 & 140 \\
\hline \multicolumn{7}{|l|}{ Classroom } \\
\hline $62 / 2001$ & 700 & 12.900 & 27.000 & 39.900 & 40.600 & 406 \\
\hline 62tracking & 100 & 7.100 & 13.100 & 20.200 & 20.300 & 203 \\
\hline C-ZeroMin & 200 & 8.300 & 15.100 & 23.400 & 23.600 & 236 \\
\hline C- $25 \%$ Min & 200 & 9.200 & 17.700 & 26.900 & 27.100 & 271 \\
\hline $62 n$ & 600 & 11.600 & 24,200 & 35.800 & 36.400 & 364 \\
\hline C-62nAreaMin & 100 & 8.300 & 15.800 & 24.100 & 24.200 & 242 \\
\hline C-Title24 & 200 & 10.200 & 19.600 & 29.800 & 30.000 & 300 \\
\hline \multicolumn{7}{|c|}{ Portable Classroom } \\
\hline $62 / 2001$ & 400 & 6.500 & 12.600 & 19.100 & 19.500 & 219 \\
\hline 62tracking & 100 & 4.200 & 7.700 & 11.900 & 12.000 & 135 \\
\hline C-ZeroMin & 100 & 4.500 & 8,100 & 12,600 & 12.700 & 143 \\
\hline C- $25 \%$ Min & 100 & 4.900 & 9.000 & 13.900 & 14.000 & 157 \\
\hline $62 n$ & 400 & 6,600 & 12.800 & 19.400 & 19.800 & 222 \\
\hline C-62nAreaMin & 100 & 5.100 & 9.600 & 14.700 & 14.800 & 166 \\
\hline C-Title24 & 200 & 6,100 & 11.400 & 17.500 & 17.700 & 199 \\
\hline \multicolumn{7}{|l|}{ Fast Food } \\
\hline $62 / 2001$ & 7.200 & 65.200 & 162,000 & 227.200 & 234.400 & 1875 \\
\hline 62 tracking & 1000 & 31.700 & 71.400 & 103.100 & 104.100 & 833 \\
\hline C-ZeroMin & 1.700 & 41.600 & 95.300 & 136.900 & 138.600 & 1109 \\
\hline C- $25 \% \mathrm{Min}$ & 2.100 & 45.200 & 106.200 & 151.400 & 153.500 & 1228 \\
\hline $62 n$ & 1.500 & 35.300 & 87.600 & 122.900 & 124.400 & 995 \\
\hline C-62nAreaMin & 200 & 25.200 & 59.500 & 84.700 & 84.900 & 679 \\
\hline C-Title24 & 1.600 & 40.300 & 94.300 & 134,600 & 136,200 & 1090 \\
\hline
\end{tabular}

Table A5 Detailed Energy Loads for Miami 


\begin{tabular}{|c|c|c|c|c|c|c|}
\hline & $\begin{array}{c}\text { Heating } \\
\text { (MJ) }\end{array}$ & $\begin{array}{c}\text { Sensible } \\
\text { cooling } \\
(\mathrm{MJ})\end{array}$ & $\begin{array}{c}\text { Latent } \\
\text { cooling } \\
(\mathrm{MJ})\end{array}$ & $\begin{array}{c}\text { Total } \\
\text { cooling } \\
\text { (MJ) }\end{array}$ & $\begin{array}{c}\text { Total } \\
\text { heating \& } \\
\text { cooling } \\
(\mathrm{MJ})\end{array}$ & $\begin{array}{c}\text { Total } \\
\text { heating \& } \\
\text { cooling } \\
\left(\mathrm{MJ} / \mathrm{m}^{2}\right)\end{array}$ \\
\hline \multicolumn{7}{|l|}{ Office } \\
\hline $62 / 2001$ & 47.100 & 7.300 & 8.500 & 15.800 & 62,900 & 63 \\
\hline 62tracking & 21.900 & 5.900 & 6.300 & 12.200 & 34.100 & 34 \\
\hline C-ZeroMin & 22.300 & 6.400 & 6.600 & 13.000 & 45,300 & 45 \\
\hline C- $25 \%$ Min & 23.000 & 6.600 & 7.000 & 13.600 & 36.600 & 37 \\
\hline $62 n$ & 7.600 & 5.000 & 5.800 & 10.800 & 18.400 & 18 \\
\hline C-62nAreaMin & 2.700 & 4.700 & 5.200 & 9.900 & 12.600 & 13 \\
\hline C-Title24 & 75.300 & 8.400 & 9.800 & 18.200 & 93.500 & 94 \\
\hline \multicolumn{7}{|c|}{ Conference Room } \\
\hline $62 / 2001$ & 63.300 & 4,600 & 4.800 & 9.400 & 72.700 & 727 \\
\hline 62tracking & 12.600 & 1.100 & 1.100 & 2.200 & 14.800 & 148 \\
\hline 62/Int & 30.900 & 2.300 & 2.400 & 4.700 & 35.600 & 356 \\
\hline C-ZeroMin & 20.000 & 1.700 & 1.600 & 3.300 & 23.300 & 233 \\
\hline C-25\%Min & 27.600 & 2.200 & 2.200 & 4.400 & 32.000 & 320 \\
\hline $62 n$ & 18.400 & 1.400 & 1.500 & 2.900 & 21.300 & 213 \\
\hline C-62nAreaMin & 5.900 & 600 & 600 & 1.200 & 7.100 & 71 \\
\hline C-Title24 & 24.100 & 2.000 & 1.900 & 3.900 & 28.000 & 280 \\
\hline \multicolumn{7}{|l|}{ Lecture Hall } \\
\hline $62 / 2001$ & 189.500 & 12.800 & 14.500 & 27.300 & 216.800 & 2168 \\
\hline 62tracking & 73.500 & 4.900 & 5.700 & 10.600 & 84.100 & 841 \\
\hline $62 /$ Int & 90,400 & 6.400 & 7.300 & 13.700 & 104.100 & 1041 \\
\hline C-ZeroMin & 107.300 & 7.400 & 8.400 & 15.800 & 123,100 & 1231 \\
\hline C- $25 \%$ Min & 121.800 & 8.300 & 9.400 & 17.700 & 139.500 & 1395 \\
\hline $62 n$ & 97.100 & 6,800 & 7.700 & 14.600 & 111.700 & 1117 \\
\hline C-62nAreaMin & 53.100 & 4.100 & 4.600 & 8.700 & 61.800 & 618 \\
\hline C-Title24 & 132.900 & 9.000 & 10.200 & 19.200 & 152.100 & 1521 \\
\hline \multicolumn{7}{|l|}{ Classroom } \\
\hline $62 / 2001$ & 39.300 & 2.400 & 2.900 & 5.300 & 44.600 & 446 \\
\hline 62tracking & 17.300 & 1.400 & 1.500 & 2.900 & 20.200 & 202 \\
\hline C-ZeroMin & 19.400 & 1.700 & 1.700 & 3.400 & 22.800 & 228 \\
\hline C- $25 \%$ Min & 22.700 & 1.800 & 1.900 & 3.700 & 26.400 & 264 \\
\hline $62 n$ & 34.900 & 2.200 & 2.600 & 4.800 & 39.700 & 397 \\
\hline C-62nAreaMin & 19.700 & 1.600 & 1.700 & 3.300 & 23.000 & 230 \\
\hline C-Title24 & 26.100 & 2.000 & 2.200 & 4.200 & 30.300 & 303 \\
\hline \multicolumn{7}{|c|}{ Portable Classroom } \\
\hline $62 / 2001$ & 18,400 & 1,200 & 1.400 & 2.600 & 21.000 & 236 \\
\hline 62tracking & 10.700 & 800 & 800 & 1.600 & 12.300 & 138 \\
\hline C-ZeroMin & 11.200 & 900 & 900 & 1.800 & 13.000 & 146 \\
\hline C- $25 \% \mathrm{Min}$ & 12.500 & 1.000 & 1000 & 2.000 & 14.500 & 163 \\
\hline $62 n$ & 18.800 & 1.200 & 1.400 & 2.600 & 21.400 & 240 \\
\hline C-62nAreaMin & 13.500 & 1.000 & 1.100 & 2.100 & 15.600 & 175 \\
\hline C-Title24 & 16.400 & 1.200 & 1.300 & 2.500 & 18.900 & 212 \\
\hline \multicolumn{7}{|l|}{ Fast Food } \\
\hline $62 / 2001$ & 241,200 & 12,100 & 18.100 & 30,200 & 271.400 & 2171 \\
\hline 62tracking & 91.400 & 6.200 & 8.300 & 14.500 & 105.900 & 847 \\
\hline C-ZeroMin & 131.400 & 8.100 & 11.000 & 19.100 & 150,500 & 1204 \\
\hline C-25\%Min & 148.800 & 8.700 & 12.100 & 20.800 & 169.600 & 1357 \\
\hline $62 n$ & 121.900 & 6.500 & 9.800 & 16.300 & 138.200 & 1106 \\
\hline C-62nAreaMin & 72.400 & 4.800 & 6.800 & 11.600 & 84.000 & 672 \\
\hline C-Title24 & 128.700 & 7.800 & 10.800 & 18.600 & 147.300 & 1178 \\
\hline
\end{tabular}

Table A6 Detailed Energy Loads for Minneapolis 


\section{Appendix B: PIER RFP Issues}

The California Energy Commission (CEC) Public Interest Energy Research (PIER) Request for Proposals (RFP) for the Buildings Energy Efficiency Program Area identified four broad issues of key concern to the CEC. These four issues identify energy problems facing buildings in California and present opportunities to have a significant positive impact. This appendix will discuss the relationship of the application of $\mathrm{CO}_{2}$-based DCV systems in small non-residential buildings to the four key issues based on information in this report.

Issue \#1 Energy consumption is rapidly increasing in hotter, inland areas as new building construction increases in these areas.

Obviously, the primary intent of $\mathrm{CO}_{2}$-based DCV systems are to reduce energy consumed to cool or heat ventilation air in buildings and, as demonstrated in this report, they are capable of achieving such reductions for many building types in a variety of climates. These results indicate that $\mathrm{CO}_{2} \mathrm{DCV}$ systems can reduce cooling energy consumption in the hotter, inland areas of California in many occupancies. As application of $\mathrm{CO}_{2}$ DCV in new construction is considered, some thought will need to be given to the possibility that these newer buildings may have low infiltration rates during unoccupied periods and some strategy may be needed to address contaminant buildup when the system is off.

Issue \#2 Development of energy efficient products and services needs to adequately consider non-energy benefits, such as comfort, productivity, durability, and decreased maintenance.

Since $\mathrm{CO}_{2}$-based DCV systems directly affect ventilation rates provided in buildings, there is the potential to have a significant impact on building occupant comfort and productivity. That impact could be either positive or negative depending on the DCV system design, installation, operation and maintenance. $\mathrm{CO}_{2}$-based DCV systems can have a positive impact on IAQ that is not commonly considered. Frequently, building zones are occupied by more people than the ventilation system design criteria. At such times, a DCV system will result in improved IAQ by increasing the ventilation supplied to the space. Additionally, ventilation systems may operate with lower ventilation effectiveness than the design criteria. Again, a DCV system can increase ventilation rates in such situations. While it is not possible to estimate potential impacts on productivity for any given building, Fisk and Rosenfeld (1997) have estimated that nationwide impacts of better indoor environments are in the billions of dollars.

Since DCV systems adjust ventilation rates based on measured concentrations of $\mathrm{CO}_{2}$ generated by building occupants, they do not directly guarantee satisfactory indoor air quality (IAQ) due to the presence of non-occupant generated contaminants. This results in a concern by some that DCV could result in poor IAQ that would negatively impact comfort and productivity. Certain steps need to be taken to avoid the occurrence of such a negative impact. The most fundamental step is to implement the same good IAQ practices that should be applied to all commercial buildings. This includes such practices as reducing contaminant sources, properly installing and maintaining equipment, etc. Additional steps that should be taken for DCV systems include appropriate selection of control algorithms and setpoints, thoughtful consideration of expected contaminant sources, establishing needed minimum base and/or purge ventilation rates and schedules, and proper maintenance and calibration of $\mathrm{CO}_{2}$ sensors.

Finally, the impacts of DCV systems on comfort and productivity have not been thoroughly studied. Since this is an important issue, more research in this area is needed.

Issue \#3 Building design, construction, and operation of energy-related features can affect public health and safety. 
The discussion above addressing Issue \#2 applies equally to public health. $\mathrm{CO}_{2}$-based DCV systems could have either a negative or positive impact on public health and care needs to be taken in their application. Specifically for moisture issues, DCV can have a very positive impact in lessening the moisture load in non-residential buildings in humid climates. Since most of the moisture load for many non-residential buildings is brought into a building through ventilation, reducing excess ventilation during times of reduced building occupancy can reduce this moisture load. This reduction in moisture load can save energy and money by eliminating the need for special equipment.

Issue \#4 Investments in energy efficiency can affect building and housing affordability and value, and the state's economy.

As discussed in response to Issue \#1, $\mathrm{CO}_{2}$-based DCV systems can reduce building heating and cooling energy use and, therefore, reduce operating costs to improve building affordability and value. However, these potential savings will vary widely depending on building type, climate, occupancy density and patterns, other HVAC equipment used, and other factors. While knowledge of these important parameters is growing, more work is needed to identify the best opportunities for energy savings. No impacts are expected on the energy-related costs of construction.

Fisk, W.J. and A.H. Rosenfeld. Estimates of Improved Productivity and Health from Better Indoor Environments (1997) Indoor Air 1997; 7:158-172. 